\title{
Does Austerity Go Along With Internal Devaluations?*
}

\author{
Luisa Lambertini \\ $\mathrm{EPFL}^{\dagger}$
}

\author{
Christian Proebsting \\ $\mathrm{EPFL}^{\ddagger}$
}

January 15, 2019

\begin{abstract}
Cuts to government spending rather than increases in consumption taxes are statistically associated with internal devaluations in the euro area during the period 2010-2014. Countries that cut spending experienced a decline in nominal wages, rising net exports, a fall in the relative price of non-tradables and a shift of consumption towards nontradables. We show that these patterns are generally consistent with a neoclassical small open economy model with GHH preferences. The main remaining discrepancy between model and data is a missing terms of trade response in the data: Export prices did not decline in austere countries (nor did import prices), giving rise to asymmetric expenditure switching: Current account improvements are solely driven by falls in imports rather than increasing exports.
\end{abstract}

*Lambertini: Luisa.Lambertini@epfl.ch; Proebsting: Christian.Probsting@epfl.ch

${ }^{\dagger}$ École Polytechnique Fédérale de Lausanne. Lambertini gratefully acknowledges financial support from the Swiss National Science Foundation grant 100018_182257.

‡École Polytechnique Fédérale de Lausanne 


\section{Introduction}

The experience of the euro area in the wake of its debt crisis has resurrected the idea of internal devaluations through fiscal austerity as a way for countries within a currency union, who cannot engage in nominal exchange rate devaluations, to improve competitiveness and export their way out of the crisis. The idea was that austerity policies, although painful, had a silver lining in that they reduced wages, restored competitiveness and corrected current account deficits by raising exports. In addition to improving the government's budget balance, fiscal austerity, so the argument, could substitute for a nominal exchange rate devaluation and thereby help countries like Greece stay in the currency union. The implemented austerity policies were unprecedented in size and scope, but not evenly enacted across countries: Figure 1 displays the raw time series for real per capita government purchases and the consumption tax rate for Greece, Spain, France and Germany. ${ }^{1}$ The period 2010 - 2014 was characterized by strong fiscal retraction in Greece and Spain that cut spending by 20 to 50 percent compared to 2009 and raised tax rates by 4 to 6 percentage points, whereas no clear trend is observed in France and Germany. Given these large changes in fiscal policies we ask whether austerity actually led to internal devaluations. Did wages fall in austere countries? Did export prices fall and exports go up? And did the composition of austerity packages - tax hikes or spending cuts - matter for internal devaluation purposes?

Motivated by these questions, we first set up a standard small open economy model to guide our empirical analysis and formalize the idea of an "internal devaluation". We define an internal devaluation as a fiscal policy that depreciates the real exchange rate measured at constant consumption tax rates. In the model, governments can engineer these internal devaluations either through cuts to government spending or higher consumption taxes. Our focus on these two policy instruments is motivated by the data. Cuts to government purchases on the expenditure side and increased consumption tax rates on the revenue side were the two prevalent fiscal policies in our sample over the 2010 -2014 period. ${ }^{2}$ Our model suggests that the resulting internal devaluations affect the economy via several channels: On the production side, they are associated with lower nominal wages and production; in the international goods market, they go along with lower export prices (i.e. a terms of trade deterioration) and improved current accounts. On the consumption side, they are associated with a decline

\footnotetext{
${ }^{1}$ The data sources are discussed in Section 3.1.

${ }^{2}$ See the Appendix for details. Including labor taxes in the analysis does not alter our qualitative results.
} 
in the relative price of non-traded consumption goods and expenditure switching towards non-tradables.

In a second step, we take these various predictions to the data. In particular, we follow a growing literature that examines empirical covariance patterns of forecast errors in fiscal and economic variables (Blanchard and Leigh, 2013; Auerbach and Gorodnichenko, 2012). Similar to House et al. (2017), we focus on forecast errors in government purchases and consumption taxes averaged over 2010 - 2014 for 13 euro area countries. In general, the model's predictions on the relationship of austerity and internal devaluations are borne out by the data. Specifically, we find that countries whose government spending was 1 percent of GDP below forecast during 2010 - 2014 saw their real exchange rate depreciate by 1.5 percent over that period. Differences in government spending account for more than 80 percent of the cross-sectional dispersion in real exchange rates over this period. In accordance with the model, spending cuts are statistically associated with lower nominal wages and employment, a fall in the relative price of non-traded consumption goods, a shift of consumption towards non-tradables, as well as an increase in net exports.

We then analyze and discuss three discrepancies between the data and the baseline model. First, the empirical evidence on the devaluationary effects of consumption taxes is weak at best, with the exception that higher taxes are associated with a stronger fall in employment. Second, the empirically observed size of the internal devaluation associated with government spending cuts is several times larger than predicted by the model. And finally, and potentially most puzzling, austerity is not associated with movements in the terms of trade. To address the first two issues, we consider a variation of our model that takes into account two features of the data: the home bias for government purchases is higher than for private consumption, and tax hikes were concentrated on tradable consumption goods. Although moving the model predictions in the right direction, these modifications have quantitatively small effects. We then propose a variation of our model economy that features Greenwood et al. (1988) (GHH) preferences. These preferences remove the wealth effect on labor supply, so that households no longer raise their labor supply (and put downward pressure on wages) in response to higher taxes. This means that higher taxes might not lead to lower wages and internal devaluations, consistent with the weak relationship found in the data. GHH preferences also feature consumption-labor complementarities that amplify the effects of cuts to government spending, bringing the model results quantitatively closer to the empirical findings.

A last discrepancy between model and data is the "missing" terms of trade response 
to fiscal austerity in the data: Austere countries did not experience deteriorating terms of trade. We show that in the data, spending cuts are associated with neither movements in import prices (consistent with the model) nor movements in export prices (inconsistent with the model). That is, we find that lower nominal wages do not translate into lower export prices. We then provide some evidence based on industry-level data consistent with the view that export prices did not fall in austere countries because exporting firms raised markups. Concurrently, we find that higher net exports observed in austere countries solely derive from a fall in imports, not a boost to exports. Taken together, austerity is linked to what we call "asymmetric" expenditure switching, with domestic agents in austere countries switching towards domestically produced goods, but foreign agents not switching to goods produced in austere countries.

Our work has important policy implications. First, our empirical results highlight that internal devaluations took place in countries pursuing austerity, but its effects were asymmetric, with domestic agents in austere countries switching towards domestically produced goods, but foreign agents not switching to goods produced in austere countries. This casts doubt on the idea that there actually is a silver lining to austerity in form of a stronger export performance. While prices of traded goods seem to react little to austerity, our analysis does, however, suggest that changes in demand affect trade patterns. Our findings therefore support the view that current account adjustments in the euro area require policy changes from both deficit and surplus countries, with expansionary fiscal policy in surplus countries potentially being a key mechanism to raise exports in deficit countries.

Second, both our empirical and theoretical results imply that the composition of austerity packages matters. According to our model with GHH preferences (that is generally consistent with the data), consumption tax increases depress economic activity, but do not make economies more competitive through lower nominal wages. In turn, spending cuts lead to strong internal devaluations with both nominal wages and the relative price of non-tradables falling. This is not only relevant for policy makers, but also for empirical researchers because it suggests that the estimated economic effects of changes in the primary government balances are bound to differ across samples, simply because these changes often hide a variety of different fiscal measures that move the economy in different directions.

Third, our analysis is consistent with the idea that fiscal policy influences prices. A fiscal authority's ability to influence real exchange rates seems particularly crucial in a monetary union, where monetary policy can no longer respond to country-specific inflation dynamics. 
National fiscal policy is therefore the only tool left to re-align real exchange rates across countries. Whether such a policy is desirable depends on the specific circumstances. As pointed out by Blanchard and Giavazzi (2002), fiscal policy should not react to real exchange rate movements caused by convergence dynamics through the Balassa-Samuelson effect (observed in poorer European countries as they entered the euro area) because such a policy would largely eliminate the benefits of economic integration. A contrasting view is provided by Schmitt-Grohé and Uribe (2016) who present a model economy with downward nominal wage rigidity. ${ }^{3}$ The inflow of capital in booms leads to a real exchange appreciation with higher nominal wages, putting the economy in a vulnerable situation for the downturn when wage rigidity and fixed exchange rates prevent real wages from falling. Our empirical observations suggests that fiscal policy, in particular cuts to government spending, can be used as a preventive tool to curb aggregate demand during the boom and avoid periods of high unemployment during subsequent recessions.

Finally, our paper documents large changes in the relative price of non-traded goods associated with cuts to government spending. To the extent that households differ in their consumption patterns, austerity might therefore have led to substantial welfare redistribution across households. ${ }^{4}$ It is also conceivable that austerity went along with changes in relative incomes, both across types of income (labor income vs. capital income) and across sectors (income from traded sectors vs. income from non-traded sectors), potentially further exacerbating redistributions of purchasing power. We therefore believe that it might be a possibly fruitful avenue for future research to analyze these distributional effects of fiscal policy.

The rest of the paper is organized as follows. After discussing the related literature, we present a small-open economy model in the next section to derive its implications of fiscal policy changes. Section 3 presents data, empirical strategy and empirical results. We then discuss data-model discrepancies in Section 4.

\footnotetext{
${ }^{3}$ Other papers have also expressed concerns about diverging inflation rates within monetary unions because they might leave some countries in deflationary territory (Sinn and Reutter, 2001; Kieler, 2003), lead to boombust cycles through balance sheets if low real interest rates (as a consequence of high inflation) fuel excessive debt accumulation (Honohan and Lane, 2003), or undermine relative competitiveness (European Central Bank, 2003).

${ }^{4} \mathrm{~A}$ recent literature has emphasized that households at different income levels consume very different baskets of goods. For instance, Cravino and Levchenko (2017) show that the 1994 devaluation of the Mexican peso raised the cost of living for poor households in particular because they consume more tradable goods.
} 


\subsection{Related Literature}

The issue of internal devaluations has most prominently been discussed in Farhi et al. (2013) who show in a theoretical framework that increases in value-added taxes together with a uniform reduction in the payroll tax can mimic the real allocations of a nominal exchange rate devaluation in a standard small open economy setting. These fiscal devaluations solely rely on relative tax changes and are revenue neutral by construction. In contrast, our starting point are actual fiscal policies implemented throughout the euro area over the 2010-2014 period: These fiscal policies were not designed to be revenue neutral and, as seen in Figure 1, involved a large fraction of cuts to government spending. We therefore extend the analysis in Farhi et al. (2013) to include changes in government spending. But since government spending itself is a real variable, the observed fiscal policy changes cannot mimic the real allocations of nominal exchange rate devaluations. Instead, we shift the focus to whether austerity policies led to a real exchange rate devaluation together with relative price changes and expenditure switching that are typically associated with real exchange rate movements.

More generally, our paper speaks to a large literature that tries to explain movements in real exchange rates. The central theoretical framework for interpreting real exchange rates is the Balassa-Samuelson model, in which persistent movements in real exchange rates are driven by cross-country differentials in total factor productivity. While initial evidence for high-income countries was weak (see e.g. Rogoff, 1996), Berka et al. (2018) find support for an amended Balassa-Samuelson effect in a sample of European countries for 1995 - 2009, where both total factor productivity and unit labor costs help explain real exchange rate movements. Our results are complementary to theirs and suggest that, for the period 2010 - 2014, fiscal policy was a key driver of real exchange rate movements in the euro area. ${ }^{5}$

We are not the first to study the relationship between government spending and real exchange rate or price movements. Overall, this literature has produced inconclusive results: In contrast to our results and standard economic models, Ravn et al. (2007) and Monacelli and Perotti (2010) find that government spending cuts lead to real exchange rate appreciations in a sample of floating exchange rate countries, giving rise to a "real exchange rate puzzle" ${ }^{6}$ Several studies report ambiguous results, including Ilzetzki et al. (2013), Perotti (2004) and

\footnotetext{
${ }^{5}$ In the Appendix, we show that variations in TFP cannot account for the observed cross-sectional variation in the real exchange rate.

${ }^{6}$ Both Monacelli and Perotti (2010) and Ravn et al. (2007) provide theories wherein non-standard preferences lead to real exchange rate appreciations in response to government spending cuts.
} 
Auerbach and Gorodnichenko (2012). In line with our results, Born et al. (2013) and Beetsma et al. (2008) also find real exchange rate depreciations in response to reductions in government purchases. Similarly, examining the experience of nine European countries during six years around the introduction of the euro, Canova and Pappa (2007) find that deficit-financed expansionary fiscal disturbances increased price differentials. Our paper differs from these studies in a number of ways: First, we focus on an episode with historically large cuts to government spending within a currency union, where real exchange rate movements are mostly driven by inflation differentials instead of nominal exchange rate movements. Second, we also study the response to tax changes. Third, and most importantly, our work differs from the papers above as we include the terms of trade and the ratio of non-traded to traded prices to our analysis, thereby capturing several facets of relative price movements.

In terms of empirical methodology, we follow Blanchard and Leigh (2013) and House et al. (2017) who examine cross-country differences in forecast errors of fiscal and economic variables during the period after the Great Recession. While both studies highlight the effects of forecast deviations in government spending on economic activity, we shift the focus on relative price effects and outcomes linked to internal devaluation. As both studies emphasized, these forecast errors are unlikely to be completely orthogonal to economic conditions, but we believe that examining their covariance patterns does provide information on the effects of arguably large fiscal policy changes on relative prices and expenditure switching. The motivating question for the empirical analysis is whether the data is consistent with the theoretical predictions of a fiscal devaluation that manifests itself in the real exchange rate, the labor market, trade and relative consumption patterns. To answer this question, we follow the lead of the aforementioned studies and deliberately employ a cross-sectional analysis (as opposed to a panel analysis) because our interest lies in whether internal devaluations actually took place, at least in the medium run, rather than their dynamic behavior.

\section{A Small-Open Economy Model}

This section describes a small-open economy model that serves as a framework to guide our data analysis. We use the model to show that austerity, which we define as cuts in government spending or increases in value added taxes (VAT), leads to an internal devaluation. Internal devaluations go along with changes in relative prices and quantities, which, in the next section, we will measure in the data and relate to empirical measures of fiscal austerity to test the 
model's predictions.

As in Gali and Monacelli (2005), we think of the small-open economy (SOE) as one of a continuum of economies that together form a currency union. We assume that both nominal prices and nominal wages are fully flexible, so that the currency union setup has no implications on the behavior of real variables. Our choice of a neoclassical setup is driven by our empirical strategy to study the average effects of fiscal policy over a five year horizon. While nominal rigidities might be important in shaping an economy's short-run response to austerity, we study the effect of austerity on prices over a five-year period. We believe that such a time period is sufficient for prices to adjust even in the presence of nominal rigidities. For this reason, the neoclassical framework is appropriate for the analysis. Moreover, it also allows us to derive the relevant implications for the data in closed-form.

We introduce two extensions to the well-known SOE framework presented in Gali and Monacelli (2005): First, we add fiscal policy by allowing the government to purchase goods and raise VAT. Second, we introduce a non-traded final consumption good to capture this important aspect of the data. This allows us to study the implications of fiscal policy on the relative price and relative consumption of non-traded to traded goods. This serves as an additional moment for our model-data comparison. The SOE is populated by a representative household, a representative producer, a representative retailer and a government. We start by discussing the household's problem.

\section{$2.1 \quad$ Households}

At date 0, the expected discounted sum of future period utilities for the representative household is given by

$$
\sum_{t=0}^{\infty} \sum_{s^{t}} \pi\left(s^{t}\right) \beta^{t}\left(\frac{C\left(s^{t}\right)^{1-\frac{1}{\sigma}}}{1-\frac{1}{\sigma}}-\kappa \frac{L\left(s^{t}\right)^{1+\frac{1}{\eta}}}{1+\frac{1}{\eta}}\right),
$$

where $\beta<1$ is the subjective time discount factor, $\sigma$ is the elasticity of intertemporal substitution, $\eta$ is the Frisch labor supply elasticity, $L_{t}$ is the household's labor input and $C_{t}$ is defined as ${ }^{7}$

$$
C_{t}=C_{T, t}^{\gamma} C_{N, t}^{1-\gamma}
$$

\footnotetext{
${ }^{7}$ Unless confusion arises, we write $X_{t}$ for $X\left(s^{t}\right)$.
} 
That is, overall consumption $C$ consists of two consumption goods, a traded good $(T)$ and a non-traded good $(N)$, with $\gamma$ denoting the weight that the household puts on consumption of the traded good. The consumption goods' nominal retail prices are $P_{T, t}^{r e t}$ and $P_{N, t}^{r e t}$. Households supply labor to the producers and in return, earn nominal wages $W_{t} L_{t}$. Households may also receive payments from state-contingent bonds, with $b_{t}\left(s_{t+1}\right)$ denoting the quantity purchased by the household after history $s^{t}$ and $a_{t}\left(s_{t+1}\right)$ their corresponding nominal price (in units of the union's currency). Finally, households receive lump-sum transfers $T_{t}$ from the government. Households choose state-contingent consumption sequences, $C_{T, t}$ and $C_{N, t}$, and labor sequences, $L_{t}$, to maximize the expected discounted sum of future period utilities subject to a sequence of budget constraints:

$$
P_{T, t}^{r e t} C_{T, t}+P_{N, t}^{r e t} C_{N, t}+\sum_{s^{t+1}} a_{t}\left(s_{t+1}\right) b_{t}\left(s_{t+1}\right)=W_{t} L_{t}+T_{t}+b_{t-1}\left(s_{t}\right)
$$

The household optimally spends a constant fraction on the traded and the non-traded good:

$$
P_{T, t}^{r e t} C_{T, t}=\gamma P_{t}^{r e t} C_{t} \quad \text { and } \quad P_{N, t}^{r e t} C_{N, t}=(1-\gamma) P_{t}^{r e t} C_{t}
$$

where the aggregate consumption retail price index is given by

$$
P_{t}^{r e t}=\left(\frac{P_{T, t}^{r e t}}{\gamma}\right)^{\gamma}\left(\frac{P_{N, t}^{r e t}}{1-\gamma}\right)^{1-\gamma}
$$

The household's Euler equation for purchases of state contingent bonds $b_{t}\left(s_{t+1}\right)$ requires

$$
\frac{a\left(s^{t}, s_{t+1}\right)}{P^{r e t}\left(s^{t}\right) C\left(s^{t}\right)}=\frac{\beta \pi\left(s^{t+1} \mid s^{t}\right)}{P^{r e t}\left(s^{t+1}\right) C\left(s^{t+1}\right)}
$$

and the labor supply condition is

$$
\kappa L_{t}^{\frac{1}{\eta}} C_{t}=\frac{W_{t}}{P_{t}^{r e t}}
$$

\section{$2.2 \quad$ Firms}

The economy is populated by two types of firms: producers and retailers. Producers are perfectly competitive and employ labor to produce an intermediate good. Some of these intermediate goods are shipped overseas. The remaining goods are sold to perfectly competitive retailers. These retailers produce two distinct goods, an $N$ good that only requires domestic 
intermediates, and a $T$ good that requires both domestic intermediates and imported intermediates. Households and the government then purchase these goods from the two retailers. We augment this production structure by a value added tax. In accordance with laws in the EU, value added taxes are also paid on imports, but are rebated for exports. In the EU, these value added taxes are assessed incrementally, based on the increase in value of a product at each stage of production. In our framework, this would suggest that intermediate good producers pay VAT on their value added. Since we assume flexible prices and perfect competition for producers, producers would simply pass-through the tax burden to retailers. The tax incidence among the two types of firms is therefore irrelevant for the dynamics of the model. For expositional purposes, we therefore assume that only retailers pay the value added tax on the total value of their output.

Retailers. Retailers operate in one of two sectors, $j=N, T$. Retailers in sector $N$ purchase intermediate goods from domestic producers, $y_{N, t}$, at the nominal price $P_{I, t}$ and sell them at price $P_{N, t}^{r e t}$. Retailers pay a value added tax to the government, with the tax rate $\tau_{t}$ applied to the pre-tax price. Tax payments per sold product are therefore given by $\frac{\tau_{t}}{1+\tau_{t}} P_{N, t}^{r e t}$. Profit maximization and perfect competition imply that the retail price of the non-traded good is simply $P_{N, t}^{r e t}=\left(1+\tau_{t}\right) P_{I, t}$.

Retailers in sector $T$ purchase both domestic intermediate goods, $y_{T, t}$, and intermediate goods from overseas, $m_{t}$, whose price is normalized to unity. Their maximization problem is

$$
\max _{y_{T, t}, m_{t}}\left\{\left(1-\frac{\tau_{t}}{1+\tau_{t}}\right) P_{T, t}^{r e t} Y_{T, t}-P_{I, t} y_{T, t}-m_{t}\right\}
$$

subject to the production function

$$
Y_{T, t}=\left(\omega^{\frac{1}{\psi}} y_{T, t}^{\frac{\psi-1}{\psi}}+(1-\omega)^{\frac{1}{\psi}} m_{t}^{\frac{\psi-1}{\psi}}\right)^{\frac{\psi}{\psi-1}}
$$

Here, $\psi$ denotes the elasticity of substitution between domestic and imported intermediate goods. Demand for domestic intermediate goods and imports is

$$
y_{T, t}=\omega Y_{T, t}\left(\frac{P_{T, t}^{r e t}}{1+\tau_{t}}\right)^{\psi} P_{I, t}^{-\psi} \quad \text { and } \quad m_{t}=(1-\omega) Y_{T, t}\left(\frac{P_{T, t}^{r e t}}{1+\tau_{t}}\right)^{\psi} \text {. }
$$


Producers. Producers of intermediate goods are perfectly competitive in both input and output markets. They sell their output at price $P_{I, t}$ to retailers that either operate domestically or abroad. To produce, they hire workers at a wage rate $W_{t}$. Assuming the production function

$$
Y_{I, t}=L_{t}
$$

perfect competition ensures that the price of the intermediate good is simply

$$
P_{I, t}=W_{t}
$$

Producers face the following demand curve for their exports:

$$
x_{t}=D P_{I, t}^{-\psi}
$$

where $D$ is a constant demand shifter.

\subsection{Fiscal Policy}

The government has access to three fiscal instruments: purchases of the government consumption good, $G_{t}$, a value added tax, $\tau_{t}$, and lump-sum transfers, $T_{t}$. Similar to households, the government splits its purchases across the two final goods, with $\gamma$ denoting the share that falls on good T. Both government purchases and the value added tax rate follow an auto-regressive process:

$$
G_{t}=\left(1-\rho_{G}\right) G+\rho_{G} G_{t-1}+\varepsilon_{t}^{G} \quad \text { and } \quad \tau_{t}=\left(1-\rho_{\tau}\right) \tau+\rho_{\tau} \tau_{t-1}+\varepsilon_{t}^{\tau}
$$

We assume that lump-sum transfers always adjust to satisfy the government budget constraint:

$$
\left[\gamma P_{T, t}+(1-\gamma) P_{N, t}\right] G_{t}+T_{t}=\frac{\tau_{t}}{1+\tau_{t}}\left(P_{T, t}^{r e t} C_{T, t}+P_{N, t}^{r e t} C_{N, t}\right)
$$

\subsection{Market Clearing}

The market clearing of the intermediate good requires its production, $Y_{I, t}$, to equal purchases by domestic retailers, $y_{N, t}$ and $y_{T, t}$, and exports, $x_{t}$ :

$$
Y_{I, t}=y_{N, t}+y_{T, t}+x_{t}
$$


Similarly, the market clearing conditions for the final goods are

$$
Y_{T, t}=\gamma G_{t}+C_{T, t} \quad \text { and } \quad Y_{N, t}=(1-\gamma) G_{t}+C_{N, t} .
$$

Real GDP is defined as the production of the intermediate good, $G D P_{t}=Y_{I, t}$, which, in our model, is equal to employment, $L_{t}$.

\subsection{Fiscal Policy and Internal Devaluation}

In this section, we present a few relationship that characterize the economy's response to changes in fiscal policy and that we will then take to the data. For that purpose, we loglinearize the model around its non-stochastic steady state.

Internal Devaluation We first formalize the idea of an internal devaluation. We define an internal devaluation as a policy that maintains a constant nominal exchange rate, but triggers a devaluation of the real exchange rate at constant VAT rates. The real exchange rate is the price of the union wide's consumption basket relative to the SOE's consumption basket. Since the nominal exchange rate is fixed, and so is the CPI abroad, changes in the real exchange rate are inversely proportional to changes in the domestic CPI. Movements in the real exchange rate at constant VAT rates are then simply changes in the relative price of consumption baskets at constant VAT rates (the tilde refers to log variations from steady-state values):

$$
\widetilde{Q}_{t}^{c t}=-\widetilde{P}_{t}
$$

where $c t$ underlines that the real exchange rate is measured 'at constant tax rates' and $P_{t}$ is the pre-tax price of the final consumption good. A real exchange rate devaluation for the $\mathrm{SOE}$ corresponds to a decline in the relative pre-tax price of the SOE's consumption basket, i.e. an increase in $Q_{t}^{c t}$. The consumption basket is a composite of traded and non-traded goods, so that

$$
\widetilde{P}_{t}=\gamma \widetilde{P}_{T, t}+(1-\gamma) \widetilde{P}_{N, t}
$$

Changes in the pre-tax price of the non-traded good are equal to changes in the cost of

producing the good, that is changes in wages, $\widetilde{P}_{N, t}=\widetilde{W}_{t}$. The price of the traded good only partially depends on domestic wages and partially on the price of imports, which, in this SOE 
setup of a currency union, is constant over time, so that $\widetilde{P}_{T, t}=\omega \widetilde{W}_{t}$. This implies that

$$
\widetilde{Q}_{t}^{c t}=-[1-\gamma(1-\omega)] \widetilde{W}_{t}
$$

Intuitively, the SOE's real exchange rate at constant VAT rates depreciates when the pretax price of the final consumption good falls, which is equivalent to a fall in nominal wages. Changes in the domestic wage level only affect the real exchange rate to the extent that the SOE consumes domestic goods, with $1-\gamma(1-\omega)$ denoting the cost share of domestic inputs in the consumer's final basket.

Fiscal Policy We now formulate our main result that fiscal austerity, defined as a cut in government spending or an increase in the VAT, leads to an internal devaluation: ${ }^{8}$

$$
\widetilde{Q}_{t}^{c t}=-\left[\frac{C\left(1-\gamma\left(1-\omega^{2}\right)\right)+\psi \gamma\left(1-\omega^{2}\right)+\eta}{(1-\gamma(1-\omega))^{2}}-C(1-\sigma)\right]^{-1}\left(\Delta G_{t}-\sigma C \frac{\Delta \tau_{t}}{1+\tau}\right)
$$

where we normalize steady-state GDP to one, so that $\Delta G$ corresponds to the change in government spending in percent of steady-state GDP and $C$ is the share of consumption in GDP. $C \frac{\Delta \tau_{t}}{1+\tau}$ is then the change in tax revenue in percent of steady-state GDP, so that both fiscal policy measures are expressed in units of steady-state GDP. ${ }^{9}$ Intuitively, austerity, $\Delta G_{t}<0$ or $\Delta \tau_{t}>0$, lowers the demand for domestic goods and, by extension, for domestic labor, either directly through a reduction in government spending, or, indirectly through an increase in the VAT that lowers households' purchasing power. This puts downward pressure on wages, which will lead to lower pre-tax retail prices and hence a depreciation of the real exchange rate at constant VAT rates, $\widetilde{Q}_{t}^{c t}>0$.

This equation also clarifies whether the composition of austerity matters. Are spendingbased or revenue-based austerity programs more effective in generating internal devaluations? If the elasticity of intertemporal substitution equals one $(\sigma=1)$, the composition of austerity programs does not matter; all that matters is the size of the program. For a lower elasticity $(\sigma<1)$, revenue-based austerity is less effective than spending-based austerity. And the opposite is true for a higher elasticity. Intuitively, a low elasticity implies a smoother response of consumption to changes in taxes. A tax hike with a low elasticity therefore leads to a

\footnotetext{
${ }^{8}$ See the Appendix for a derivation.

${ }^{9}$ This assumes static scoring that ignores the response of $C$ (and associated changes in tax revenue) to changes in fiscal policy.
} 
smaller fall in consumption and demand, putting less downward pressure on wages and the real exchange rate.

Discussion and Testable Implications So far, we have shown that austerity leads to a real exchange rate devaluation (see equation (2.6)) and a fall in wages (see equation (2.5)). A first implication of this is that austerity is also recessionary. This can be seen from the labor supply condition stating that the real wage equals the marginal rate of substitution of the household:

$$
\widetilde{W}_{t}-\widetilde{P}_{t}^{r e t}=\frac{1}{\eta} \widetilde{L}_{t}+\frac{1}{\sigma} \widetilde{C}_{t}
$$

The Backus-Smith condition guarantees that movements in consumption are directly linked to changes in the real exchange rate, which, in a currency union, are inversely related to changes in the retail price level: $\frac{1}{\sigma} \widetilde{C}_{t}=-\widetilde{P}_{t}^{r e t}$. It therefore follows a simple relationship between the nominal wage and employment:

$$
\widetilde{L}_{t}=\eta \widetilde{W}_{t}
$$

Austerity therefore lowers employment because it depresses wages by reducing demand for domestic goods.

But there is a flip side to this fall in wages emphasized in debates in the policy arena and the media, where internal devaluations are generally understood as a fall in wages that boosts a country's "competitiveness" in the absence of nominal exchange rate movements (see e.g. Eichengreen, 2012). ${ }^{10}$ The idea is that lower wages will translate into lower export prices and higher exports. Similar to an external devaluation, an internal devaluation is therefore intended to lower the price of exports relative to the price of imports. This link between wages and the terms of trade is present in our model. As a matter of fact, the terms of trade, defined as the price of exports relative to the price of imports and denoted by $S_{t}$, is identical to the nominal wage in our model because import prices are equal to one and export prices are identical to the wage rate:

$$
\widetilde{S}_{t}=\widetilde{W_{t}}
$$

A terms of trade deterioration is a fall in the relative price of exports, i.e. a decline in $S_{t}$ and $W_{t}$. This terms of trade deterioration goes along with a current account improvement.

\footnotetext{
${ }^{10}$ See also the Financial Times that defines internal devaluation as "the reduction in nominal wages to regain labour competitiveness." https://www.ft.com/content/8626a02e-a35d-11e1-988e-00144feabdc0
} 
To see this, note that net exports in percent of steady-state GDP are proportional to percent changes in exports minus percent changes in imports ${ }^{11}$

$$
\begin{aligned}
\Delta n x_{t} & =\gamma(1-\omega)\left(\widetilde{x}_{t}-\widetilde{m}_{t}\right) \\
& =\gamma(1-\omega)\left(-\psi \widetilde{S}_{t}-\omega \psi \widetilde{S}_{t}-\widetilde{Y}_{T, t}\right)
\end{aligned}
$$

where $\gamma(1-\omega)$ is the economy's overall import (and export) share in steady state. The expression shows that both exports and imports depend on changes in domestic wages, which, in our setup with a constant price for imports, equal changes in the terms of trade, $\widetilde{W}_{t}=$ $\widetilde{S}_{t}$. Intuitively, since austerity will lower wages and hence the price of exports, exports are predicted to increase as foreigners switch towards these cheaper goods, whereas imports are predicted to fall. Imports fall because the fall in wages makes domestic products relatively cheaper, so that consumers switch from imports to domestic products, and because of an overall reduction in expenditure on the traded good, $Y_{T}$.

Our model has also implications for expenditure switching across consumption goods. As discussed above, the relative (retail) price of the non-traded good is directly linked to changes in wages

$$
\widetilde{P}_{N, t}^{r e t}-\widetilde{P}_{T, t}^{r e t}=(1-\omega) \widetilde{W}_{t}
$$

The fall in wages benefits more non-traded goods, so that their relative price should fall. This implies that austerity goes along with a rise in the relative consumption of non-traded goods because

$$
\widetilde{C}_{N, t}-\widetilde{C}_{T, t}=-\left(\widetilde{P}_{N, t}^{r e t}-\widetilde{P}_{T, t}^{r e t}\right)
$$

Of course, the magnitude of this expenditure switching in response to changes in relative retail prices depends on the elasticity of substitution between traded and non-traded goods, which, by assumption, is set to one in equation (2.1).

\footnotetext{
${ }^{11} \log$-linearizing the demand for exports and noting that $\widetilde{P}_{I, t}=\widetilde{W}_{t}=\widetilde{S}_{t}$ gives

$$
\widetilde{x}_{t}=-\psi \widetilde{S}_{t}
$$
}

Log-linearizing the demand for imports gives

$$
\widetilde{m}_{t}=\psi \widetilde{P}_{T, t}+\widetilde{Y}_{T, t}
$$

with $\widetilde{P}_{T, t}=\omega \widetilde{W}_{t}=\omega \widetilde{S}_{t}$ 
Table 1 summarizes the predictions of the model. The columns entitled 'Model' display elasticities to government purchases and consumption taxes (both expressed in percent of steady-state GDP) of the real exchange rate at constant tax rates, nominal wages, employment, the terms of trade, net exports and the relative price and consumption of non-tradables. To put values on these elasticities, we calibrate our model to standard values in the literature (see Table 2). The share of traded goods and the home bias for traded goods are in the range of values for European countries reported in Lambertini and Proebsting (2018). They imply an overall import share of 0.24 . The elasticity of intertemporal substitution is set to the standard value of 0.5 as in Heathcote and Perri (2002) and Backus et al. (1994). Given equation (2.6), this implies that consumption taxes are half as effective as cuts to government spending in generating an internal devaluation. For example, according to Table 1 a cut in government spending by 1 percent of GDP lowers nominal wages by 0.47 percent. An increase

in consumption taxes by 1 percent of GDP lowers nominal wages by half of that, that is 0.23 percent. Apart from this difference in magnitudes, austerity through either cuts to government spending or increases in consumption taxes are predicted to lead to an internal devaluation that will

(i) lower nominal wages and employment,

(ii) deteriorate the terms of trade and raise net exports, and

(iii) lower the relative retail price and raise relative consumption of non-tradables.

By summarizing the model's prediction, Table 1 serves as a benchmark for our empirical results, both in qualitative and quantitative terms. Although we acknowledge that our model is deliberately simple and not set up for a rigorous quantitative exercise, we believe that there is still a value added in examining whether the empirical results roughly match the magnitudes predicted by the model.

\section{Empirical Relationships Between Austerity and In- ternal Devaluation}

After discussing the data sources, we present our main empirical approach and results. 


\subsection{Data}

Geographical Coverage We focus our analysis on the eleven initial members of the euro area, plus Greece that joined in 2001 two years after the introduction of the euro, and Denmark whose currency is pegged to the euro and is also a member of the European Union. ${ }^{12}$ We exclude the seven Central and Eastern European countries that joined the euro area later from our analysis because their real exchange rate dynamics were arguably influenced by an economic catching up process that is unrelated to fiscal policy (Égert, 2011). This leaves us with thirteen relatively homogenous economies with no movements in bilateral exchange rates. All data is taken from Eurostat.

Data on Fiscal Variables Government purchases are the sum of government consumption and government gross fixed capital formation, deflated by the GDP deflator. Government consumption is directly published in the national accounts, while data on gross fixed capital formation is taken from the government accounts. ${ }^{13}$

We measure changes in the consumption tax rate as the difference between the consumer price inflation and consumer price inflation measured at constant tax rates. Data on consumer price inflation is provided by the Harmonized Index of Consumer Prices (HICP) that measures the change in retail prices for all countries of the European Union using a common methodology. Eurostat also publishes an HICP at constant tax rates that keeps VAT and excise duties (e.g. on alcoholic beverages, tobacco and energy items) constant. By subtracting this constant-tax-rate inflation from the actual inflation rate, we obtain an implicit measure of the change in consumption taxes. One advantage of this measure relative to changes in the standard VAT rate is that it encompasses all consumption tax changes and weights them according to the basket weights of the HICP. ${ }^{14}$

Data on Real Exchange Rate Consistent with model equation (2.4), our measure of country $i$ 's real exchange rate at constant tax rates is the country's HICP at constant tax rates relative to the sample-wide HICP at constant tax rates. Changes in this real exchange rate indicate changes in the (pre-tax) price of country $i$ 's consumption good relative to the

\footnotetext{
${ }^{12}$ The founding members are Austria, Belgium, France, Finland, Germany, Ireland, Italy, Luxembourg, the Netherlands, Portugal and Spain.

${ }^{13}$ The data on gross fixed capital formation includes used goods, which we remove as much as possible.

${ }^{14}$ The HICP at constant tax rates is provided by Eurostat at the overall level and for five main categories since 2003, and at the detailed level since 2006.
} 
(pre-tax) price of the average consumption good in our sample.

Data on Labor Market We measure wages using the Harmonized Labor Cost Index (HLCI) published by Eurostat. The HLCI is the counterpart of the HICP for labor costs. As the HICP, the HLCI is a chain-linked Laspeyres index that takes a weighted average of wage growth across industries. One important advantage of this index is that it tracks salaries of specific jobs and is therefore less prone to composition bias than unit labor cost indices based on aggregate data. To measure wage growth, we use the main index 'total labor costs per effective hour of work' that comprise the total costs incurred by an employer including non-wage payments such as obligatory social security contributions.

Data on employment is taken from the auxiliary indicators of the national accounts. Employment is measured as a share of the active population to control for long-term trends in employment that are due to population movements, population ageing and changes in labor force participation by women.

Data on Trade Changes in the terms of trade are calculated as the change in the export price index less the change in the import price index. Export and import price indices are calculated as the implicit price deflator from national account data on exports and imports in nominal and real terms. These indices are commonly used in the literature (see e.g. Burstein and Gopinath, 2014, and citations therein).

Data on net exports is taken from the national accounts. The net export measure is real exports in date t, less real imports in date t divided by real GDP averaged over 2003 - 2009.

Data on Relative Consumption To calculate changes in the relative price of non-traded consumption, we make use of the HICP subindices. The HICP published by Eurostat distinguishes between 90 different consumption categories (COICOP 4-digit). ${ }^{15}$ We classifiy these consumption categories into traded and non-traded goods along the lines of Lambertini and Proebsting (2018) who use country-specific input-output tables to calculate direct import shares for each consumption category. ${ }^{16}$ Then, averaging across countries, they find that about 37 out of 90 goods, representing about 40 percent of countries' consumption baskets,

\footnotetext{
${ }^{15}$ COICOP stands for 'Classification of Individual Consumption by Purpose'.

${ }^{16}$ The direct import share is based only on the share of consumption goods that are directly imported, ignoring indirect imports of intermediate goods that are then used for the production of domestic consumption goods.
} 
have an import share of less than 10 percent, most of them being services. We classify these goods as non-traded, and all other goods as traded. We then calculate the change in the relative price of non-traded consumption as the inflation rate of non-traded goods less the inflation rate of traded goods. ${ }^{17}$

Data on consumption of non-traded and traded goods is taken from the detailed breakdown of the national accounts. Eurostat publishes annual data on final consumption expenditure of households for 48 consumption categories (COICOP 3-digit). We disaggregate this data to the 4-digit level by applying annually updated consumption basket weights used for constructing the HICP. We then apply the same classification as above to construct series of non-traded and traded consumption. We deflate the two series using the price indices for traded and non-traded consumption goods.

\subsection{Empirical Strategy}

To quantify the movements in government spending and tax rates observed in Figure 1 and relate them to our measures of internal devaluations discussed in the previous section, we draw on earlier work by House et al. (2017) who regress average forecast errors in macroeconomic variables on average forecast errors on fiscal variables over the time period 2010 - 2014. Our main specification is

$$
\tilde{x}_{i,{ }^{\prime} 10-' 14}=\alpha+\beta_{g} g_{i} \widetilde{G}_{i,{ }^{\prime} 10-'{ }^{\prime} 14}+\beta_{\tau} \frac{c_{i}}{1+\tau_{i}} \Delta \tau_{i,{ }^{\prime} 10-'{ }^{\prime} 14}+\varepsilon_{i}
$$

where $\tilde{x}_{i,{ }^{\prime} 10-'{ }^{\prime} 14}=\frac{1}{5} \sum_{t={ }^{\prime} 10}^{\prime}\left(\ln x_{i, t}-\ln \hat{x}_{i, t}\right)$ is the average forecast error of country $i$ 's macroeconomic variable $x, \widetilde{G}_{i,{ }^{\prime} 10-' 14}$ is the average forecast error of government spending, and $\Delta \tau_{i,{ }^{\prime} 10-{ }^{\prime} 14}=$ $\frac{1}{5} \sum_{t=' 10}^{\prime 14}\left(\tau_{i, t}-\hat{\tau}_{i}\right)$ is the average forecast error of the consumption tax rate expressed in percentage points.

We premultiply the forecast error in $G$ by a country's (pre-crisis) share of government purchases in GDP, $g_{i}$, to express it in percent of GDP. Similarly, we premultiply the forecast error in the consumption tax rate by a country's (pre-crisis) share of household consumption in GDP, $c_{i}$, and divide it by the gross tax rate, $1+\tau_{i}$. By doing so, we express our tax variable in

\footnotetext{
${ }^{17}$ In constructing separate price indices for traded and non-traded goods, we exclude categories whose prices are directly set by the government since the dynamics of these prices are less likely to reflect market forces. Information specifying which consumption categories feature partially or fully administered prices is provided by Eurostat at an annual frequency and specific to each country. We find that the set of administered prices changes little over time. Still, to avoid compositional effects, we apply the classification of 2009 to our entire sample. Overall, goods with administered prices account for about 11 percent of the consumption basket.
} 
terms of revenue as percent of GDP and therefore in the same units as our spending variable. The coefficients $-\beta_{g}$ and $\beta_{\tau}$ therefore indicate the change in a macroeconomic variable $x$ associated with an austerity policy corresponding to 1 percent of GDP (either through reduced government purchases or an increased tax rate). Scaling our fiscal variables is also consistent with the model and accounts for differences in the size of fiscal sectors observed across countries (see equation (2.6)).

Implementing regression (3.1) requires forecast measures of the various macroeconomic variables. For government purchases, we directly take the forecasts provided in House et al. (2017), which account for both growth convergence dynamics and cyclical patterns. ${ }^{18}$

For the remaining variables, we set up forecasts ourselves. While some studies in similar contexts have resorted to professional forecasts (Blanchard and Leigh, 2013; Auerbach and Gorodnichenko, 2012), such forecasts are only available for a limited set of variables and are done for short horizons of one to three years. Our forecast for country i's tax rate is its value in 2009 , that is

$$
\hat{\tau}_{i}=\tau_{i,{ }^{\prime} 09}
$$

Similarly, for all our price and quantity measures, our forecast is their value in 2009, but updated using their average growth rate over the previous business cycle period 2003 - 2009. Denoting this growth rate by $g r_{i}^{x}$, our forecast is simply

$$
\hat{x}_{i, t}=x_{i,{ }^{\prime} 09}\left(1+g r_{i}^{x}\right)^{t-’ 09}
$$

For the terms of trade, net exports, as well as the relative price and consumption of non-traded goods, we derive forecasts for each of the two components (e.g. export price and import price) and then take the log-difference. ${ }^{19}$ Figures A1a - A1e in the Appendix display actual data and forecasts for all countries in our sample.

\subsection{Austerity and Internal Devaluation in the Data}

We first analyze the relationship between austerity and the CPI-based real exchange rate at constant tax rates. Figure 2 contains simple scatter plots to illustrate this relationship.

\footnotetext{
${ }^{18}$ See our Appendix for more details.

${ }^{19}$ For example, for the terms of trade, we have $\widetilde{T o T}_{i,{ }^{\prime} 10-{ }^{\prime} 14}=\frac{1}{5} \sum_{t={ }^{\prime} 10}^{\prime}\left(\ln P_{i, t}^{x}-\ln \hat{P}_{i, t}^{x}\right)-\left(\ln P_{i, t}^{m}-\ln \hat{P}_{i, t}^{m}\right)$, where $P^{x}$ and $P^{m}$ denote the export and import price indices, respectively. For net exports, we express imports and exports in percent of pre-crisis GDP.
} 
The left panels depict the forecast errors for the real exchange rate on the vertical axis and the two fiscal variables (expressed in percent of GDP) on the horizontal axis (top panel: government purchases, bottom panel: consumption taxes). For the average country in our sample, the real exchange rate was just 1 percent below forecast throughout the period, but the variation across countries is surprisingly large. Since the countries in our sample all share the same currency, the variation in the real exchange rate stems from diverging inflation rates. The cross-sectional standard deviation is 2.7 percent, with countries like Finland and Austria experiencing an average appreciation of 1.5 percent, while others, like Ireland and Greece, seeing their real exchange rate depreciate by an average of 5 percent of more.

Regarding the austerity measures, we observe that (i) spending cuts were four times larger than increases in consumption tax rates, (ii) both policies display a large variation in the cross section, and (iii) both policies were highly correlated, with countries pursuing austerity on the spending side, implementing austerity also on the revenue side. The average country cut its spending by more than 2.5 percent of GDP (with a standard deviation of 2.5 percent) and raised its consumption tax revenue by 0.6 percent of GDP (standard deviation of 0.9 percent). The correlation between the two policies is -0.90 . Overall, Greece tops the austerity list with government purchases about 9 percent of GDP below forecast and a consumption tax revenue of 3 percent of GDP point above its 2009 level throughout the 2010-2014 period. Virtually no country implemented a significant fiscal expansion over this time period, although some countries (e.g. Germany) kept a neutral stance.

When we consider each fiscal policy in isolation (top and bottom left panels of Figure 2), we find that both larger (than forecasted) spending cuts and larger (than forecasted) consumption tax increases are accompanied by larger internal devaluations and real exchange rate depreciations. The estimated coefficient for government spending $\beta_{g}$ is -0.99 and the estimated coefficient for the consumption $\operatorname{tax} \beta_{\tau}$ is 2.34 ; both coefficients are highly significant. When we regress the forecast errors for the real exchange rate on both fiscal measures in the same equation, the estimated coefficient for government spending remains strongly significant while that for the consumption tax switches sign (top and bottom right panels of Figure 2). The strong correlation between the two fiscal measures prevents us from estimating with precision the contribution of each fiscal policy on the real exchange rate. Since government spending forecast errors better explain internal devaluations than tax increases, as suggested by the adjusted $R^{2}$ of the individual regressions, $\beta_{g}$ falls to -1.51 (standard deviation of 0.27 ) at the expense of $\beta_{\tau}$ that changes sign (1.69 with standard deviation of 0.79 ). 
Table 1 summarizes the estimated coefficients obtained from regressing the forecast error for our other measures associated with internal devaluations on one fiscal variable at a time and then on both variables in the same equation as specified in regression (3.1). The elasticities predicted by the model are also reported. The table conveys three main messages.

First, fiscal austerity led to internal devaluation. Austerity was indeed not only accompanied by real exchange rate devaluation at constant VAT rates $\left(Q^{c t}\right)$, but also by a fall in nominal wages $(W)$ and a reduction in the relative price of non-traded goods. In general, the reported adjusted $R^{2}$ s range between 0.7 and 0.9 , suggesting that austerity can account for a large share of the observed relative price movements across countries. An important exception is that we do not find evidence for a terms of trade $(S)$ deterioration. Austerity does not explain the variation in terms of trade observed during our sample period, as illustrated by the negative adjusted $R^{2}$ of that specific regression; the estimated coefficients fail to be significantly different from zero and the coefficient for the VAT rate has the opposite sign relative to the model's prediction. We find that quantities responded according to the narrative of internal devaluation as net exports rose with austerity. There is evidence, as shown by the adjusted $R^{2}$, that austerity also increased the relative consumption of non-traded goods and services even though neither coefficient is statistically significant. As predicted by the model, fiscal austerity was also accompanied by a reduction in employment.

Second, the empirical support for the relationship between austerity and internal devaluation is almost entirely driven by cuts in government spending while the evidence for increases in VAT rates is weak at best and typically mixed. The consumption tax is generally significant and with the predicted sign when it is the only regressor, but it loses significance and, in some cases, also changes sign in the joint regression with government spending. For the case of wages, terms of trade, net exports, and relative price of non-traded goods, adding the forecast error of the VAT rates does not improve the adjusted $R^{2}$. For the case of relative consumption of non-traded goods and services, adding either forecast error does not improve the adjusted $R^{2}$. There is one exception. Employment remains strongly and negatively affected by the consumption tax even after accounting for government spending cuts. When interpreting the numbers in Table 1, we have to keep in mind that our two fiscal policy measures are highly correlated. This multicollinearity poses a problem in precisely estimating the contributions of spending cuts and tax changes. Still, we find it instructive that the regression results typically favor government spending as the more relevant fiscal policy for accounting for the cross-sectional variation observed in the various outcome variables. 
Third, the estimated elasticities of both prices and quantities to government spending cuts are often several times larger than those predicted by the model. Hence, our simple model under-predicts the impact of fiscal policy.

To summarize, we find that the relationship between fiscal austerity and internal devaluation predicted by our model generally holds in the data. There are three important discrepancies: the counterfactual response to consumption tax increases; the model's under-prediction

of the effects of government spending cuts; and a missing terms of trade effect of austerity in the data. We turn to these issues next.

\section{Discrepancies between Model and Data}

As seen in the last section, the model predictions of the internal devaluation effects of austerity are generally borne out by the data. We have noticed three main discrepancies. We start with the first two discrepancies that, taken together, suggest that the composition of austerity packages matters more than the baseline model predicts.

\subsection{Compositional Effects of Austerity}

The first key discrepancy between model and data is the response of the various prices to an increase in the consumption tax rate. The model unambiguously predicts that a tax increase should lead to a devaluation with lower wages and lower relative retail prices of non-traded consumption goods. The empirical results provide little support for this prediction, with point estimates having the wrong sign. The only statistically significant result for consumption taxes is a negative relationship with employment, which - from the model's point of view is surprising given the non-significant effect on nominal wages (see equation (2.5)). A second discrepancy is that government spending cuts lead to substantially larger devaluations in the data than predicted by the model.

As a first step, we consider a simple extension of the model to acknowledge that the direct effects of fiscal policy are unevenly distributed across goods: government spending is concentraded on non-traded goods and services, whereas consumption taxes fall more on traded ones. Both features have the potential to help rationalize the empirical results: Wages should fall more in response to lower spending if this spending was concentrated on nontraded goods. A consumption tax increase on traded goods should fall more on imports and 
therefore have fewer effects on the domestic economy. To test these hypotheses, we make two modifications to the model. First, we assume that 95 percent of government purchases fall on non-traded goods (instead of 40 percent), in line with data from the World Input-Output Tables. Second, we allow for different tax rates for the two consumption goods and consider a tax hike that falls to 80 percent on traded goods and to 20 percent on non-traded goods. The relative size of the two tax changes is consistent with what we observe for the average country in our data sample. Table 3 show the elasticities predicted by the model. The first two rows display the results for the baseline model. Rows 3 and 4 show the elasticities in the modified model that takes the composition of government spending and taxes into account. We observe indeed that cuts to spending have stronger devaluationary effects if spending is more biased towards non-traded goods, with the real exchange now predicted to depreciate by 0.48 percent instead of 0.35 . But this number is still far off the empirical estimate of -1.51 . Similarly, the tax increase is now predicted to lead to a smaller devaluation, but the difference is minor. These changes to the model go in the right directions, but have small quantitative effects.

In a second step, we modify the household's preferences. The model's prediction that consumption taxes lower nominal wages relies on the wealth effect on labor supply. Given a nominal wage $W_{t}$, an increase in the consumption tax rate will raise retail prices $P_{t}^{r e t}$ and lower the real wage. This reduces the household's willingness to supply labor. In the baseline model with separable preferences, the negative wealth effect from a tax increase counterbalances this fall in labor supply. As discussed above, the two effects cancel out and labor supply is only a function of the nominal wage, but not of the consumption tax rate:

$$
\frac{1}{\eta} \widetilde{L}_{t}=\widetilde{W}_{t}
$$

A higher tax rate, however, reduces labor demand because it depresses consumption. Taken together, an increase in taxes will necessarily depress wages through reduced labor demand, and labor will only fall to the extent that nominal wages fall. As we have seen, both of these predictions find little support in the data, where tax hikes have statistically insignificant effects on wages, but a negative effect on employment.

An alternative modelling approach consistent with the empirical results is to assume preferences with small or no wealth effect on labor supply. Prominent examples include the specification introduced by Greenwood et al. (1988) (GHH) or the type of preferences pro- 
posed by Galí (2011). In both cases, the marginal rate of substitution in log-linear form is simply $\frac{1}{\eta} \widetilde{L}_{t}$ and the labor supply condition reads

$$
\frac{1}{\eta} \widetilde{L}_{t}=\gamma(1-\omega) \widetilde{W_{t}}-\frac{\Delta \tau_{t}}{1+\tau}
$$

where we used that $\widetilde{P}_{t}=[1-\gamma(1-\omega)] \widetilde{W}_{t}$. In the absence of the wealth effect, a higher tax lowers the real wage and reduces labor supply. If this effect is strong enough it can outweigh the labor demand effect, so that nominal wages stay put or even go up, while real wages fall. This fall in real wages leads to a decrease in employment, consistent with the empirical results.

The last two rows of Table 3 quantify these differences for the case with GHH preferences. The predictions for the price elasticities of the consumption tax flip signs relative to the baseline model, with nominal wages now predicted to increase following a tax increase. This wage increase goes along with a strong drop in employment.

The table also reveals substantially stronger responses to a cut in government spending relative to the case of separable preferences of both prices and quantities, with magnitudes similar to those observed in the data. For example, the real exchange rate is predicted to depreciate by 1.5 percent for every 1 percent of GDP cut in spending (as in the data). Wages and the terms of trade are predicted to fall by 2 percent, employment by about 1 percent, and net exports are predicted to increase by 0.9 percent. These stronger responses are reminiscent, but different from the finding in Monacelli and Perotti (2010), Bilbiie (2011) and more recently Auclert and Rognlie (2017) who have emphasized that GHH preferences can generate large government spending multipliers in New Keynesian models thanks to labor-consumption complementarities.

The results in Table 3 show that large multipliers do not require sticky prices or wages, but can also occur in neoclassical open economy models. Intuitively, in an open economy, a cut to government spending reduces demand for the domestic good and reduces its price relative to the price of the imported good. This translates into a lower real wage that reduces labor supply. Since consumption and labor are complements, the fall in labor causes a drop in private consumption, which further reduces demand for the domestic good, leading to an even stronger drop in the real wage and employment, and so on. This loop is only at play in open economies because closed economies do not feature any terms of trade effects and hence, the real wage remains unaffected by changes in government spending. As a matter of fact, neoclassical closed economy models with GHH preferences feature a zero multiplier with 
government spending simply crowding out private consumption.

To summarize, this section has rationalized the lack of empirical evidence relating internal devaluation and consumption tax rate and the magnitude of the elasticities to government spending cuts. The first finding is consistent with preferences that have small or no wealth effects on labor supply. The second finding can result from labor-consumption complementarities. A model with GHH preferences therefore produces model predictions that are more in line with the data, compared to a model with separable preferences.

These results suggest that the composition of austerity matters: consumption tax increases depress economic activity, but do not make economies more competitive through lower nominal wages. In turn, cuts to government spending lead to strong internal devaluations, at least in terms of lower nominal wages, and lower relative prices of non-traded consumption goods. However, despite lower nominal wages, the terms of trade are not observed to deteriorate in countries that cut spending. This final discrepancy will be discussed in the next section.

\subsection{Missing Terms of Trade Response}

A final key discrepancy between model and data relates to the terms of trade response. In the model, a cut in government spending reduces wages and therefore the price of exports, leading to a terms of trade deterioration. The results from column (4) (or (6)) in Table 1, however, indicate a very weak response of the terms of trade to cuts in government purchases, especially compared to the much stronger response of domestic wages.

To investigate this discrepancy further, we break up the terms of trade into its two components, the price of exports and the price of imports. Scatter plots in Figure 3 display the relationship between forecast errors in government purchases, and forecast errors in the price of exports (panel (a)) and the price of imports (panel (b)). The two scatter plots reveal a very weak relationship between government purchases and both export and import prices. Consistent with the model, import prices do not seem to react to changes in government purchases. However, in contrast to the model, export prices do not react either. Export prices in austere countries did not fall relative to less austere countries, despite strong declines in wages.

Panel (c) and (d) display the scatter plots for real exports and imports. We observe that austere countries strongly reduced their imports: for every 1 euro cut to government spending, imports fell by 1.42 euros. But austere countries did not manage to raise their exports. If anything, the point estimate of the regression indicates that cuts to government purchases led 
to lower (!), not higher exports. Taken together, we conclude that internal devaluations led to asymmetric expenditure switching, with net export improvements solely driven by lower imports instead of higher exports. That is, domestic agents in austere countries switched towards domestically produced goods, but foreign agents did not switch to goods produced in austere countries. $^{20}$

The missing export response is less surprising given the weak reaction of export prices. But this raises the question why export prices did not fall in austere countries despite the fall in wages. Broadly speaking, one can organize possible answers into two categories: export prices did not fall because (i) exporter's marginal costs did not fall and / or (ii) exporters raised their markup. Both explanations would require modifications to the baseline model that assumes that labor is the only input to production and firms are perfectly competitive.

Starting with the first explanation, our model is overly simplistic on the production side in that it ignores cost components beyond wages, such as capital costs and costs of other inputs. If these costs increased in austere countries, then the fall in wages overestimates the fall in marginal costs. The role of financial accelerator effects à la Bernanke et al. (1999) and associated rising capital costs for firms in austere countries has been emphasized in the literature (see e.g. Semmler, 2013; House et al., 2017). A simple extension to the baseline model to include capital and a financial accelerator mechanism might then rationalize that export (and other output) prices did not fall in austere countries despite the fall in wages. The alternative explanation is that marginal costs fell, but firms raised their markups. The literature has developed several models of variable markups (see Burstein and Gopinath, 2014, for an overview), including models of pricing-to-market where firms set prices as a function of their own marginal costs and local demand conditions. A distinguishing feature of this class of models is that export prices should not move hand-in-hand with domestic prices if demand conditions diverge between domestic and export markets.

To explore these explanations, we compare export prices to the GDP deflator. As a measure of the level of prices of domestically produced goods, the GDP deflator reflects changes in firms' overall costs, including the cost of capital, and might therefore better proxy for changes in marginal costs and production conditions. In a setting with financial frictions, the relationship between GDP deflator and export prices should be stable and unperturbed

\footnotetext{
${ }^{20} \mathrm{~A}$ fall in imports does not necessarily imply that households have switched their expenditure towards domestic goods. Instead, imports could fall if households reduce their overall expenditure. The evidence provided in Table 1 suggests that at least part of the fall in imports observed in austere countries is driven by expenditure switching from traded to non-traded consumption goods.
} 
by austerity. In contrast, a pricing-to-market model would predict a relative increase in the export price in austere countries because stable demand conditions abroad would keep export prices up. Panel (a) of Figure 4 plots the average forecast error in export prices less the average forecast error in the GDP deflator (on the vertical axis) against the forecast error in government purchases. The relationship is strongly negative, i.e. export prices did not fall despite a strong fall in the GDP deflator. For a cut in government spending by 1 percent of GDP, the relative export price increased by 1 percent. $^{21}$ This decline in the GDP deflator is consistent with the view that production costs fell for the average firm in austere countries and therefore casts doubt on the explanation that export prices did not fall because marginal costs did not fall.

Using aggregate data, however, has at least two shortcomings. The first relates to measurement issues. Both the export price index and the GDP deflator do not track a stable basket of goods and are therefore affected by composition changes or measurement errors. Export prices are often derived from unit values that increase with the quality of the good. Relatively high export prices in austere countries could e.g. hide a compositional change towards highquality goods in these countries' export basket. Second, the cost structure of exporting firms and industries might strongly differ from the economy-wide average. For example, data from the World Input-Output Database reveal that about 40 percent of Greek exports stem from the industry 'Water transport services', which has very low labor costs. ${ }^{22}$ Even if marginal costs for the average Greek firm declined during the European Debt Crisis, rising capital costs could mean an increase in marginal costs for the water transport sector in Greece and hence, relatively high export prices.

To address these issues, we re-run our regression using industry data. Eurostat publishes producer price indices (PPI) for 22 manufacturing industries for both domestic and nondomestic markets. While these PPI only cover a subsection of the economy, they are based on actual, observed prices reported by firms to the statistical agency (similar to the HICP). In many instances, exporting firms report two (potentially different) prices for the same good, one for the domestic market and one for the non-domestic market. This data allows us to compare domestic prices to export prices for the same industry, so that we can condition

\footnotetext{
${ }^{21}$ Comparing these results to those obtained for wages in Table 1, one can deduce that the GDP deflator did not fall as much as wages. Besides a relative increase in capital costs, countercyclical markups throughout the economy could explain this phenomenon. See Rotemberg and Woodford (1999) for evidence on countercyclical markups.

${ }^{22}$ According to the socio-economic accounts of the WIOD, capital costs are about four times higher than labor costs for this industry in Greece.
} 
on the industry's cost structure. Price differences are therefore less likely to be driven by differences in marginal costs.

To implement the regression, we first calculate the forecast error of the relative export price for each industry and country and then, for each country, choose the median forecast error across all industries, ${ }^{23}$ i.e. we run

$$
\operatorname{med}\left(\widetilde{P}_{\text {exp }, i,{ }^{\prime} 10-{ }^{\prime} 14}^{j}-\widetilde{P}_{d o m, i,{ }^{\prime} 10-{ }^{\prime} 14}^{j}\right)=\alpha+\beta_{g} g_{i} \widetilde{G}_{i,{ }^{\prime} 10-{ }^{\prime} 14}+\varepsilon_{i},
$$

where $\widetilde{P}_{\text {exp,i,'10-'14 }}^{j}$ is the forecast error of the export price in country $i$ and industry $j$, $\widetilde{P}_{d o m, i,{ }^{\prime} 10-' 14}^{j}$ is the forecast error of the domestic price, and med() takes the median across all industries $j$. Forecast errors are calculated as in equation (3.2). Panel (b) of Figure 4 displays the results. As with the aggregate data, relative export prices substantially increased in countries that cut government spending, with an estimated coefficient of $\widehat{\beta}_{g}=-1.20(0.29)$. This result casts additional doubt on marginal costs being the main driver for the relatively high export prices in austere countries. Instead, we read this as suggestive evidence that markups for exporting firms increased in austere countries.

To conclude this section, we ask whether these results are consistent with standard models of pricing to market. Our brief answer is no. A standard model of pricing to market suggests that a firm's pricing decision depends both on its marginal costs of production and demand conditions in the local market (Burstein and Gopinath, 2014; Auer et al., 2017). A Greek firm exporting to Germany might not lower its export price despite falling marginal costs because demand conditions in Germany are stable. This can explain the evidence presented in Figure 4. However, a pricing-to-market model would also predict that German exporters lowered their price for exports to Greece, but this is inconsistent with the observed, fairly weak relationship between import prices and austerity (see panel (b) in Figure 3). While developing a model consistent with this empirical patterns observed is beyond the scope of this paper, a promising route might be a model where exporting firms price to the euro-area average demand conditions instead of country-specific demand conditions. If exporting firms perceive the euro area as a single market, export prices for the euro area would move in parallel across all countries of the euro area, consistent with the empirical evidence in Figure 3.

\footnotetext{
${ }^{23}$ Alternatively, we could run this regression at the country $\times$ industry level. Since our explanatory variable, the forecast error in government purchases, is only country-specific, it cannot explain differences in relative prices across industries within a country. We therefore decide to use the median observation for each country as the relative price of a typical industry.
} 


\section{Conclusion}

Did austerity policies implemented in the euro area during the debt crisis restore competitiveness and improve current account balances? To shed light on this question, we exploit cross-country variations in implemented austerity measures across euro area countries over the period $2010-2014$.

The results in this paper indicate that cuts to government spending were indeed associated with real exchange rate devaluations, falling wages and expenditure switching towards nontraded goods. We show that the decomposition of austerity packages mattered. We find a much stronger association of government spending cuts as opposed to consumption tax rate increases with internal devaluations. Higher taxes were mostly correlated with depressed employment, rather than lower nominal wages or prices. We show that these responses are generally in line with a neoclassicial model featuring GHH preferences.

While our results indicate that fiscal policy, and government purchases in particular, could potentially be used as a tool to combat current account imbalances in a currency union, the adjustment mechanism might be asymmetric. Spending cuts improved current accounts, but these improvements are entirely driven by falling imports instead of rising exports. That is, expenditure switching is asymmetric, with domestic households switching towards nontradables, but foreign households not importing more goods from austere countries. One possible reason for this missing export effect could be our finding that exporters in austere countries did not cut prices, despite falling wages. We show that the response of export and import prices observed in the euro area during the austerity period is inconsistent with existing models of variable markups and pricing-to-market. We therefore believe that further investigating and understanding the response of the terms of trade would be a fruitful avenue for future research.

As a final remark, we want to emphasize that our analysis solely focused on a period characterized by austerity and therefore might not directly speak to the effects of fiscal expansion. Several recent papers have argued that fiscal policy has asymmetric effect, depending on whether it is expansionary or recessionary (Auerbach and Gorodnichenko, 2012). Whether fiscal expansions go along with internal revaluations therefore requires further investigation. 


\section{References}

Auclert, Adrien and Matthew Rognlie, "A Note on Multipliers in NK Models with GHH Preferences," Technical Report, Working Paper 2017.

Auer, Raphael A., Andrei A. Levchenko, and Philip Sauré, "International Inflation Spillovers Through Input Linkages," Technical Report 2017. NBER Working Paper.

Auerbach, Alan J and Yuriy Gorodnichenko, "Fiscal Multipliers in Recession and Expansion," in "Fiscal Policy after the Financial Crisis," University of Chicago press, 2012, pp. 63-98.

Backus, David K., Patrick J. Kehoe, and Finn E. Kydland, "Dynamics of the Trade Balance and the Terms of Trade: The J-Curve?," American Economic Review, 1994, 84 (1), 84-103.

Beetsma, Roel, Massimo Giuliodori, and Franc Klaassen, "The Effects of Public Spending Shocks on Trade Balances and Budget Deficits in the European Union," Journal of the European Economic Association, 2008, 6 (2-3), 414-423.

Berka, Martin, Michael B. Devereux, and Charles Engel, "Real Exchange Rates and Sectoral Productivity in the Eurozone," American Economic Review, 2018, 108 (6), 15431581.

Bernanke, Ben S., Mark Gertler, and Simon Gilchrist, "The Financial Accelerator in a Quantitative Business Cycle Framework," in John B. Taylor and Michael Woodford, eds., Handbook of Macroeconomics, Vol. 1, Elsevier, 1999, pp. 1341-1393.

Bilbiie, Florin O, "Nonseparable Preferences, Frisch Labor Supply, and the Consumption Multiplier of Government Spending: One Solution to a Fiscal Policy Puzzle," Journal of Money, Credit and Banking, 2011, 43 (1), 221-251.

Blanchard, Oliver and David Leigh, "Growth Forecast Errors and Fiscal Multipliers," American Economic Review: Papers and Proceedings, 2013, 103 (3), 117-120.

Blanchard, Olivier and Francesco Giavazzi, "Current Account Deficits in the Euro Area: the End of the Feldstein-Horioka Puzzle?," Brookings Papers on Economic Activity, 2002, 2002 (2), 147-186. 
Born, Benjamin, Falko Juessen, and Gernot J. Müller, "Exchange Rate Regimes and Fiscal Multipliers," Journal of Economic Dynamics and Control, 2013, 37 (2), 446-465.

Burstein, Ariel and Gita Gopinath, "International Prices and Exchange Rates," in "Handbook of International Economics," Vol. 4, Elsevier, 2014.

Canova, Fabio and Evi Pappa, "Price Differentials in Monetary Unions: The Role of Fiscal Shocks," The Economic Journal, 2007, 117 (520), 713-737.

Christiano, Lawrence J., Roberto Motto, and Massimo Rostagno, "Risk Shocks," American Economic Review, 2014, 104 (1), 27-65.

Cravino, Javier and Andrei A. Levchenko, "The Distributional Consequences of Large Devaluations," American Economic Review, 2017, 107 (11), 3477-3509.

Égert, Balázs, "Catching-Up and Inflation in Europe: Balassa-Samuelson, Engel's Law and Other Culprits," Economic Systems, 2011, 35 (2), 208-229.

Eichengreen, Barry, "Implications of the Euros Crisis for International Monetary Reform," Journal of Policy Modeling, 2012, 34 (4), 541-548.

European Central Bank, "Inflation Differentials in the Euro Area: Potential Causes and Policy Implications?," Technical Report 2003.

Farhi, Emmanuel, Gita Gopinath, and Oleg Itskhoki, "Fiscal Devaluations," Review of Economic Studies, 2013, 81 (2), 725-760.

Galí, Jordi, "The Return of the Wage Phillips Curve," Journal of the European Economic Association, 2011, 9 (3), 436-461.

Gali, Jordi and Tommaso Monacelli, "Monetary Policy and Exchange Rate Volatility in a Small Open Economy," The Review of Economic Studies, 2005, 72 (3), 707-734.

Greenwood, Jeremy, Zvi Hercowitz, and Gregory W Huffman, "Investment, Capacity Utilization, and the Real Business Cycle," The American Economic Review, 1988, pp. 402417.

Heathcote, Jonathan and Fabrizio Perri, "Financial Autarky and International Real Business Cycles," Journal of Monetary Economics, 2002, 49 (3), 601-627. 
Honohan, Patrick and Philip R Lane, "Divergent Inflation Rates in EMU," Economic Policy, 2003, 18 (37), 357-394.

House, Christopher L., Christian Proebsting, and Linda L. Tesar, "Austerity in the Aftermath of the Great Recession," 2017. NBER Working Paper No. 23147.

Ilzetzki, Ethan, Enrique G. Mendoza, and Carlos A. Végh, "How Big (Small?) are Fiscal Multipliers?," Journal of Monetary Economics, 2013, 60 (2), 239 - 254.

Kieler, Mads, "The ECB's Inflation Objective," 2003. IMF Working Paper.

Lambertini, Luisa and Christian Proebsting, "Fiscal Policy, Inflation and Trade Linkages," 2018.

Monacelli, Tommaso and Roberto Perotti, "Fiscal Policy, the Real Exchange Rate and Traded Goods," The Economic Journal, 2010, 120 (544), 437-461.

Perotti, Roberto, "Estimating the Effects of Fiscal Policy in OECD Countries," 2004. Working Paper.

Ravn, Morten O, Stephanie Schmitt-Grohé, and Martin Uribe, "Explaining the Effects of Government Spending Shocks on Consumption and the Real Exchange Rate," Technical Report, National Bureau of Economic Research 2007.

Rogoff, Kenneth, "The Purchasing Power Parity Puzzle," Journal of Economic Literature, 1996, 34 (2), 647-668.

Rotemberg, Julio J and Michael Woodford, "The Cyclical Behavior of Prices and Costs," Handbook of Macroeconomics, 1999, 1, 1051-1135.

Schmitt-Grohé, Stephanie and Martin Uribe, "Downward Nominal Wage Rigidity, Currency Pegs, and Involuntary Unemployment," Journal of Political Economy, 2016, 124 (5), $1466-1514$.

Semmler, Willi, "The Macroeconomics of Austerity in the European Union," Social Research, 2013, 80 (3), 883-914.

Sinn, Hans-Werner and Michael Reutter, "The Minimum Inflation Rate for Euroland," Technical Report, National Bureau of Economic Research 2001. 
Table 1: Austerity And Internal Devaluations

\begin{tabular}{|c|c|c|c|c|c|c|c|c|}
\hline \multirow[b]{3}{*}{ Gov't purchases } & Model & \multicolumn{3}{|c|}{ Data } & Model & \multicolumn{3}{|c|}{ Data } \\
\hline & \multicolumn{4}{|c|}{ Real Exchange Rate $\left(Q^{c t}\right)$} & & & & \\
\hline & 0.35 & $\begin{array}{c}0.99 \\
(0.13)\end{array}$ & & $\begin{array}{c}1.51 \\
(0.27)\end{array}$ & & & & \\
\hline Cons tax & -0.18 & & $\begin{array}{c}-2.34 \\
(0.65)\end{array}$ & $\begin{array}{c}1.69 \\
(0.79)\end{array}$ & & & & \\
\hline \multirow[t]{2}{*}{$R_{a d j}^{2}$} & & 0.83 & 0.50 & 0.87 & & & & \\
\hline & \multicolumn{4}{|c|}{ Wages $(W)$} & \multicolumn{4}{|c|}{ Employment $(L)$} \\
\hline Gov't purchases & 0.47 & $\begin{array}{c}2.27 \\
(0.29)\end{array}$ & & $\begin{array}{c}2.50 \\
(0.72)\end{array}$ & 0.47 & $\begin{array}{c}1.59 \\
(0.18)\end{array}$ & & $\begin{array}{c}0.75 \\
(0.36)\end{array}$ \\
\hline Cons tax & -0.23 & & $\begin{array}{c}-5.93 \\
(1.26)\end{array}$ & $\begin{array}{c}0.74 \\
(2.12)\end{array}$ & -0.23 & & $\begin{array}{c}-4.72 \\
(0.51)\end{array}$ & $\begin{array}{c}-2.71 \\
(1.05)\end{array}$ \\
\hline \multirow[t]{2}{*}{$R_{a d j}^{2}$} & & 0.83 & 0.64 & 0.82 & & 0.86 & 0.88 & 0.91 \\
\hline & \multicolumn{4}{|c|}{ Terms of Trade $(S)$} & \multicolumn{4}{|c|}{ Net Exports $(n x)$} \\
\hline Gov't purchases & 0.47 & $\begin{array}{c}0.02 \\
(0.31)\end{array}$ & & $\begin{array}{c}0.54 \\
(0.76)\end{array}$ & -0.40 & $\begin{array}{c}-0.85 \\
(0.14)\end{array}$ & & $\begin{array}{r}-1.15 \\
(0.32)\end{array}$ \\
\hline Cons tax & -0.23 & & $\begin{array}{c}0.25 \\
(0.92)\end{array}$ & $\begin{array}{c}1.69 \\
(2.24)\end{array}$ & 0.20 & & $\begin{array}{c}2.11 \\
(0.57)\end{array}$ & $\begin{array}{c}-0.96 \\
(0.95)\end{array}$ \\
\hline \multirow[t]{2}{*}{$R_{a d j}^{2}$} & & -0.09 & -0.08 & -0.14 & & 0.76 & 0.51 & 0.76 \\
\hline & \multicolumn{4}{|c|}{ Relative Price NT $\left(\frac{P_{N}^{\text {ret }}}{P_{T}^{\text {ret }}}\right)$} & \multicolumn{4}{|c|}{ Relative Consumption NT $\left(\frac{C_{N}}{C_{T}}\right)$} \\
\hline Gov't purchases & 0.19 & $\begin{array}{c}0.95 \\
(0.16)\end{array}$ & & $\begin{array}{c}1.32 \\
(0.39)\end{array}$ & -0.19 & $\begin{array}{c}-2.75 \\
(0.50)\end{array}$ & & $\begin{array}{c}-1.26 \\
(1.15)\end{array}$ \\
\hline Cons tax & -0.09 & & $\begin{array}{c}-2.31 \\
(0.67)\end{array}$ & $\begin{array}{c}1.21 \\
(1.14)\end{array}$ & 0.09 & & $\begin{array}{c}8.18 \\
(1.43)\end{array}$ & $\begin{array}{c}4.81 \\
(3.37)\end{array}$ \\
\hline$R_{a d j}^{2}$ & & 0.73 & 0.48 & 0.73 & & 0.71 & 0.73 & 0.73 \\
\hline
\end{tabular}

Notes: Table displays the model-implied elasticities (columns 'Model') and their estimated values from the data (columns 'Data'). The numbers for the 'Data' columns are the estimated coefficients of regression (3.1). The explained variable is the forecast error of the real exchange rate at constant tax rates $\left(Q^{c t}\right)$, the nominal wage rate $(W)$, the terms of trade defined as the price of exports relative to the price of imports $(S)$, the retail price of non-traded consumption goods relative to the retail price of traded consumption goods $\left(\frac{P_{N}^{\text {ret }}}{P_{T}^{\text {ret }}}\right)$, employment $(L)$, real net exports over GDP $(n x)$, and the consumption of non-traded goods relative to the consumption of traded goods $\left(\frac{C_{N}}{C_{T}}\right)$. The explanatory variables are the forecast errors in government purchases and the consumption tax revenue, both expressed in percent of GDP. OLS standard errors are in parentheses and adjusted $R^{2}$ s are also provided. 
Table 2: CALiBration

\begin{tabular}{lccl}
\hline \hline Parameter & & Value & Target / Source \\
\hline $\begin{array}{l}\text { Elasticity of intertemporal } \\
\text { substitution }\end{array}$ & $\sigma$ & 0.5 & $\begin{array}{l}\text { Standard value, Heathcote and Perri (2002) } \\
\text { Backus et al. (1994) }\end{array}$ \\
Elasticity of labor supply & $\eta$ & 1 & $\begin{array}{l}\text { Standard value, Christiano et al. (2014) } \\
\text { Trade demand elasticity }\end{array}$ \\
& $\psi$ & 1 & $\begin{array}{l}\text { Standard value, Heathcote and Perri (2002) } \\
\text { Backus et al. (1994) }\end{array}$ \\
Share traded goods & $\gamma$ & 0.60 & Lambertini and Proebsting (2018) \\
Home bias for traded goods & $\omega$ & 0.60 & Lambertini and Proebsting (2018) \\
Share of gov't purchases & $\frac{G}{G D P}$ & 0.24 & Eurostat (2003-2009) \\
Value added tax & $\tau$ & 0.14 & Lambertini and Proebsting (2018) \\
\hline \hline
\end{tabular}

Notes: Table only depicts values for those parameters that are required to calculate the elasticities in Table 1. Other parameters are not reported (such as the discoun factor, $\beta$ or the persistence of the shocks, $\rho_{g}$ and $\left.\rho_{\tau}\right)$.

Table 3: Alternative Model Specifications

\begin{tabular}{|c|c|c|c|c|c|c|c|}
\hline & \multirow{2}{*}{$\begin{array}{c}\mathrm{RER} \\
Q^{c t}\end{array}$} & \multicolumn{2}{|c|}{ Labor Market } & \multicolumn{2}{|c|}{ Trade } & \multicolumn{2}{|c|}{ Rel Consumption } \\
\hline & & $W$ & $L$ & $S$ & $n x$ & $\frac{P_{N}^{r e t}}{P_{T}^{r e t}}$ & $\frac{C_{N}}{C_{T}}$ \\
\hline \multicolumn{8}{|l|}{ Baseline } \\
\hline Gov't purch & 0.35 & 0.47 & 0.47 & 0.47 & -0.40 & 0.19 & -0.19 \\
\hline Cons tax & -0.18 & -0.23 & -0.23 & -0.23 & 0.20 & -0.09 & 0.09 \\
\hline \multicolumn{8}{|c|}{ Composition of $G$ and $\tau$} \\
\hline Gov't purch & 0.48 & 0.63 & 0.63 & 0.63 & -0.18 & 0.25 & -0.25 \\
\hline Cons tax & -0.15 & -0.19 & -0.19 & -0.19 & 0.25 & -1.17 & 1.17 \\
\hline \multicolumn{8}{|c|}{ Composition of $G$ and $\tau+G H H$ preferences } \\
\hline Gov't purch & 1.55 & 2.05 & 0.49 & 2.05 & -0.75 & 0.82 & -0.82 \\
\hline Cons tax & 0.37 & 0.49 & -1.20 & 0.49 & 0.27 & -0.90 & 0.90 \\
\hline
\end{tabular}

Notes: Table displays the model-implied elasticities of the real exchange rate at constant tax rates $\left(Q^{c t}\right)$, the nominal wage rate $(W)$, employment $(L)$, the terms of trade defined as the price of exports relative to the price of imports $(S)$, real net exports over GDP $(n x)$, the retail price of non-traded consumption goods relative to the retail price of traded consumption goods $\left(\frac{P_{N}^{\text {ret }}}{P_{T}^{\text {ret }}}\right)$, and the consumption of non-traded goods relative to the consumption of traded goods $\left(\frac{C_{N}}{C_{T}}\right)$, with respect to government purchases (in percent of steady-state GDP) and consumption taxes (in percent of steady-state GDP). Baseline parameters as in Table 2. In the model 'Composition of $G$ and $\tau^{\prime}$, the home bias parameter for the goverment good is set to 0.95 , and the model features different tax changes for the non-traded and traded consumption good. The coefficient reported for the consumption tax refers to an increase in the two tax rates corresponding to a total of 1 percent of steadystate GDP, with the rise in the tax rate on traded goods accounting for 0.8 percent. The last specification features GHH preferences. 


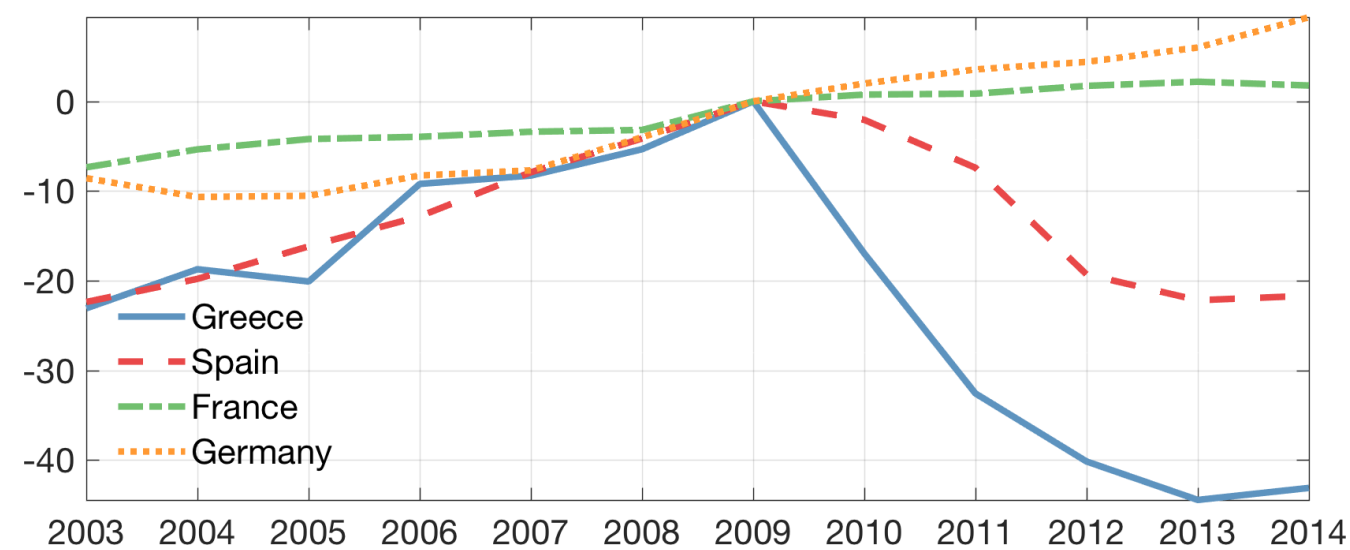

(a) Government Purchases

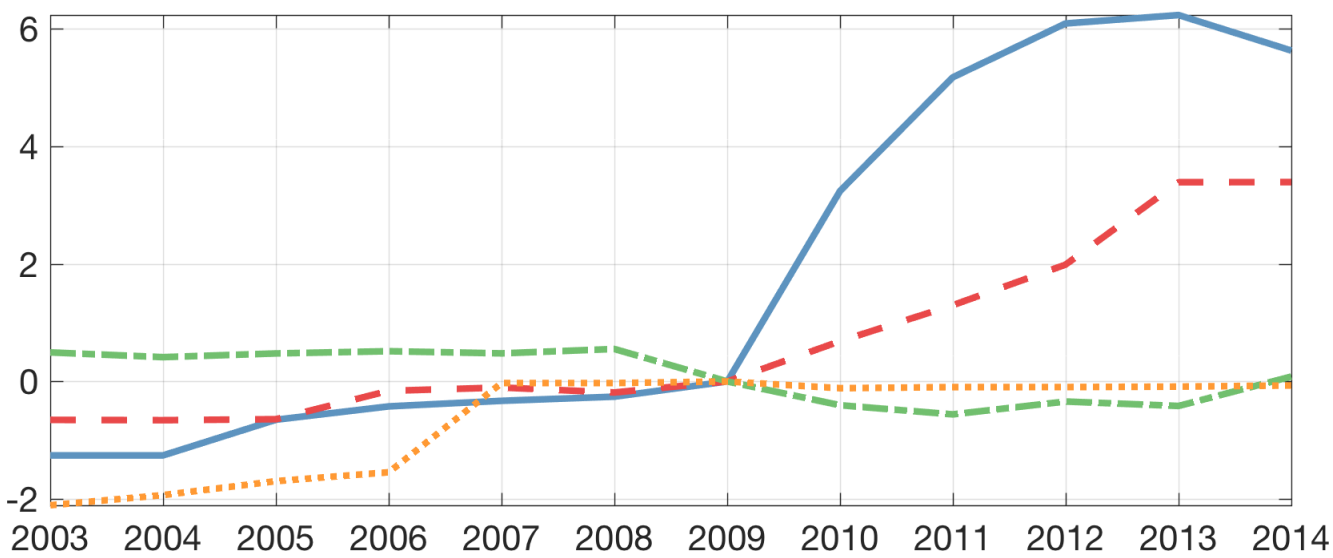

(b) Consumption Tax Rate

Figure 1: Time Series: Fiscal Variables

Notes: Figures display time series for four countries: Greece, Spain, France and Germany. Data is indexed to 0 in 2009. The first panel plots the log of real government purchases per capita, with a value of 10 indicating that government purchases were $10 \log$ points above their value in 2009. The second panel plots the consumption tax rate, with a value of 10 indicating that the tax rate was 10 percentage points higher than in 2009 . 

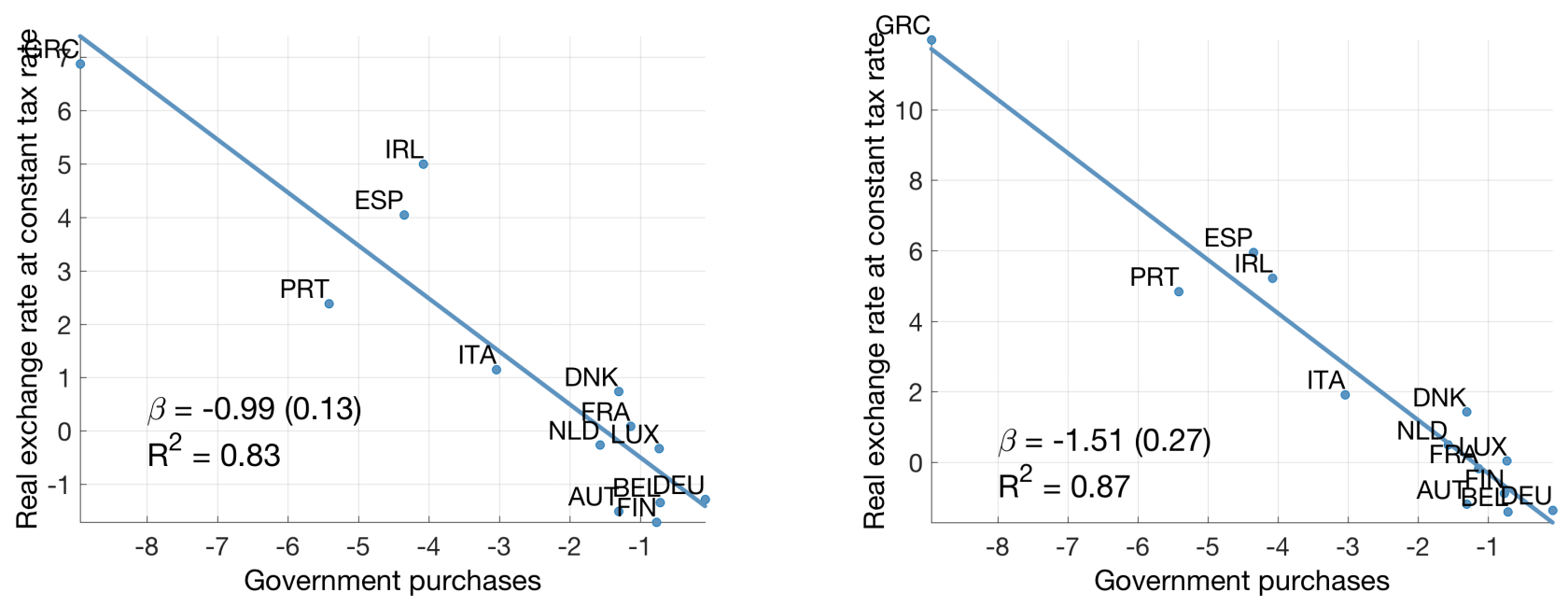

(a) Government Purchases
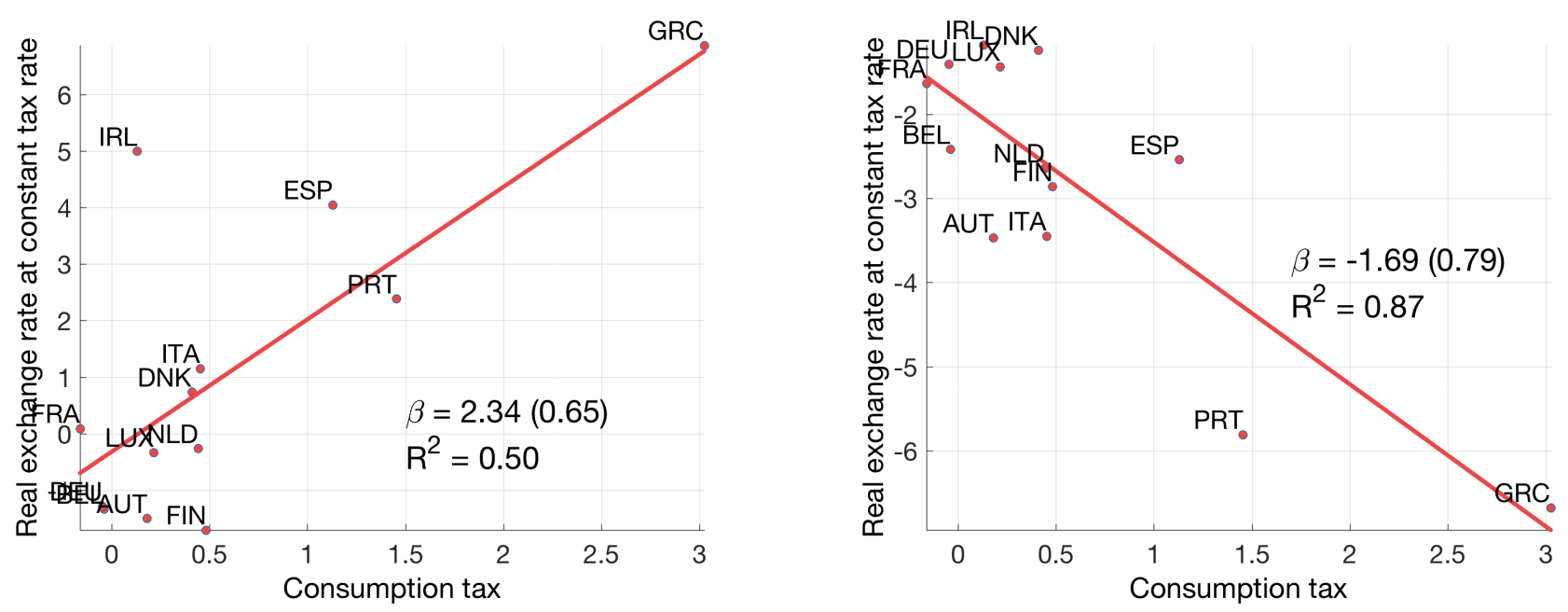

(b) Consumption Tax Rate

Figure 2: Austerity and Internal Devaluation

Notes: Figures display scatter plots of the average forecast error for the real exchange rate at constant tax rates vs. the average forecast residual for government purchases (expressed in GDP) in log points (Panel a) and the average forecast residual for the consumption tax revenue (expressed in GDP) in percent (Panel b). The right panels display the residual of the real exchange rate forecast error after controling for the forecast error of the other fiscal variable, i.e. $\tilde{Q}_{i,{ }^{c t} 10-'{ }^{\prime} 14}-\hat{\beta}_{\tau} \frac{c_{i}}{1+\tau_{i}} \Delta \tau_{i,{ }^{\prime} 10-{ }^{\prime} 14}$ for Panel (a) and $\tilde{Q}_{i,{ }^{c t} 10-{ }^{\prime} 14}^{c t}-\hat{\beta}_{g} g_{i} \widetilde{G}_{i,{ }^{\prime} 10-'{ }^{\prime} 14}$ for Panel (b). The real exchange rate is based on the CPI at constant tax rates. Slope coefficients, standard OLS errors and adjusted $R^{2}$ are reported as well. 

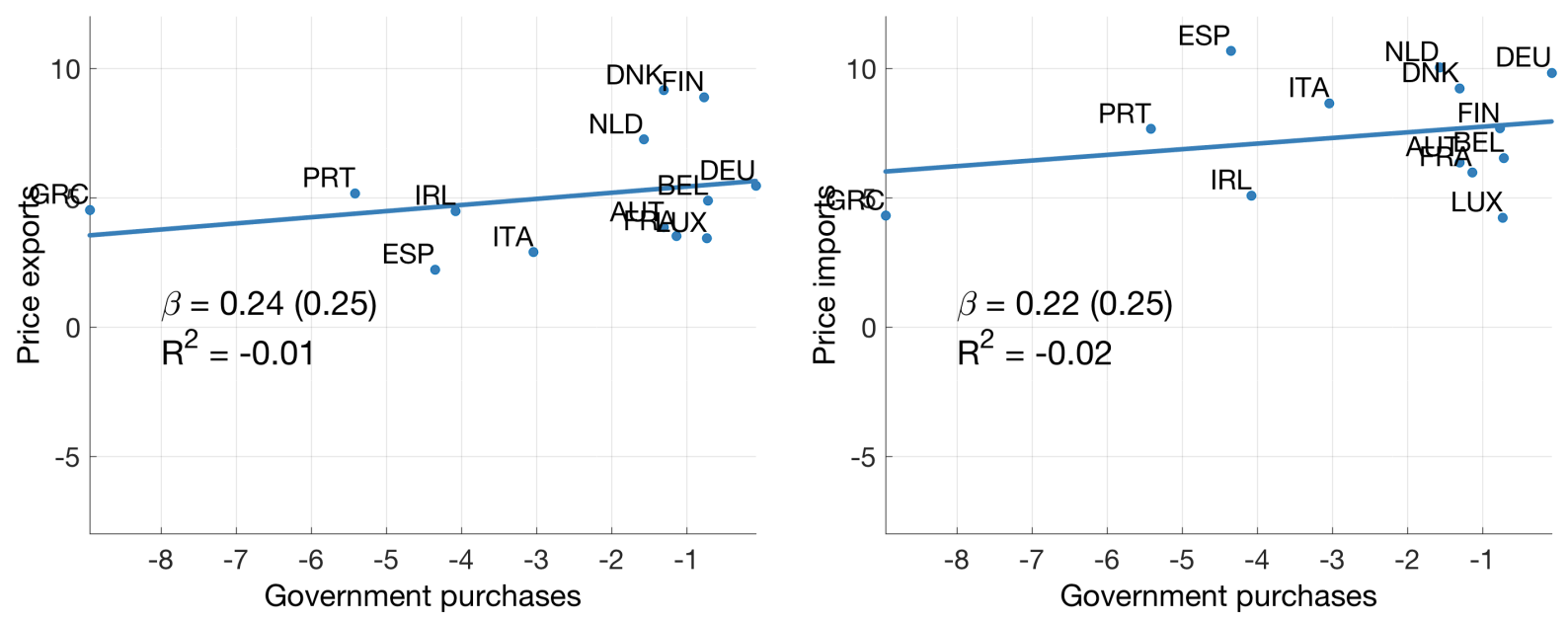

(a) EXPORT PRICE INDEX

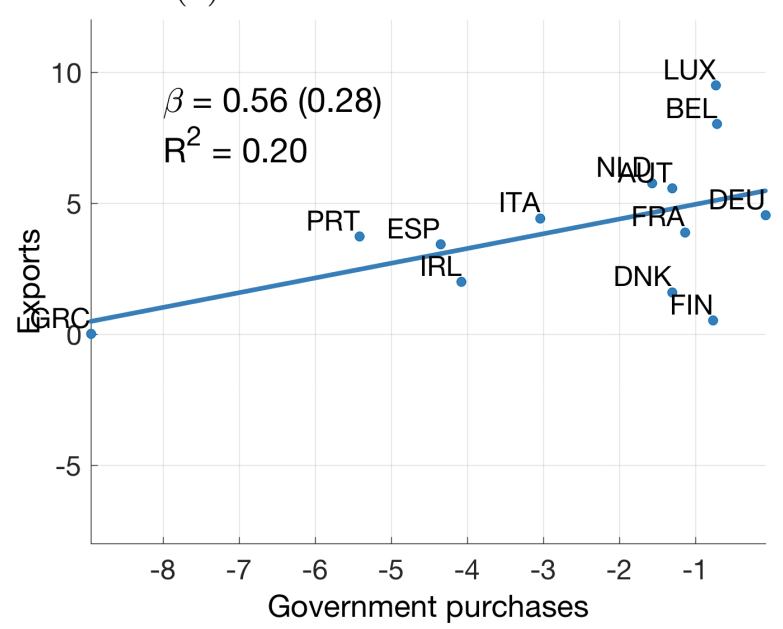

(c) ExpORTS (b) IMPort PRICE INDEX

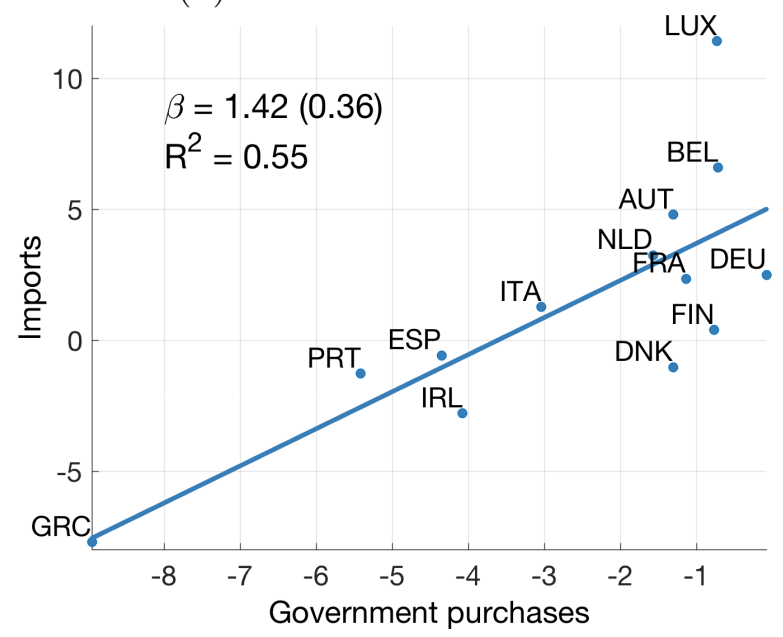

(d) IMPORTS

\section{Figure 3: Government Purchases And Trade}

Notes: Figures display scatter plots of the average forecast error for (a) the export price, (b) the import price, (c) exports and (d) imports vs. the average forecast residual for government purchases (expressed in GDP) in log points. Export and import price indices are the implicit price deflators of real exports and imports. Exports and imports are in real values and expressed in percent of GDP. 


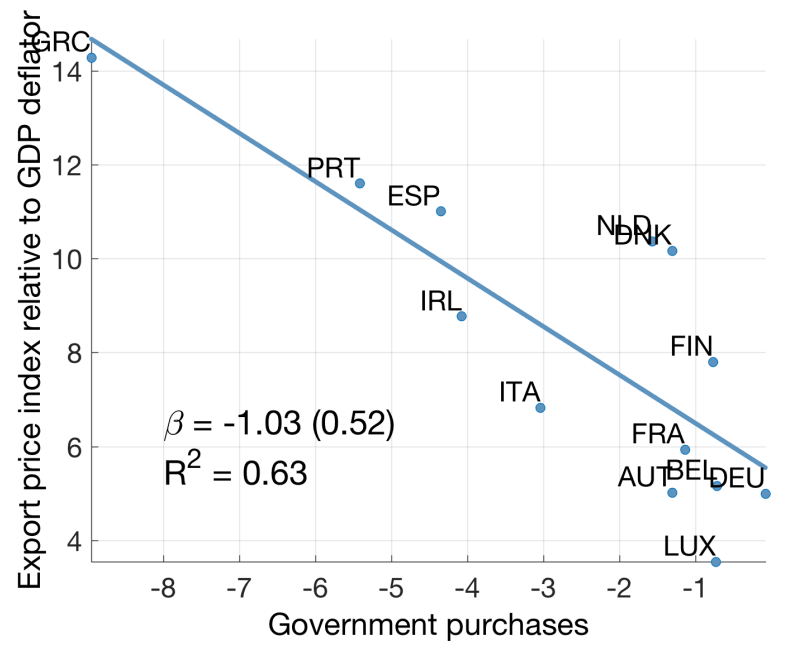

(a) Aggregate Data

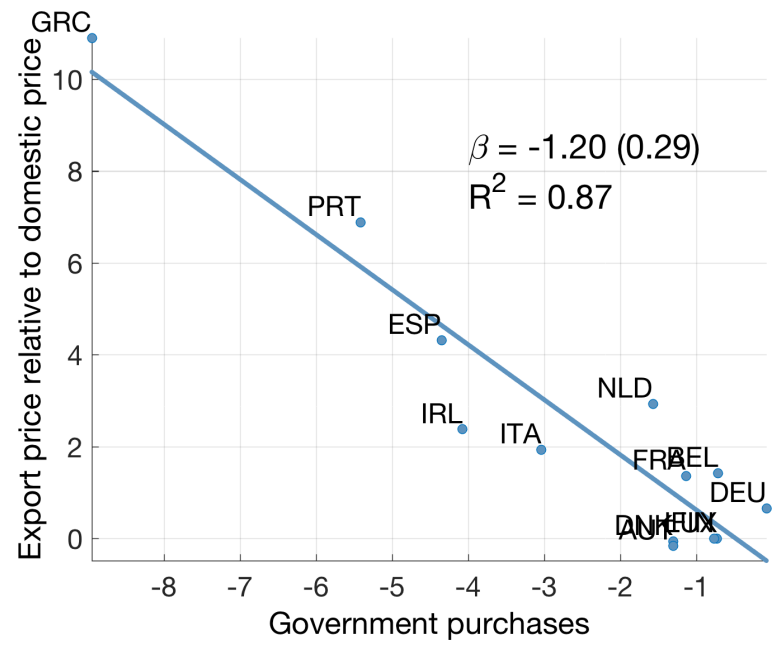

(b) Industry-Level DatA

\section{Figure 4: Government Purchases and Relative Export Prices}

Notes: Figures display scatter plots of the average forecast error for the relative export price vs. the average forecast residual for government purchases (expressed in GDP) in log points. For panel (a), changes in the relative export price are calculated as changes in the export price index less changes in the GDP deflator. For panel (b), changes in the relative export price are calculated as changes in the price index for non-domestic markets less changes in the price index for domestic markets. This data is available for 22 manufacturing industries for each country. For each country, the median forecast error across industries is displayed. Slope coefficients, standard OLS errors and adjusted $R^{2}$ are reported as well. 


\title{
APPENDIX TO:
}

\section{Does Austerity Go Along With Internal Devaluations?*}

\author{
Luisa Lambertini Christian Proebsting \\ $\mathrm{EPFL}^{\dagger} \quad \mathrm{EPFL}^{\ddagger}$
}

January 15, 2019

*Lambertini: Luisa.Lambertini@epfl.ch; Proebsting: Christian.Probsting@epfl.ch

${ }^{\dagger}$ École Polytechnique Fédérale de Lausanne

‡École Polytechnique Fédérale de Lausanne 


\section{Contents}

A Model $\quad 3$

A.1 Log-Linearized Equilibrium Conditions . . . . . . . . . . . . . . . . . 3

A.2 Model Solution . . . . . . . . . . . . . . . . . . . 6

B Forecasting Specification for Government Purchases $\quad 8$

$\begin{array}{ll}\text { C Other Austerity Measures } & 9\end{array}$

D Total Factor Productivity and Internal Devaluations 10

\section{List of Tables}

A1 Austerity Measures in Percent of GDP . . . . . . . . . . . . . . . . 12

A2 Austerity and Internal Devaluations: Including Labor Tax . . . . . . . . . . 13

A3 Austerity and Internal Devaluations: Including TFP . . . . . . . . . . . . . . . 14

\section{List of Figures}

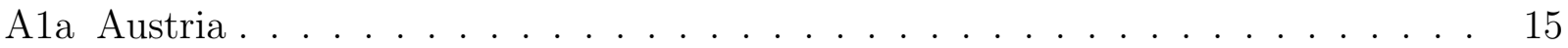

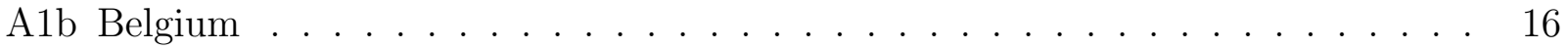

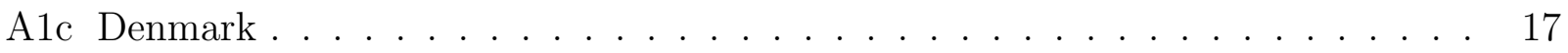

Ald Germany . . . . . . . . . . . . . . . . . . 18

Ale Finland . . . . . . . . . . . . . . . . . . . . . . . . 19

A1f France ........................... . . 20

Alg Greece . . . . . . . . . . . . . . . . . . . . . . 21

Alh Ireland . . . . . . . . . . . . . . . . . . . . . 22

A1i Italy . . . . . . . . . . . . . . . . . . . . . . 23

A1j Luxembourg . . . . . . . . . . . . . . . . . . . . . 24

A1k Netherlands ......................... . . . 25

A1l Portugal ............................. 26

A1m Spain . . . . . . . . . . . . . . . . . . . . . . . . . 27 


\section{A Model}

\section{A.1 Log-Linearized Equilibrium Conditions}

Real prices are defined as the nominal price divided by the retail price index, $P_{t}^{r e t}$ and are denoted by lower-case letters.

1. Marginal utility of consumption

- With separable preferences

$$
\widetilde{U}_{1, t}=-\frac{1}{\sigma} \widetilde{C}_{t}
$$

- With GHH preferences ${ }^{1}$

$$
-\sigma\left(P^{r e t} C-\frac{\eta}{1+\eta}\right) \tilde{U}_{1, t}=P^{r e t} C \tilde{C}_{t}-P^{r e t} \tilde{L}_{t}
$$

2. Marginal rate of substitution

- With separable preferences

$$
\widetilde{m r} s_{t}=\frac{1}{\eta} \widetilde{L}_{t}-\widetilde{U}_{1, t}
$$

- With GHH preferences

$$
\widetilde{m r} s_{t}=\frac{1}{\eta} \widetilde{L}_{t}
$$

3. Labor supply

$$
\begin{aligned}
\frac{W_{t}}{P_{t}^{r e t}} & =m r s_{t} \\
\widetilde{W_{t}}-\widetilde{P}_{t}^{r e t} & =\widetilde{m r s_{t}}
\end{aligned}
$$

${ }^{1}$ The marginal utility of consumption is

$$
U_{1, t}^{-\sigma}=C_{t}-\kappa \frac{L_{t}^{1+\frac{1}{\eta}}}{1+\frac{1}{\eta}}
$$

Log-linearizing, we obtain

$$
\begin{aligned}
-\sigma U_{1} \tilde{U}_{1, t} & =C \tilde{C}_{t}-\kappa L^{1+\frac{1}{\eta}} \tilde{L}_{t} \\
-\sigma\left(C-\frac{1-\alpha}{\left(1+\frac{1}{\eta}\right) P^{r e t}}\right) \tilde{U}_{1, t} & =C \tilde{C}_{t}-\frac{1-\alpha}{P^{r e t}} \tilde{L}_{t}
\end{aligned}
$$

where used that steady state labor satisfies $\kappa L^{\frac{1}{\eta}}=\frac{1-\alpha}{P^{r e t}} L^{-\alpha}$. and $Q=L^{1-\alpha}=1$. 
4. First-order condition with respect to $C_{T}$

$$
\begin{aligned}
C_{T, t} & =\gamma \frac{P_{t}^{r e t} C_{t}}{P_{T, t}^{r e t}} \\
\widetilde{C}_{T, t} & =\widetilde{C}_{t}+\widetilde{P}_{t}^{r e t}-\widetilde{P}_{T, t}^{r e t}
\end{aligned}
$$

5. First-order condition with respect to $C_{N}$

$$
\begin{aligned}
C_{N, t} & =(1-\gamma) \frac{P_{t}^{r e t} C_{t}}{P_{N, t}^{r e t}} \\
\widetilde{C}_{N, t} & =\widetilde{C}_{t}+\widetilde{P}_{t}^{r e t}-\widetilde{P}_{N, t}^{r e t}
\end{aligned}
$$

6. Aggregate consumption $C$

$$
\begin{aligned}
C_{t} & =C_{T, t}^{\gamma} C_{N, t}^{1-\gamma} \\
\widetilde{C}_{t} & =\gamma \widetilde{C}_{T, t}+(1-\gamma) \widetilde{C}_{N, t}
\end{aligned}
$$

7. Production of $Y_{T, t}$

$$
\begin{aligned}
& Y_{T, t}=\left(\omega^{\frac{1}{\psi}} y_{T, t}^{\frac{\psi-1}{\psi}}+(1-\omega)^{\frac{1}{\psi}} x_{t}^{\frac{\psi-1}{\psi}}\right)^{\frac{\psi}{\psi-1}} \\
& \widetilde{Y}_{T, t}=\omega \widetilde{y}_{T, t}+(1-\omega) \widetilde{x}_{t}
\end{aligned}
$$

8. Production of $Y_{N, t}$

$$
\begin{aligned}
& Y_{N, t}=y_{N, t} \\
& \widetilde{Y}_{N, t}=\widetilde{y}_{N, t}
\end{aligned}
$$

9. Demand for domestic goods ( $N$ wholesalers)

$$
\begin{aligned}
& P_{I, t}=P_{N, t} \\
& \widetilde{P}_{I, t}=\widetilde{P}_{N, t}
\end{aligned}
$$


10. Demand for domestic goods ( $T$ wholesalers)

$$
\begin{aligned}
& P_{I, t}=P_{T, t}\left(\frac{\omega Y_{T, t}}{y_{T, t}}\right)^{\frac{1}{\psi}} \\
& \widetilde{y}_{T, t}=-\psi\left(\widetilde{P}_{I, t}-\widetilde{P}_{T, t}\right)+\widetilde{Y}_{T, t}
\end{aligned}
$$

11. Demand for imports

$$
\begin{aligned}
1 & =P_{T, t}\left(\frac{(1-\omega) Y_{T, t}}{m_{t}}\right)^{\frac{1}{\psi}} \\
\widetilde{m}_{t} & =\psi \widetilde{P}_{T, t}+\widetilde{Y}_{T, t}
\end{aligned}
$$

12. Demand for exports

$$
\begin{aligned}
& x_{t}=D\left(P_{I, t}\right)^{-\psi} \\
& \widetilde{x}_{t}=-\psi \widetilde{P}_{I, t}
\end{aligned}
$$

13. Market clearing for wholesale good $T$

$$
\begin{aligned}
Y_{T, t} & =\nu G_{t}+C_{T, t} \\
Y_{T} \widetilde{Y}_{T, t} & =\gamma G \widetilde{G}_{t}+C_{T} \widetilde{C}_{T, t}
\end{aligned}
$$

14. Market clearing for wholesale good $N$

$$
\begin{aligned}
Y_{N, t} & =(1-\nu) G_{t}+C_{N, t} \\
Y_{N} \widetilde{Y}_{N, t} & =(1-\gamma) G \widetilde{G}_{t}+C_{N} \widetilde{C}_{N, t}
\end{aligned}
$$

15. Production of intermediate good $Q_{t}$

$$
\begin{aligned}
& Y_{I, t}=L_{t} \\
& \widetilde{Y}_{I, t}=\widetilde{L}_{t}
\end{aligned}
$$


16. Market clearing for intermediate good

$$
\begin{aligned}
& Y_{I, t}=y_{N, t}+y_{T, t}+y_{*, t} \\
& \widetilde{Y}_{I, t}=y_{N} \widetilde{y}_{N, t}+y_{T}\left(\omega \widetilde{y}_{T, t}+(1-\omega) \widetilde{y}_{*, t}\right)
\end{aligned}
$$

17. Labor demand

$$
\begin{aligned}
& W_{t}=P_{I, t}(1-\alpha) L_{t}^{-\alpha} \\
& \widetilde{W}_{t}=\widetilde{P}_{I, t}
\end{aligned}
$$

18. Retailers (for $j=N, T$ )

$$
\begin{aligned}
P_{N, t}^{r e t} & =\left(1+\tau_{t}\right) P_{I, t} \\
\tilde{p}_{j, t} & =\tilde{p}_{j, t}^{r e t}+\frac{\Delta \tau_{t}}{1+\tau}
\end{aligned}
$$

19. Complete markets condition

$$
\begin{aligned}
a\left(s^{t}, s_{t+1}\right) \frac{U_{1}\left(s^{t}\right)}{P^{r e t}\left(s^{t}\right)} & =\beta \pi\left(s^{t+1} \mid s^{t}\right) \frac{U_{1}\left(s^{t+1}\right)}{P^{r e t}\left(s^{t+1}\right)} \\
\widetilde{U}_{1, t} & =\widetilde{P}_{t}^{r e t}
\end{aligned}
$$

20. $G$ shock

$$
\widetilde{G}_{t}=\left(1-\rho_{G}\right) \widetilde{G}_{t-1}+\epsilon_{t}
$$

21. VAT shock

$$
\tilde{\tau}_{t}=\left(1-\rho_{\tau}\right) \widetilde{\tau}_{t-1}+\epsilon_{t}
$$

\section{A.2 Model Solution}

Starting from the market clearing condition for intermediate goods,

$$
\widetilde{L}_{t}=(1-\gamma) \widetilde{y}_{N, t}+\gamma\left(\omega \widetilde{y}_{T, t}+(1-\omega) \widetilde{x}_{t}\right)
$$


we replace $\widetilde{y}_{N, t}=\widetilde{Y}_{N, t}, \widetilde{y}_{T, t}=-\psi\left(\widetilde{W}_{t}-\widetilde{P}_{T, t}\right)+\widetilde{Y}_{T, t}$ and $\widetilde{x}_{t}=-\psi \widetilde{W}_{t}$ to obtain

$$
\widetilde{L}_{t}=(1-\gamma) \widetilde{Y}_{N, t}+\gamma \omega \widetilde{Y}_{T, t}+\gamma \omega \psi \widetilde{P}_{T, t}-\gamma \psi \widetilde{W}_{t}
$$

Given $\widetilde{P}_{T, t}=\omega \widetilde{W}_{t}$, this can be rewritten as

$$
\widetilde{L}_{t}=(1-\gamma) \widetilde{Y}_{N, t}+\gamma \omega \widetilde{Y}_{T, t}-\psi \gamma\left(1-\omega^{2}\right) \widetilde{W}_{t}
$$

The market clearing conditions for the two wholesale goods $(j=N, T)$ are

$$
\widetilde{Y}_{j, t}=\Delta G_{t}+C \widetilde{C}_{j, t}
$$

Inserting the first-order condition with respect to $C_{j}$

$$
\widetilde{C}_{j, t}=\widetilde{C}_{t}+\widetilde{P}_{t}-\widetilde{P}_{j, t}
$$

we can write

$$
(1-\gamma) \widetilde{Y}_{N, t}+\gamma \omega \widetilde{Y}_{T, t}=(1-\gamma(1-\omega))\left(\Delta G_{t}+C\left(\widetilde{P}_{t}+\widetilde{C}_{t}\right)\right)-C(1-\gamma) \widetilde{P}_{N, t}-C \gamma \omega \widetilde{P}_{T, t}
$$

We can simplify this term by recalling $\widetilde{P}_{N, t}=\widetilde{W}_{t}$ and $\widetilde{P}_{T, t}=\omega \widetilde{W}_{t}$ :

$$
(1-\gamma) \widetilde{Y}_{N, t}+\gamma \omega \widetilde{Y}_{T, t}=(1-\gamma(1-\omega))\left(\Delta G_{t}+C\left(\widetilde{P}_{t}+\widetilde{C}_{t}\right)\right)-C\left((1-\gamma)+\gamma \omega^{2}\right) \widetilde{W}_{t}
$$

Inserting this back into our market clearing condition (A.1), we have

$$
\widetilde{L}_{t}=(1-(1-\omega) \gamma)\left(\Delta G_{t}+C\left(\widetilde{P}_{t}+\widetilde{C}_{t}\right)\right)-C\left(1-\gamma\left(1-\omega^{2}\right)\right) \widetilde{W}_{t}-\psi \gamma\left(1-\omega^{2}\right) \widetilde{W}_{t}
$$

Separable preferences The complete market condition reads

$$
\widetilde{C}_{t}=-\sigma \widetilde{P}_{t}^{r e t}=-\sigma\left(\widetilde{P}_{t}+\frac{\Delta \tau_{t}}{1+\tau}\right)
$$

Further, labor supply is

$$
\widetilde{W}_{t}-\widetilde{P}_{t}^{r e t}=\frac{1}{\eta} \widetilde{L}_{t}-\widetilde{U}_{1, t}
$$


where the complete market condition states $\widetilde{U}_{1, t}=\widetilde{P}_{t}^{r e t}$. This implies

$$
\widetilde{L}_{t}=\eta \widetilde{W}_{t}
$$

Inserting these two equations into (A.2):

$$
\begin{aligned}
(1-(1-\omega) \gamma)\left(\Delta G_{t}-\frac{C}{1+\tau} \Delta \tau_{t}+(1-\sigma) C \widetilde{P}_{t}\right) & =\left(C\left(1-\gamma\left(1-\omega^{2}\right)\right)+\psi \gamma\left(1-\omega^{2}\right)+\eta\right) \widetilde{W}_{t} \\
\Delta G_{t}-\sigma \frac{C}{1+\tau} \Delta \tau_{t}+(1-\sigma) C \widetilde{P}_{t} & =\frac{C\left(1-\gamma\left(1-\omega^{2}\right)\right)+\psi \gamma\left(1-\omega^{2}\right)+\eta}{1-(1-\omega) \gamma} \widetilde{W_{t}}
\end{aligned}
$$

Setting $\sigma=1$ and replacing $\widetilde{W}_{t}=[1-\gamma(1-\omega)]^{-1} \widetilde{Q}_{t}^{c t}$ yields

$$
\Delta G_{t}-\sigma C \frac{\Delta \tau_{t}}{1+\tau}=\left[\frac{C\left(1-\gamma\left(1-\omega^{2}\right)\right)+\psi \gamma\left(1-\omega^{2}\right)+\eta}{(1-\gamma(1-\omega))^{2}}-C(1-\sigma)\right] \widetilde{Q}_{t}^{c t}
$$

GHH preferences Labor supply is

$$
\begin{aligned}
\widetilde{W_{t}}-\widetilde{P}_{t}-\frac{\Delta \tau_{t}}{1+\tau} & =\frac{1}{\eta} \widetilde{L}_{t} \\
\frac{1}{\eta} \widetilde{L}_{t} & =\gamma(1-\omega) \widetilde{W}_{t}-\frac{\Delta \tau_{t}}{1+\tau}
\end{aligned}
$$

The complete market condition reads

$$
\begin{aligned}
C \tilde{C}_{t}-\tilde{L}_{t} & =-\sigma\left(C-\frac{\eta}{1+\eta} \frac{1}{1+\tau}\right) \widetilde{P}_{t}^{r e t} \\
C \tilde{C}_{t}-\tilde{L}_{t} & =-\sigma\left(C-\frac{\eta}{1+\eta} \frac{1}{1+\tau}\right)\left(\widetilde{W}_{t}-\frac{1}{\eta} \widetilde{L}_{t}\right) \\
& =-\sigma\left(C-\frac{\eta}{1+\eta} \frac{1}{1+\tau}\right)\left((1-\gamma(1-\omega)) \widetilde{W}_{t}+\frac{\Delta \tau_{t}}{1+\tau}\right)
\end{aligned}
$$

\section{B Forecasting Specification for Government Purchases}

This section briefly presents the forecasting specification for government purchases. It is the same as outlined in House et al. (2017). The forecast for government spending in country $i$ at time $t$ is

$\ln \widehat{G}_{i, t}=\left\{\begin{array}{rr}\ln G_{i, t-1}+\Delta \hat{Y}+\hat{\gamma}\left(\ln \hat{Y}_{t-1}-\ln Y_{i, t-1}\right)+\hat{\theta}\left(\Delta \ln Y_{i, t}-\Delta \ln \hat{Y}_{i, t}\right) & \forall t \leq 2010 \\ \ln \widehat{G}_{i, t-1}+\Delta \hat{Y}+\hat{\gamma}\left(\ln \hat{Y}_{t-1}-\ln Y_{i, t-1}\right)+\hat{\theta}\left(\Delta \ln Y_{i, t}-\Delta \ln \hat{Y}_{i, t}\right) & \forall t>2010 .\end{array}\right.$ 
where $\ln G_{i, t}$ is the $\log$ of real government spending per capita in country $i$ at time $t$ (deflated by the GDP deflator), $\ln Y_{i, t}$ is the $\log$ of real GDP per capita in country $i, \Delta \ln Y_{i, t}=$ $\ln Y_{i, t}-\ln Y_{i, t-1}$ is its $\log$ difference, and $\ln Y_{t}$ is the log of real GDP per capita averaged across all countries. The "hat" indicates a predicted value of the variable. This forecast specification accounts for both average sample-wide growth in GDP (through the parameter $\Delta Y$ ) and growth convergence dynamics (through the parameter $\gamma$, as well as a cyclical relationship (through the parameter $\theta$ ). We take the predicted values for $\ln \hat{Y}_{i, t}$ and the estimated parameter values from House et al. (2017) who estimate the average growth rate, $\Delta Y$, to be 1.8 percent, $\gamma$ to be 2.4 percent (indicating that poorer economies grow faster) and $\theta=0.38$ (indicating that government spending is pro-cyclical). The forecasting specification for GDP is

$$
\ln \widehat{Y}_{i, t}= \begin{cases}\ln Y_{i, t-1}+\Delta \hat{Y}+\hat{\gamma}\left(\ln \widehat{Y}_{t-1}-\ln Y_{i, t-1}\right) & \forall t \leq 2010 \\ \ln \widehat{Y}_{i, t-1}+\Delta \hat{Y}+\hat{\gamma}\left(\ln \widehat{Y}_{t-1}-\ln \widehat{Y}_{i, t-1}\right) & \forall t>2010\end{cases}
$$

Here, $X_{i, t}$ is country $i$ 's GDP, consumption or investment at time $t$, and $\widehat{X}_{i, t}$ is its forecast. The specification takes last period's value of (the log of) $X_{i, t}$ and adds a country- and time-specific growth rate, which is composed of two parts: a common term capturing the average rate of growth of the core European countries, $\Delta \hat{Y}$, and a catch-up term that raises this growth rate for poorer countries and lowers it for richer countries, $\gamma\left(\ln \widehat{Y}_{t-1}-\ln Y_{i, t-1}\right)$.

\section{Other Austerity Measures}

The main body of the text focuses on government purchases and consumption taxes. Here, we discuss two other fiscal instruments: labor taxes and capital taxes. To measure changes in these tax rates we rely on effective tax rates. This approach builds on early work by Mendoza et al. (1994), which was further refined in Eurostat and European Commission (2014). The principal idea is to classify tax revenue by economic function using data from the National Tax Lists and then approximate the base with data from the national sector accounts. Compared to statutory tax rates, the advantages of these rates are that they take into account the net effect of existing rules regarding exemptions and deductions, and also incorporate social security contributions in labor taxes. In calculating forecast errors for labor and capital taxes, we proceed as with consumption taxes. We premultiply the forecast errors in the tax rates by a country's (pre-crisis) tax base in percent of GDP, and then divide it by the gross tax 
rate. Table A1 lists the average forecast errors of government purchases, consumption taxes, labor taxes and capital taxes for the period 2010 - 2014. On average, the cuts in government spending were twice as large as the overall increases in tax revenues. Among the three tax measures, consumption tax rates were raised the most and also display the strongest variation in the cross section.

We also repeat the empirical analysis to include labor tax rates. Table A2 displays the results. Overall, the empirical results discussed in the main body of the text are robust to introducing labor taxes. The coefficient on labor taxes is always imprecisely estimated and does not show any clear patterns.

\section{Total Factor Productivity and Internal Devaluations}

The Balassa-Samuelson effect predicts that changes in total factor productivity (TFP) drive real exchange rate movements. Most recently, Berka et al. (2018) provide evidence for this hypothesis in a sample of European countries from 1995 - 2009. Here, we show that variations in the paths for TFP account for little of the cross-sectional variation observed in real exchange rate for the period 2010 - 2014. We measure TFP as multifactor productivity, which is an annual index published by the OECD. We apply the same unit-root plus trend forecast specification as we do for all other variables:

$$
\widehat{T F P}_{i, t}=T F P_{i,{ }^{\prime} 09}\left(1+g r_{i}^{T F P}\right)^{t-' 09}
$$

where $g r_{i}^{T F P}$ is country $i$ 's average growth rate of TFP for 2003 - 2009.

We now repeat our empirical analysis to include forecast errors in TFP. Table A3 displays the results. Overall, forecast errors in TFP are not a strong predictor for the cross-sectional variation of the various measures associated with internal devaluation. In general, the $R^{2}$ for the regression just based on TFP is very low. This is supportive of the idea that TFP changes were not a main driving force of the observed cross-sectional variation in economic outcomes across Europe. 


\section{References}

Berka, Martin, Michael B. Devereux, and Charles Engel, "Real Exchange Rates and Sectoral Productivity in the Eurozone," American Economic Review, 2018, 108 (6), 15431581.

Eurostat and European Commission, "Taxation Trends in the European Union - Data for the EU member states, Iceland and Norway," Technical Report 2014.

House, Christopher L., Christian Proebsting, and Linda L. Tesar, "Austerity in the Aftermath of the Great Recession," 2017. NBER Working Paper No. 23147.

Mendoza, Enrique G, Assaf Razin, and Linda L Tesar, "Effective Tax Rates in Macroeconomics: Cross-Country Estimates of Tax Rates on Factor Incomes and Consumption," Journal of Monetary Economics, 1994, 34 (3), 297-323. 
Table A1: AUSTERITY MEASURES IN PERCENT OF GDP

\begin{tabular}{lcrrr}
\hline \hline & $\begin{array}{c}\text { Gov't } \\
\text { purchases }\end{array}$ & $\begin{array}{c}\text { Cons } \\
\text { tax }\end{array}$ & $\begin{array}{c}\text { Labor } \\
\text { tax }\end{array}$ & $\begin{array}{c}\text { Capital } \\
\text { tax }\end{array}$ \\
\hline Greece & 8.95 & 3.02 & 1.38 & 0.67 \\
Portugal & 5.41 & 1.45 & 1.38 & -0.17 \\
Spain & 4.35 & 1.13 & 0.78 & -0.02 \\
Ireland & 4.07 & 0.13 & 1.34 & -0.60 \\
Italy & 3.04 & 0.45 & 0.02 & 0.32 \\
Netherlands & 1.57 & 0.44 & 0.66 & -0.61 \\
Austria & 1.30 & 0.18 & 0.48 & 0.15 \\
Denmark & 1.30 & 0.41 & -0.09 & 1.09 \\
France & 1.14 & -0.16 & 0.53 & 1.15 \\
Finland & 0.76 & 0.48 & -0.02 & 0.28 \\
Belgium & 0.71 & -0.04 & 0.48 & 1.50 \\
Luxembourg & 0.73 & 0.22 & 0.19 & -0.46 \\
Germany & 0.08 & -0.05 & -0.13 & 0.31 \\
Average & 2.57 & 0.59 & 0.54 & 0.28 \\
Std deviation & 2.53 & 0.86 & 0.55 & 0.68 \\
Average (GIIPS) & 5.16 & 1.24 & 0.98 & 0.04 \\
\hline \hline
\end{tabular}

Notes: Table displays average forecast errors for various fiscal instruments expressed in percent of GDP. 
Table A2: Austerity and Internal Devaluations: Including Labor Tax

\begin{tabular}{|c|c|c|c|c|c|c|c|c|}
\hline \multirow[b]{2}{*}{ Gov't purchases } & \multicolumn{4}{|c|}{ Real Exchange Rate $\left(Q^{c t}\right)$} & & & & \\
\hline & $\begin{array}{r}-0.99 \\
(0.13)\end{array}$ & & & $\begin{array}{r}-1.73 \\
(0.42)\end{array}$ & & & & \\
\hline Cons tax & & $\begin{array}{c}2.34 \\
(0.65)\end{array}$ & & $\begin{array}{r}-2.00 \\
(0.94)\end{array}$ & & & & \\
\hline Labor tax & & & $\begin{array}{c}3.74 \\
(0.98)\end{array}$ & $\begin{array}{c}-0.67 \\
(1.01)\end{array}$ & & & & \\
\hline \multirow[t]{2}{*}{$R_{a d j}^{2}$} & 0.83 & 0.50 & 0.53 & 0.86 & & & & \\
\hline & \multicolumn{4}{|c|}{ Wages $(W)$} & \multicolumn{4}{|c|}{ Employment $(L)$} \\
\hline Gov't purchases & $\begin{array}{c}2.27 \\
(0.29)\end{array}$ & & & $\begin{array}{c}1.92 \\
(1.13)\end{array}$ & $\begin{array}{c}1.59 \\
(0.18)\end{array}$ & & & $\begin{array}{c}1.11 \\
(0.55)\end{array}$ \\
\hline Cons tax & & $\begin{array}{r}-5.93 \\
(1.26)\end{array}$ & & $\begin{array}{c}-0.11 \\
(2.51)\end{array}$ & & $\begin{array}{c}-4.72 \\
(0.51)\end{array}$ & & $\begin{array}{c}-2.19 \\
(1.23)\end{array}$ \\
\hline Labor tax & & & $\begin{array}{c}-8.88 \\
(2.10)\end{array}$ & $\begin{array}{c}-1.82 \\
(2.68)\end{array}$ & & & $\begin{array}{c}-4.90 \\
(1.83)\end{array}$ & $\begin{array}{c}1.12 \\
(1.31)\end{array}$ \\
\hline \multirow[t]{2}{*}{$R_{a d j}^{2}$} & 0.83 & 0.64 & 0.58 & 0.81 & 0.86 & 0.88 & 0.34 & 0.90 \\
\hline & \multicolumn{4}{|c|}{ Terms of Trade $(S)$} & \multicolumn{4}{|c|}{ Net Exports $(n x)$} \\
\hline Gov't purchases & $\begin{array}{c}0.02 \\
(0.31)\end{array}$ & & & $\begin{array}{c}1.31 \\
(1.18)\end{array}$ & $\begin{array}{c}-0.85 \\
(0.14)\end{array}$ & & & $\begin{array}{r}-1.30 \\
(0.51)\end{array}$ \\
\hline Cons tax & & $\begin{array}{c}0.25 \\
(0.92)\end{array}$ & & $\begin{array}{c}2.82 \\
(2.62)\end{array}$ & & $\begin{array}{c}2.11 \\
(0.57)\end{array}$ & & $\begin{array}{c}-1.18 \\
(1.14)\end{array}$ \\
\hline Labor tax & & & $\begin{array}{c}0.28 \\
(1.43)\end{array}$ & $\begin{array}{c}2.43 \\
(2.80)\end{array}$ & & & $\begin{array}{c}3.15 \\
(0.93)\end{array}$ & $\begin{array}{c}-0.47 \\
(1.22)\end{array}$ \\
\hline \multirow[t]{2}{*}{$R_{a d j}^{2}$} & -0.09 & -0.08 & -0.09 & -0.16 & 0.76 & 0.51 & 0.46 & 0.74 \\
\hline & \multicolumn{4}{|c|}{ Relative Price NT $\left(\frac{P_{N}^{r e t}}{P_{T}^{r e t}}\right)$} & \multicolumn{4}{|c|}{ Relative Consumption NT $\left(\frac{C_{N}}{C_{T}}\right)$} \\
\hline Gov't purchases & $\begin{array}{c}0.95 \\
(0.16)\end{array}$ & & & $\begin{array}{c}0.90 \\
(0.59)\end{array}$ & $\begin{array}{r}-2.75 \\
(0.50)\end{array}$ & & & $\begin{array}{c}-2.34 \\
(1.78)\end{array}$ \\
\hline Cons tax & & $\begin{array}{r}-2.31 \\
(0.67)\end{array}$ & & $\begin{array}{c}0.59 \\
(1.32)\end{array}$ & & $\begin{array}{c}8.18 \\
(1.43)\end{array}$ & & $\begin{array}{c}3.22 \\
(3.96)\end{array}$ \\
\hline Labor tax & & & $\begin{array}{c}-4.05 \\
(0.88)\end{array}$ & $\begin{array}{c}-1.34 \\
(1.41)\end{array}$ & & & $\begin{array}{c}8.03 \\
(3.72)\end{array}$ & $\begin{array}{c}-3.40 \\
(4.23)\end{array}$ \\
\hline$R_{a d j}^{2}$ & 0.73 & 0.48 & 0.63 & 0.73 & 0.71 & 0.73 & 0.23 & 0.72 \\
\hline Obs. & 13 & 13 & 13 & 13 & 13 & 13 & 13 & 13 \\
\hline
\end{tabular}

Notes: See Table 1. 
Table A3: Austerity and Internal Devaluations: Including TFP

\begin{tabular}{|c|c|c|c|c|c|c|c|c|}
\hline \multirow[b]{2}{*}{ Gov't purchases } & \multicolumn{4}{|c|}{ Real Exchange Rate $\left(Q^{c t}\right)$} & & & & \\
\hline & $\begin{array}{c}-0.99 \\
(0.13)\end{array}$ & & & $\begin{array}{c}-1.30 \\
(0.31)\end{array}$ & & & & \\
\hline Cons tax & & $\begin{array}{c}2.34 \\
(0.65)\end{array}$ & & $\begin{array}{c}-0.90 \\
(0.98)\end{array}$ & & & & \\
\hline TFP & & & $\begin{array}{c}0.05 \\
(0.17)\end{array}$ & $\begin{array}{c}0.09 \\
(0.07)\end{array}$ & & & & \\
\hline \multirow[t]{2}{*}{$R_{a d j}^{2}$} & 0.83 & 0.50 & -0.08 & 0.88 & & & & \\
\hline & \multicolumn{4}{|c|}{ Wages $(W)$} & \multicolumn{4}{|c|}{ Employment $(L)$} \\
\hline Gov't purchases & $\begin{array}{c}2.27 \\
(0.29)\end{array}$ & & & $\begin{array}{c}1.36 \\
(0.56)\end{array}$ & $\begin{array}{c}1.59 \\
(0.18)\end{array}$ & & & $\begin{array}{c}0.97 \\
(0.43)\end{array}$ \\
\hline Cons tax & & $\begin{array}{c}-5.93 \\
(1.26)\end{array}$ & & $\begin{array}{c}-3.45 \\
(1.76)\end{array}$ & & $\begin{array}{c}-4.72 \\
(0.51)\end{array}$ & & $\begin{array}{r}-1.92 \\
(1.35)\end{array}$ \\
\hline TFP & & & $\begin{array}{c}-0.15 \\
(0.38)\end{array}$ & $\begin{array}{c}-0.50 \\
(0.13)\end{array}$ & & & $\begin{array}{c}0.30 \\
(0.25)\end{array}$ & $\begin{array}{c}0.09 \\
(0.10)\end{array}$ \\
\hline \multirow[t]{2}{*}{$R_{a d j}^{2}$} & 0.83 & 0.64 & -0.07 & 0.92 & 0.86 & 0.88 & 0.04 & 0.91 \\
\hline & \multicolumn{4}{|c|}{ Terms of Trade $(S)$} & \multicolumn{4}{|c|}{ Net Exports $(n x)$} \\
\hline Gov't purchases & $\begin{array}{c}0.02 \\
(0.31)\end{array}$ & & & $\begin{array}{l}1.45 \\
(0.77)\end{array}$ & $\begin{array}{c}-0.85 \\
(0.14)\end{array}$ & & & $\begin{array}{r}-1.33 \\
(0.39)\end{array}$ \\
\hline Cons tax & & $\begin{array}{c}0.25 \\
(0.92)\end{array}$ & & $\begin{array}{l}5.02 \\
(2.44)\end{array}$ & & $\begin{array}{c}2.11 \\
(0.57)\end{array}$ & & $\begin{array}{r}-1.63 \\
(1.23)\end{array}$ \\
\hline TFP & & & $\begin{array}{c}0.16 \\
(0.15)\end{array}$ & $\begin{array}{c}0.40 \\
(0.18)\end{array}$ & & & $\begin{array}{c}-0.07 \\
(0.15)\end{array}$ & $\begin{array}{c}-0.08 \\
(0.09)\end{array}$ \\
\hline \multirow[t]{2}{*}{$R_{a d j}^{2}$} & -0.09 & -0.08 & 0.01 & 0.18 & 0.76 & 0.51 & -0.07 & 0.76 \\
\hline & \multicolumn{4}{|c|}{ Relative Price NT $\left(\frac{P_{N}^{r e t}}{P_{T}^{r e t}}\right)$} & \multicolumn{4}{|c|}{ Relative Consumption NT $\left(\frac{C_{N}}{C_{T}}\right)$} \\
\hline Gov't purchases & $\begin{array}{c}0.95 \\
(0.16)\end{array}$ & & & $\begin{array}{l}0.87 \\
(0.39)\end{array}$ & $\begin{array}{c}-2.75 \\
(0.50)\end{array}$ & & & $\begin{array}{r}-0.76 \\
(1.40)\end{array}$ \\
\hline Cons tax & & $\begin{array}{c}-2.31 \\
(0.67)\end{array}$ & & $\begin{array}{c}-0.45 \\
(1.25)\end{array}$ & & $\begin{array}{l}8.18 \\
(1.43)\end{array}$ & & $\begin{array}{c}6.67 \\
(4.43)\end{array}$ \\
\hline TFP & & & $\begin{array}{c}-0.10 \\
(0.17)\end{array}$ & $\begin{array}{c}-0.20 \\
(0.09)\end{array}$ & & & $\begin{array}{r}-0.30 \\
(0.49)\end{array}$ & $\begin{array}{c}0.22 \\
(0.33)\end{array}$ \\
\hline$R_{a d j}^{2}$ & 0.73 & 0.48 & -0.06 & 0.80 & 0.71 & 0.73 & -0.05 & 0.72 \\
\hline Obs. & 13 & 13 & 13 & 13 & 13 & 13 & 13 & 13 \\
\hline
\end{tabular}

Notes: See Table 1. 

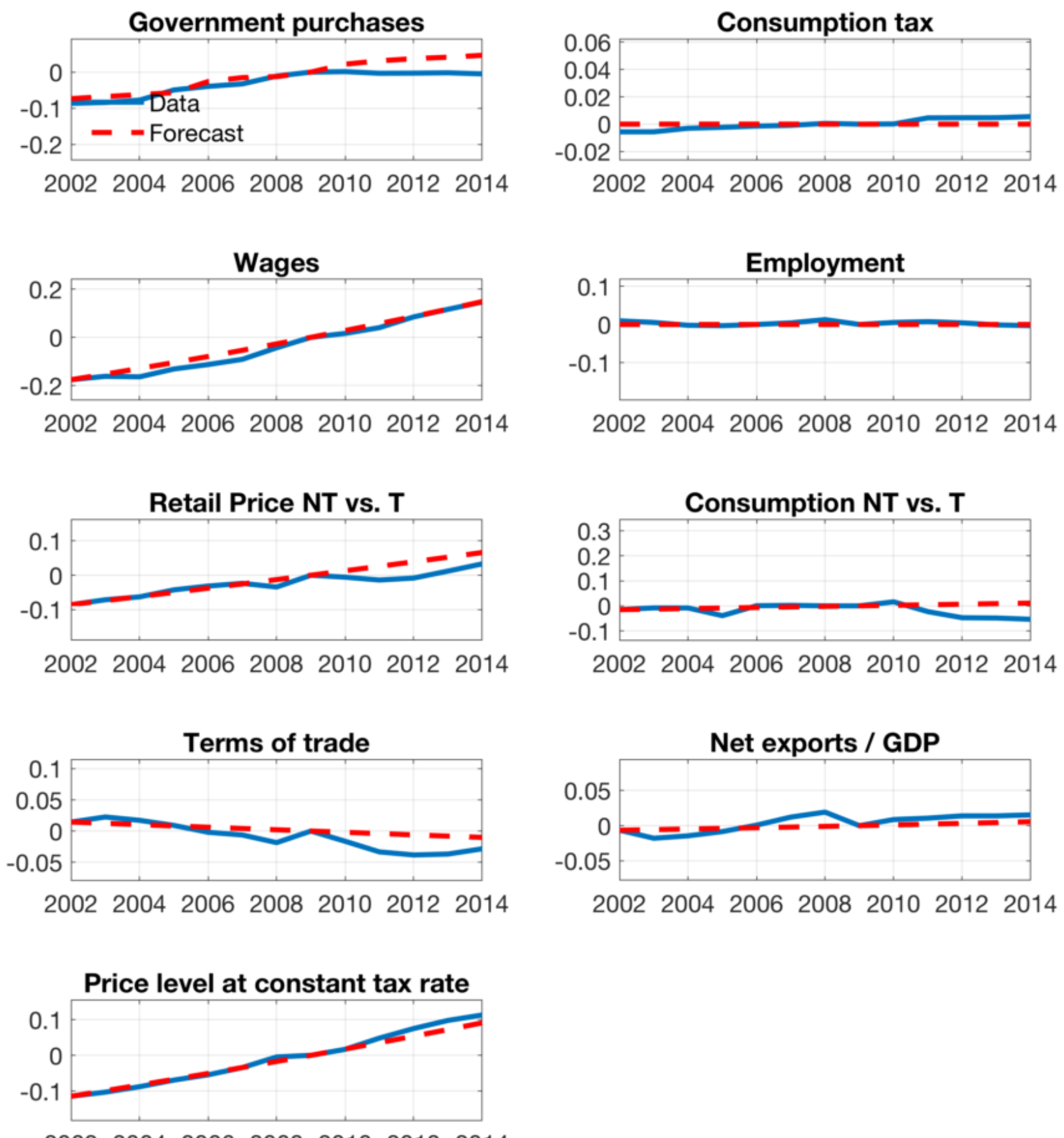

2002200420062008201020122014

Figure A1a: Austria

Notes: Actual data and forecasts. Values are indexed to 0 in 2009. A value of 0.1 means that the variable is 10 percent above its level in 2009. For tax rates, a value of 0.1 means that the tax rate is 10 percentage points higher than in 2009. For government purchases, a value of 0.1 means that government purchases were $10 \log$ points above their value in 2009. For price indices and tax rates, values refer to the end of the year. Net exports are the difference between exports and imports, expressed in percent of 2003-2009 average GDP. Net exports are also normalized to 0 in 2009. 

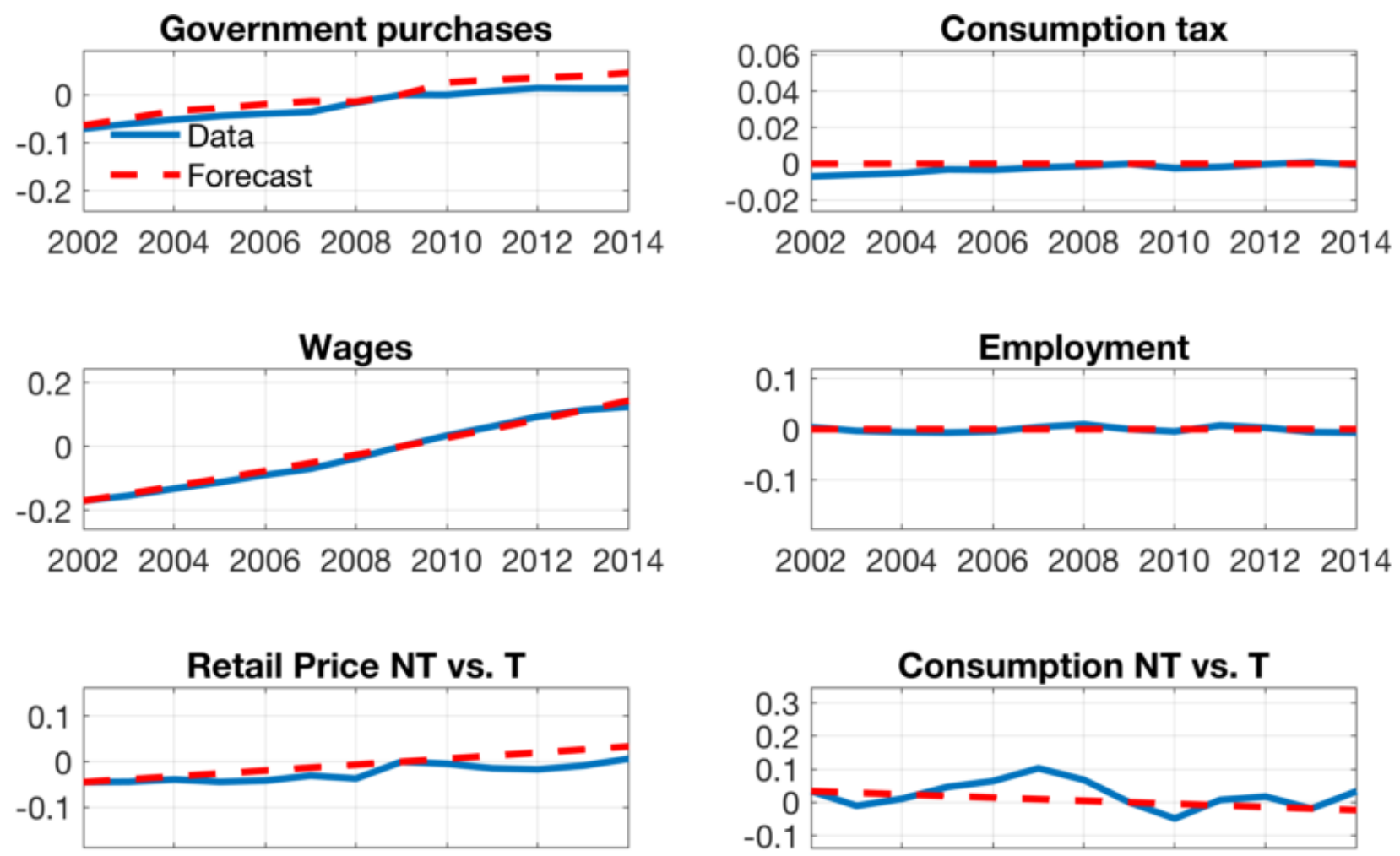

2002200420062008201020122014
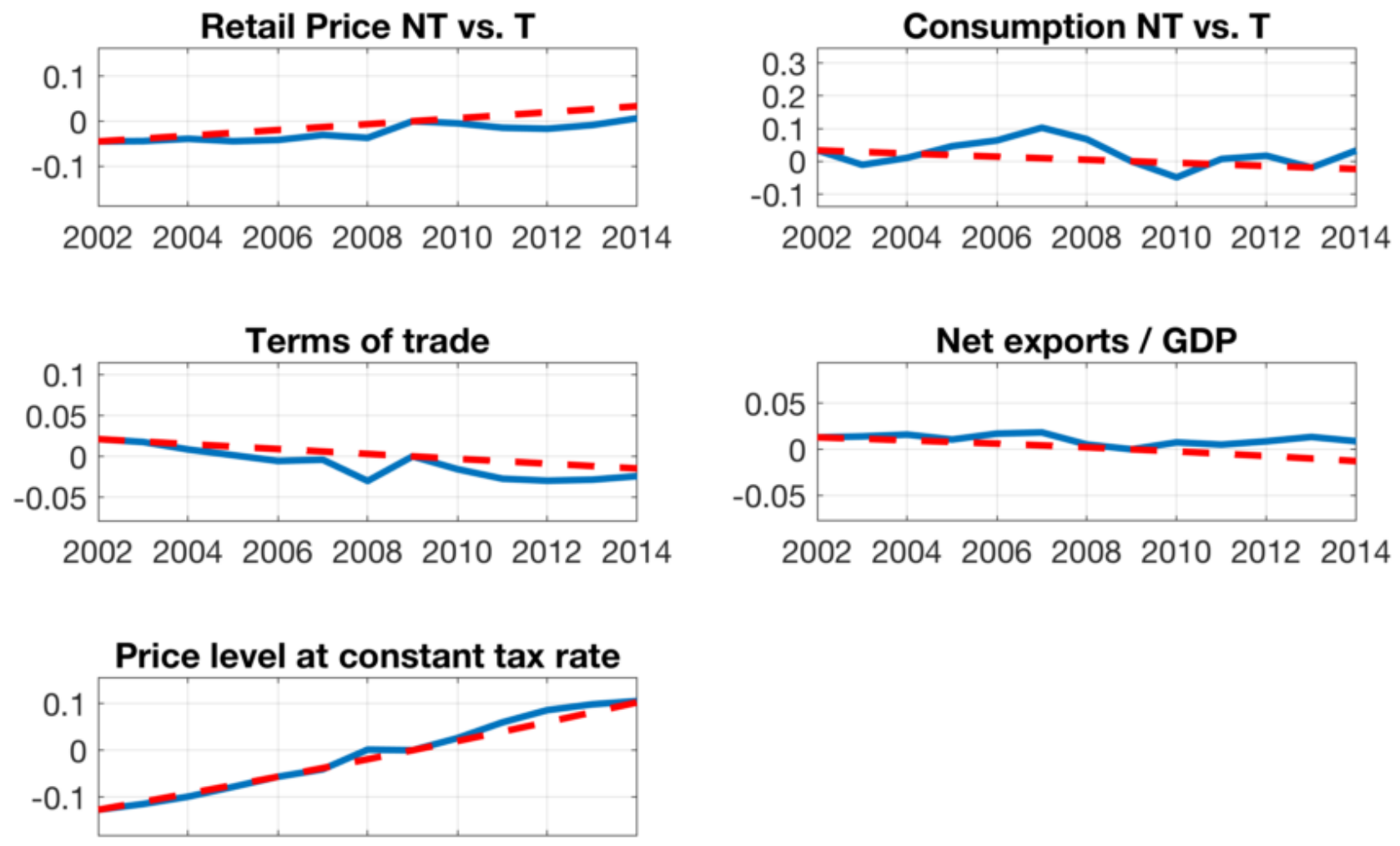

2002200420062008201020122014

Figure A1b: Belgium

Notes: See Figure A1a. 

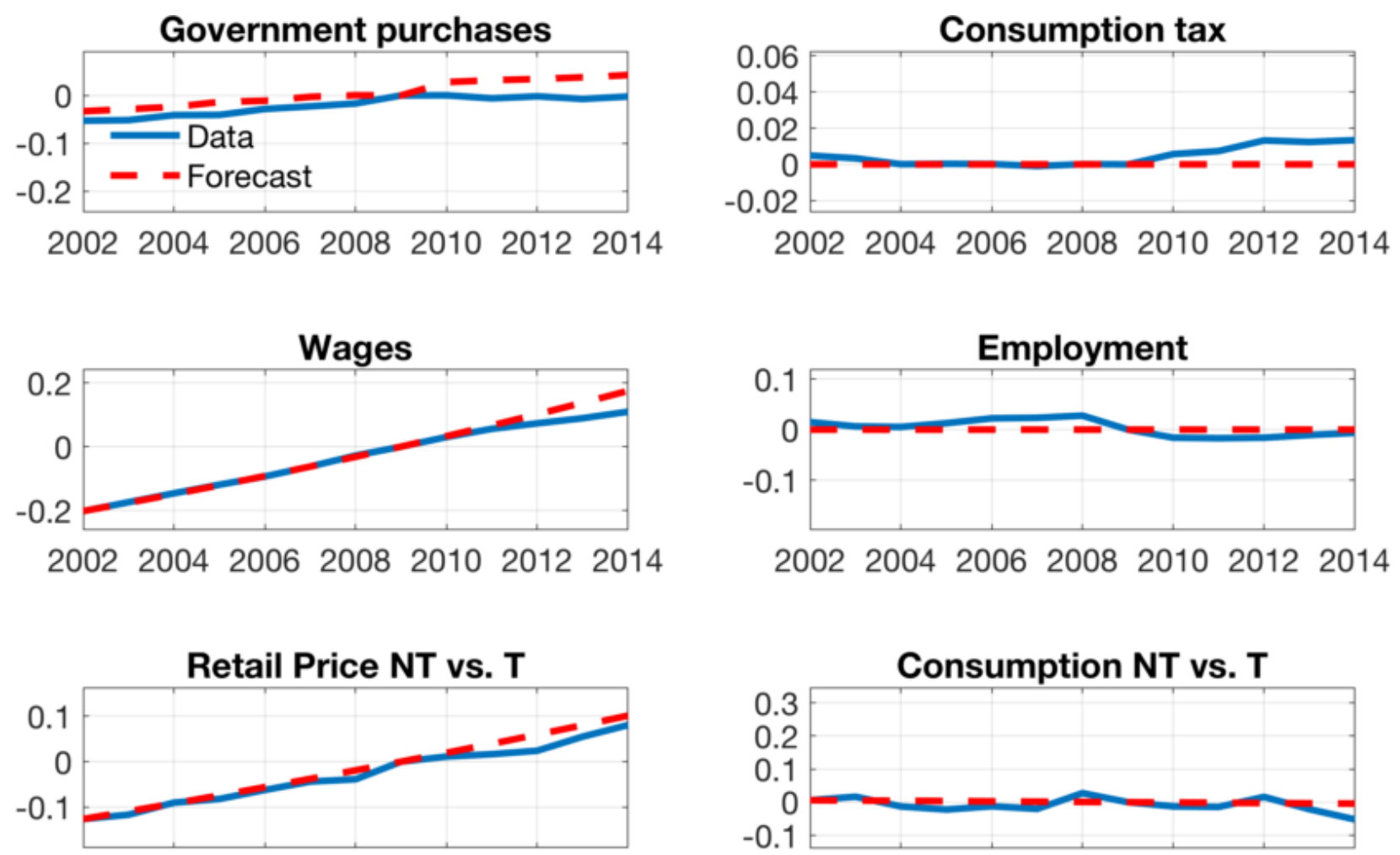

2002200420062008201020122014
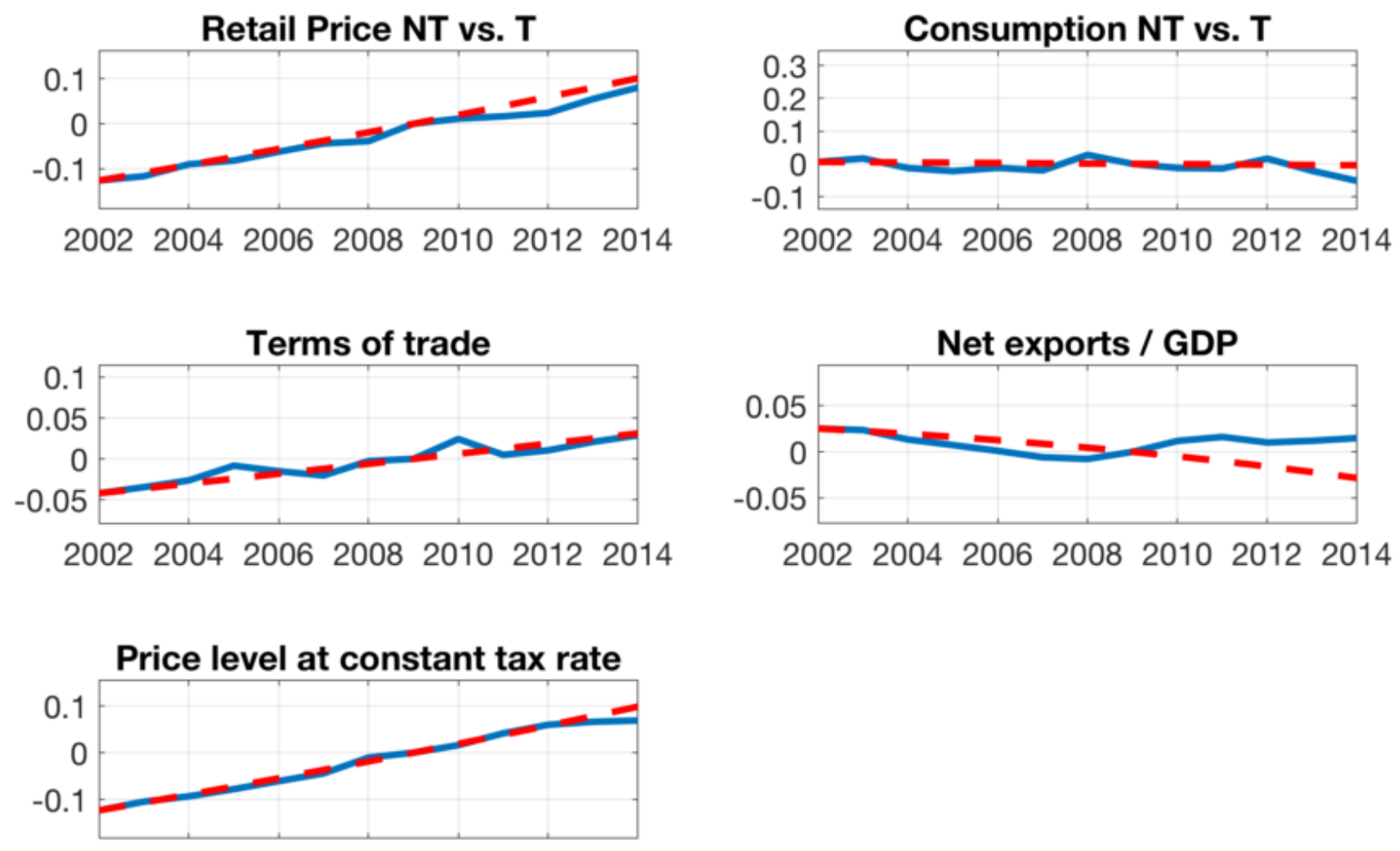

2002200420062008201020122014

Figure A1c: DenMARK

Notes: See Figure A1a. 

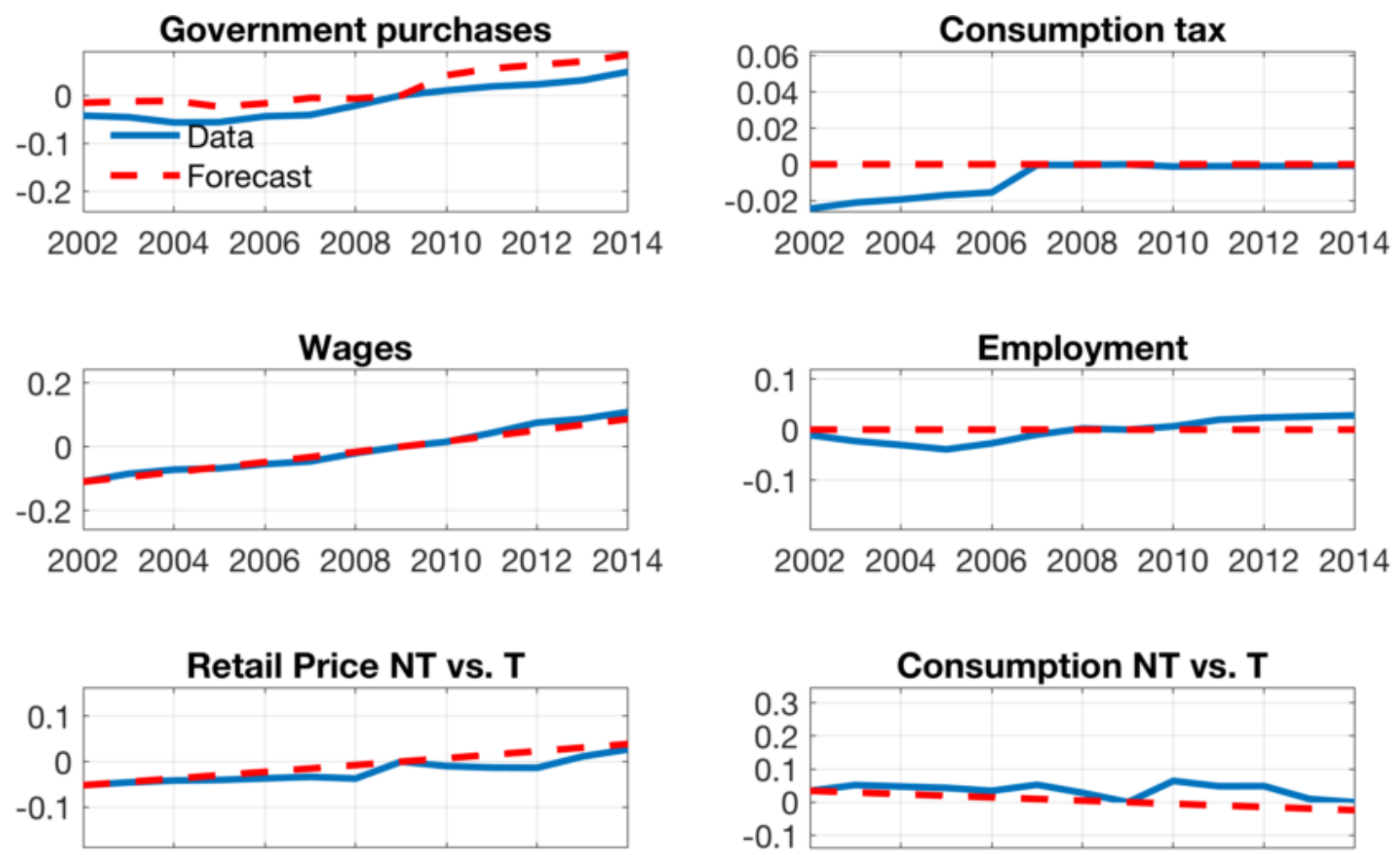

2002200420062008201020122014
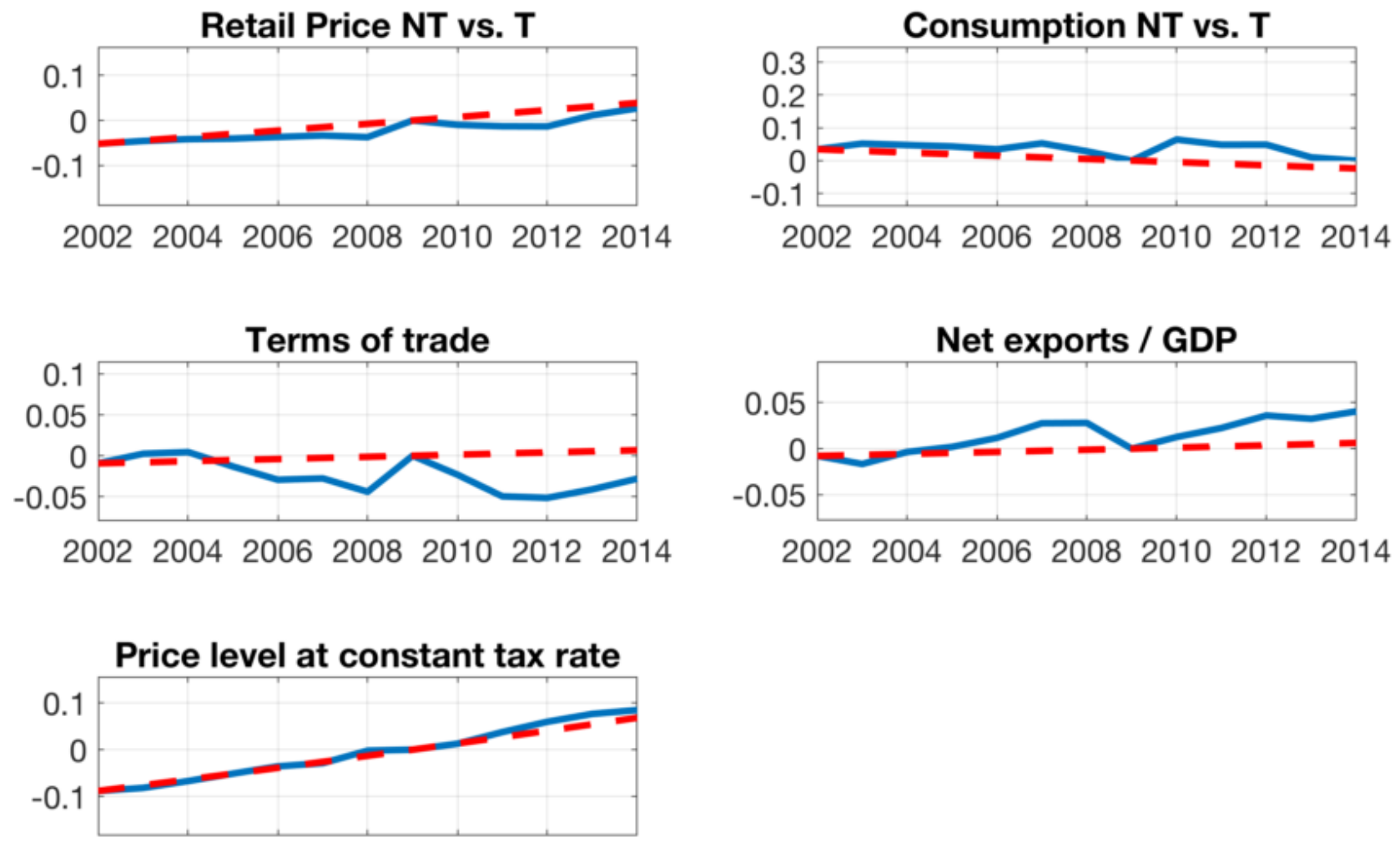

2002200420062008201020122014

Figure A1d: Germany

Notes: See Figure A1a. 

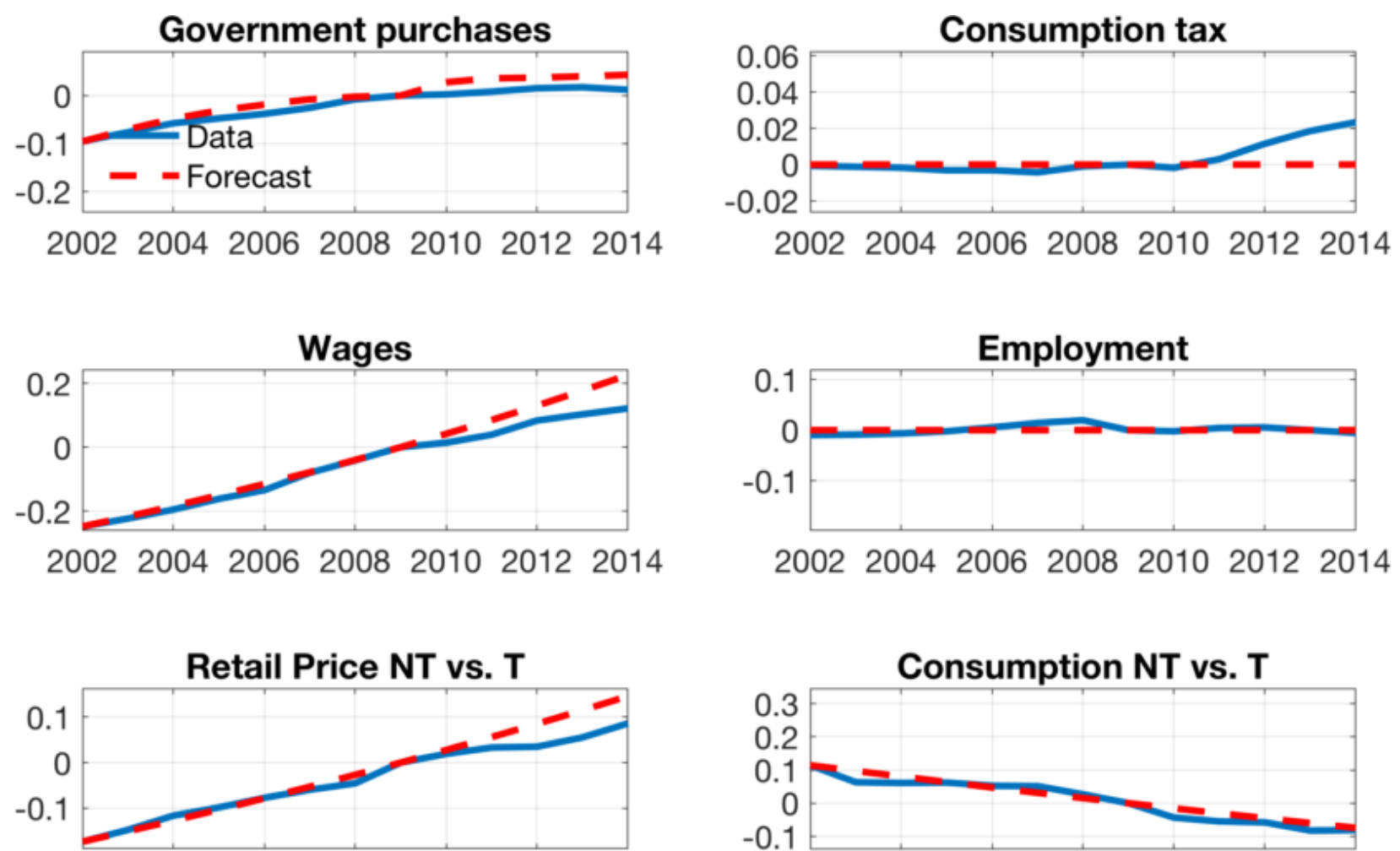

2002200420062008201020122014
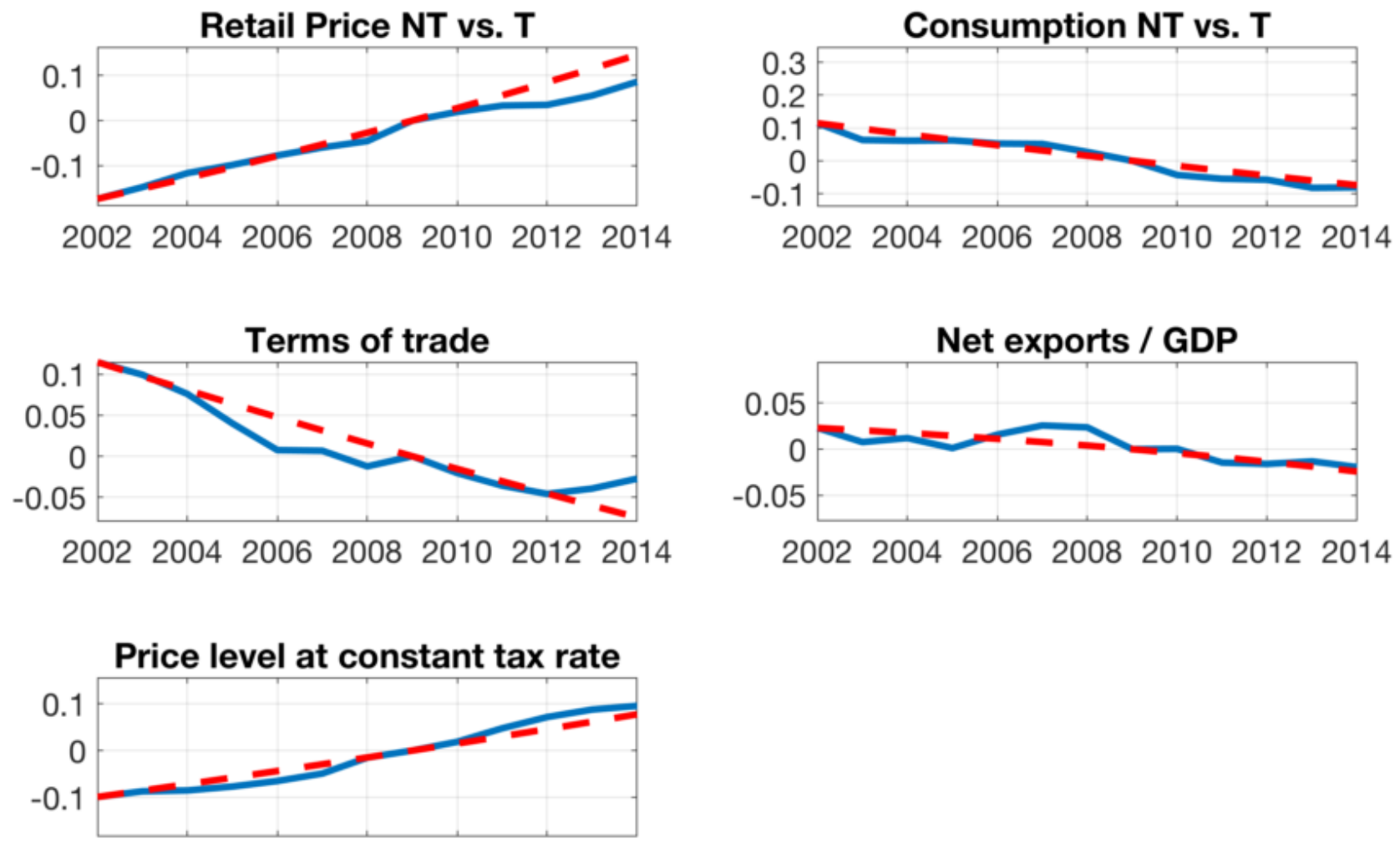

2002200420062008201020122014

Figure A1e: Finland

Notes: See Figure A1a. 

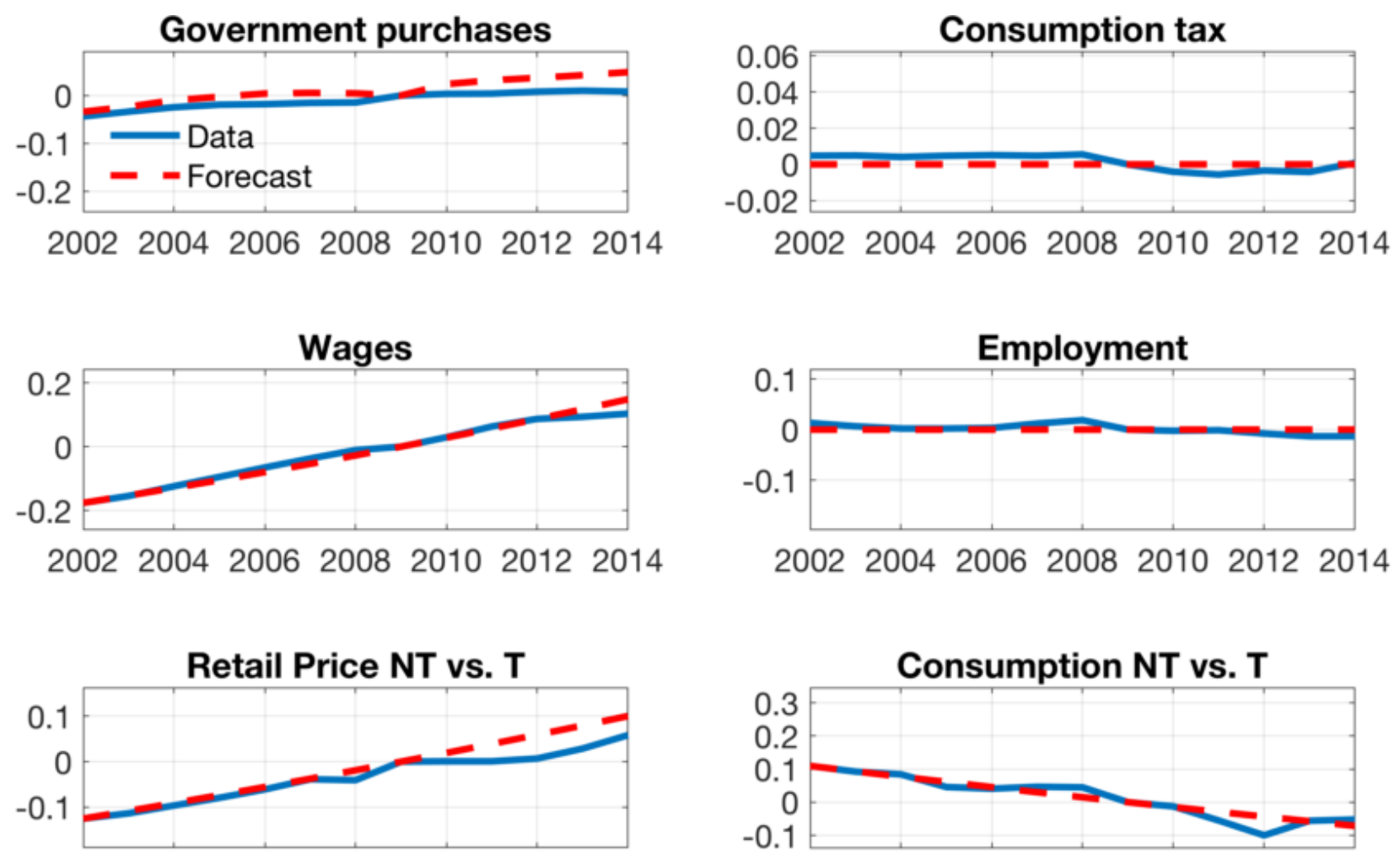

2002200420062008201020122014
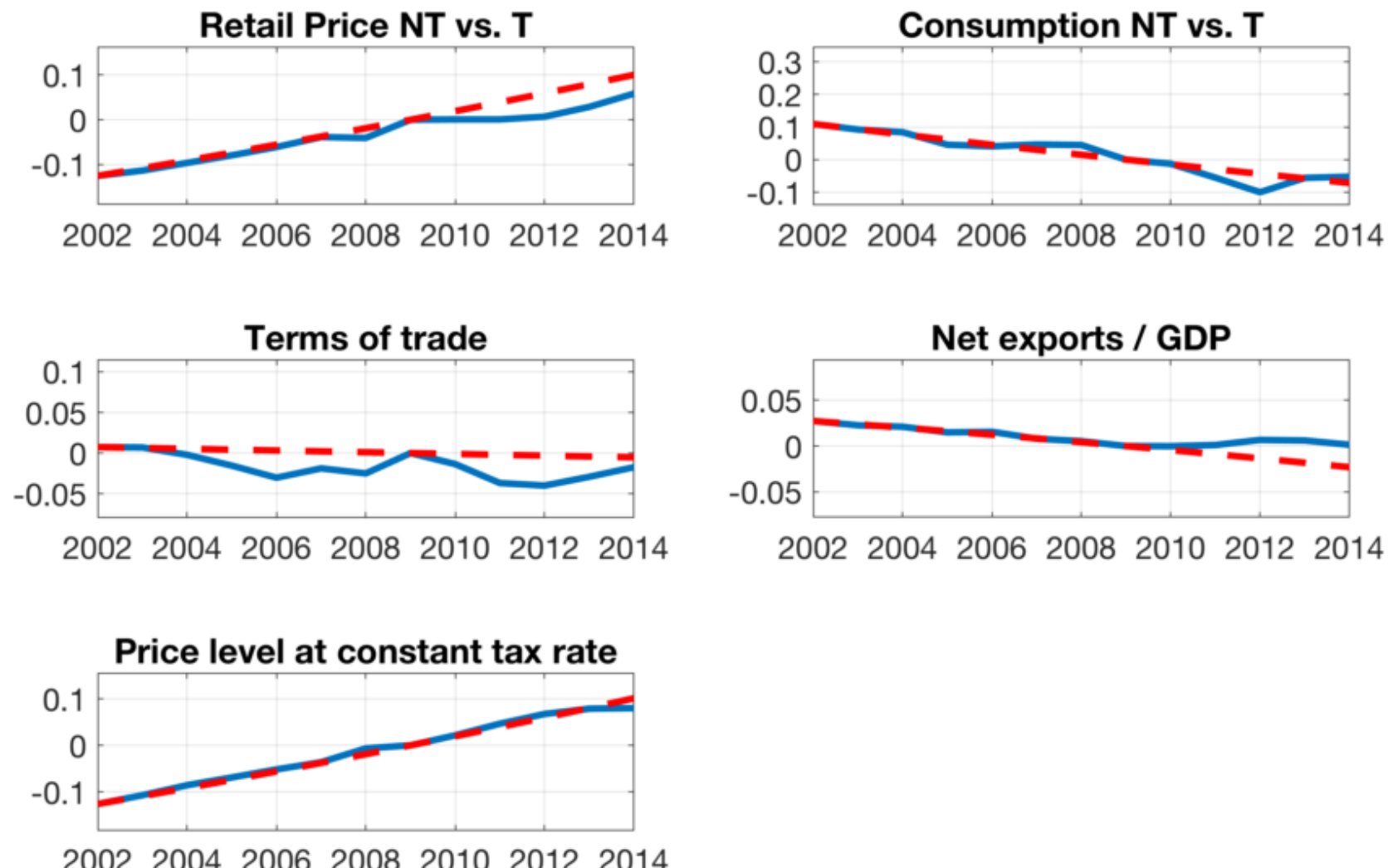

Figure A1f: FRANCE

Notes: See Figure A1a. 

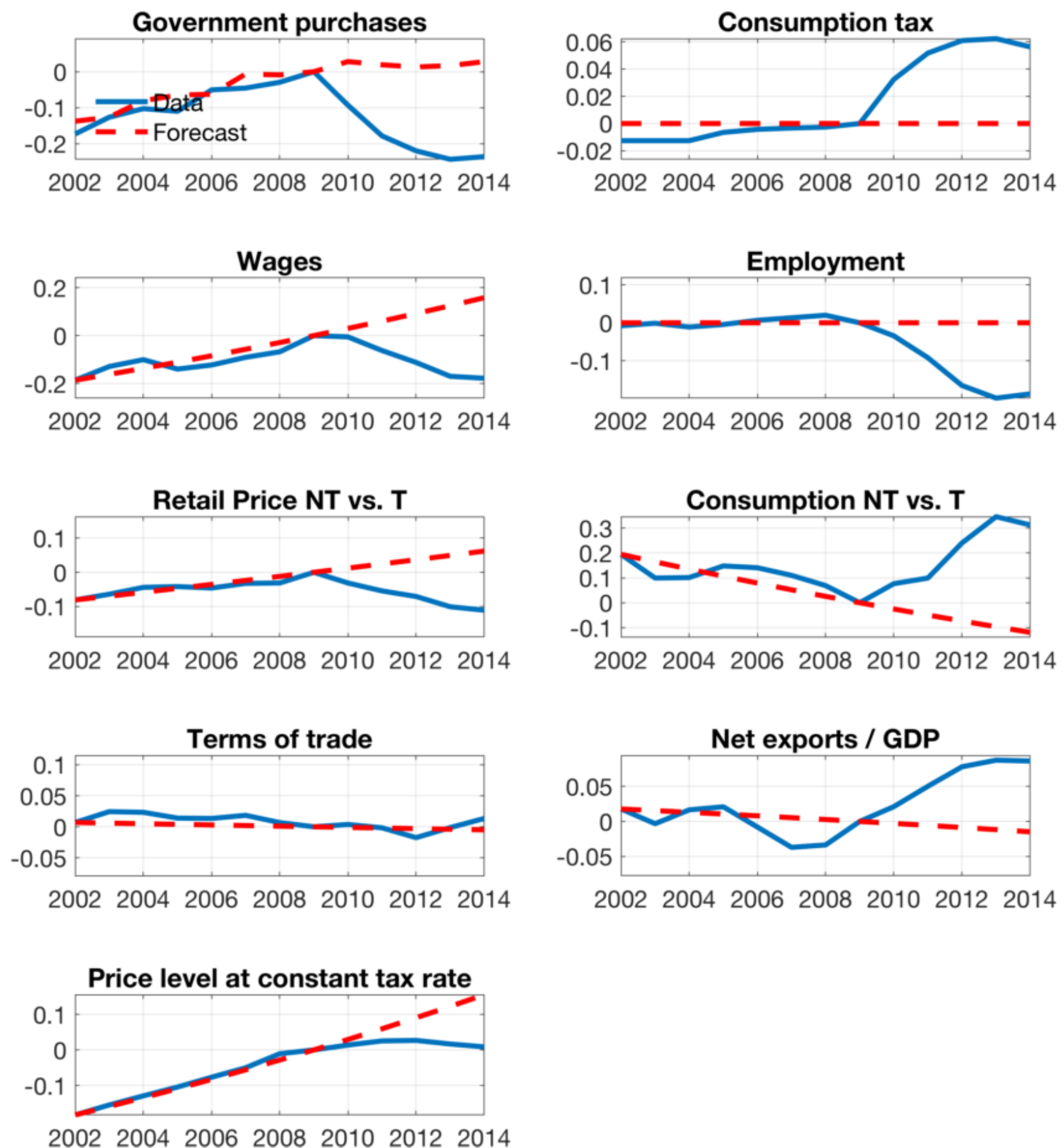

Figure A1g: GREECE

Notes: See Figure A1a. 

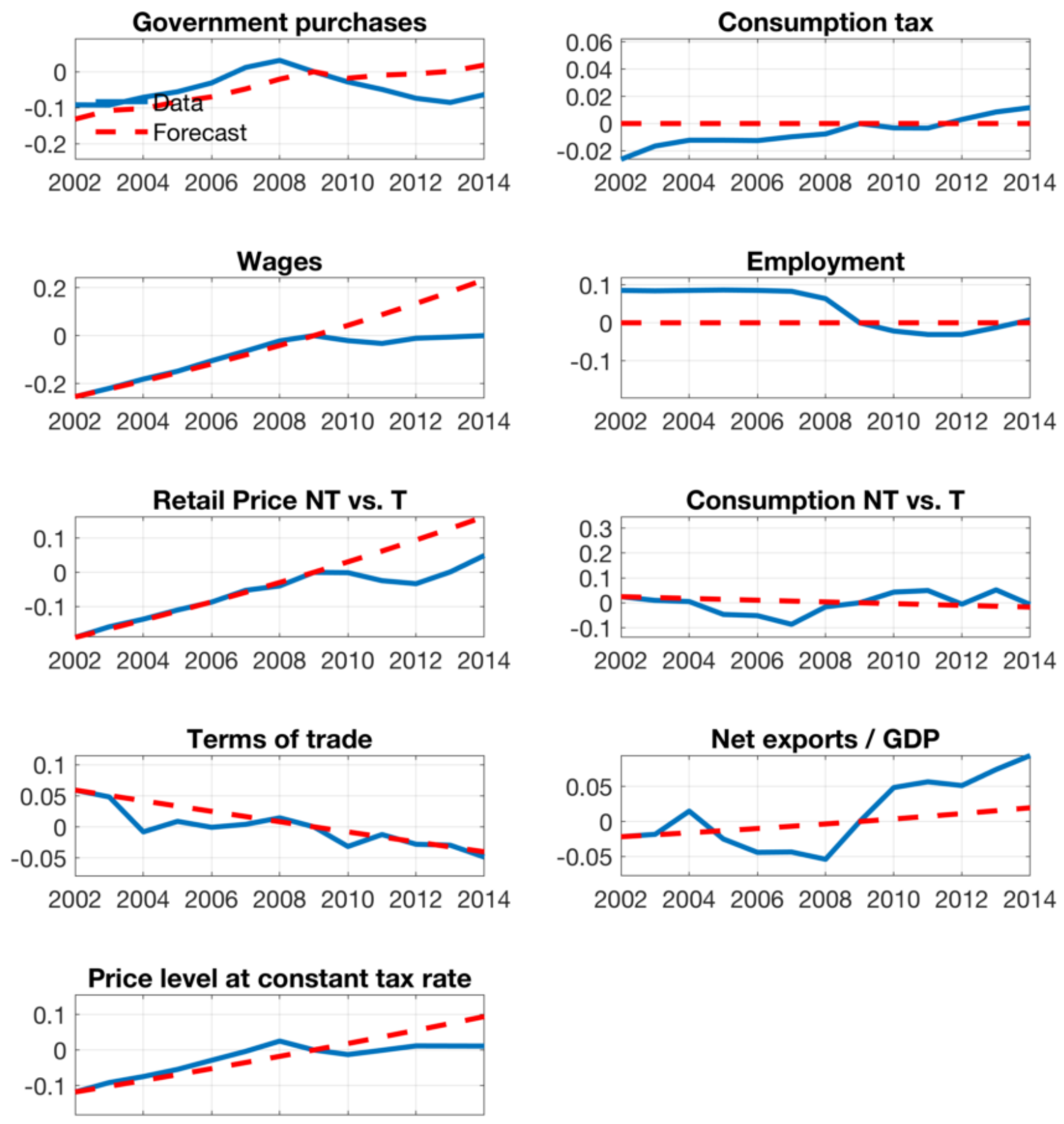

2002200420062008201020122014

Figure A1h: IRELAND

Notes: See Figure A1a. 

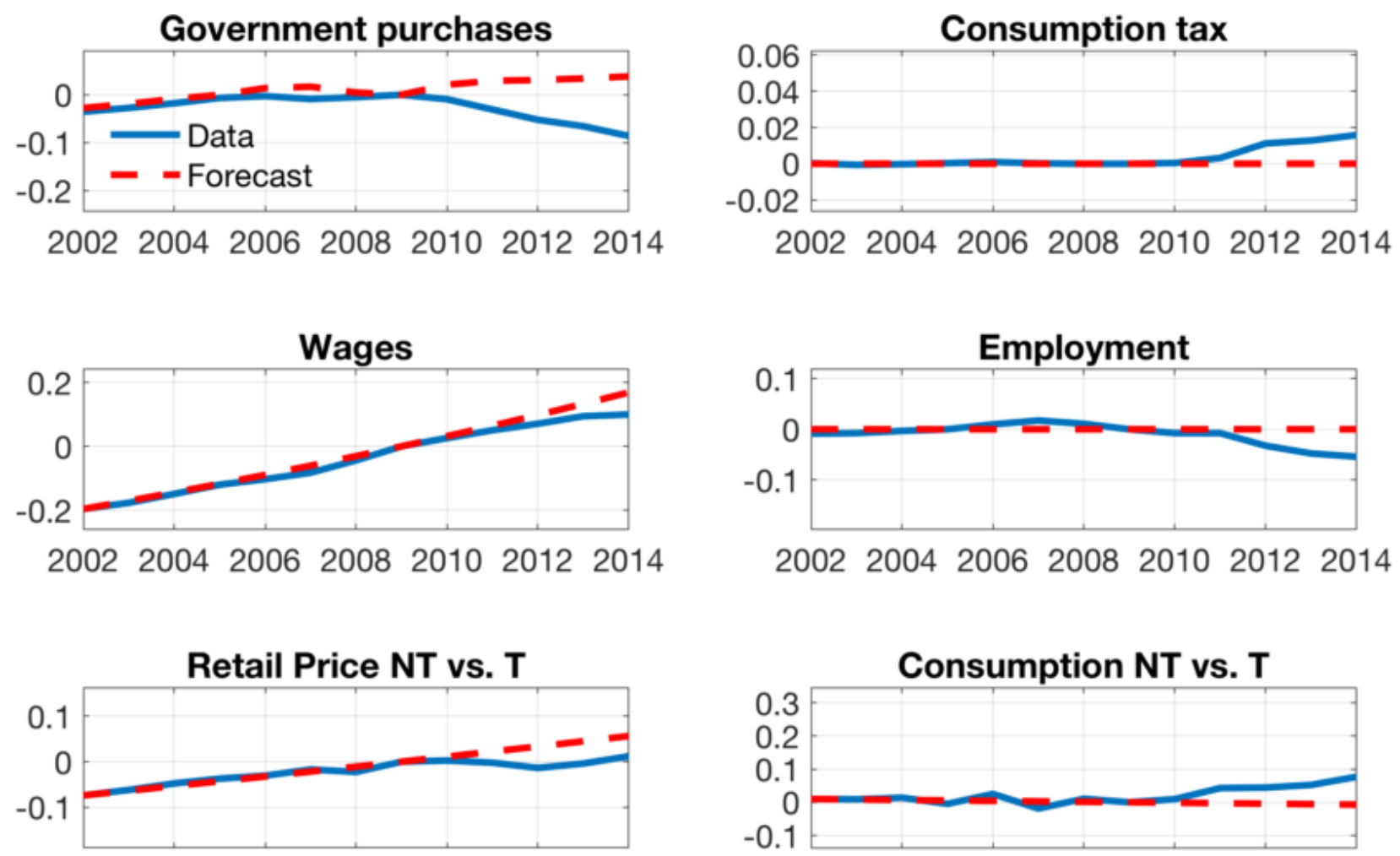

2002200420062008201020122014
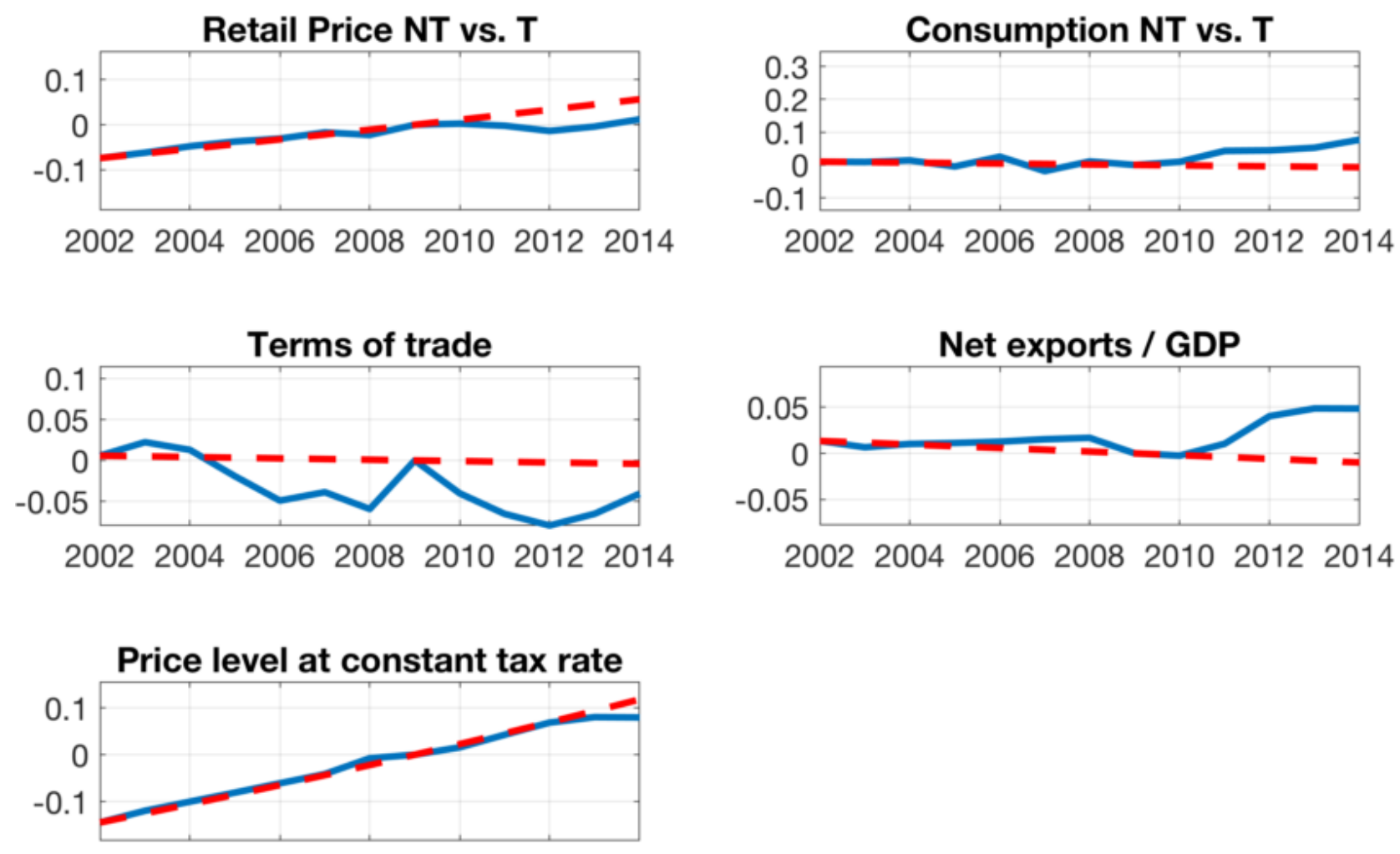

2002200420062008201020122014

Figure A1i: ITALY

Notes: See Figure A1a. 

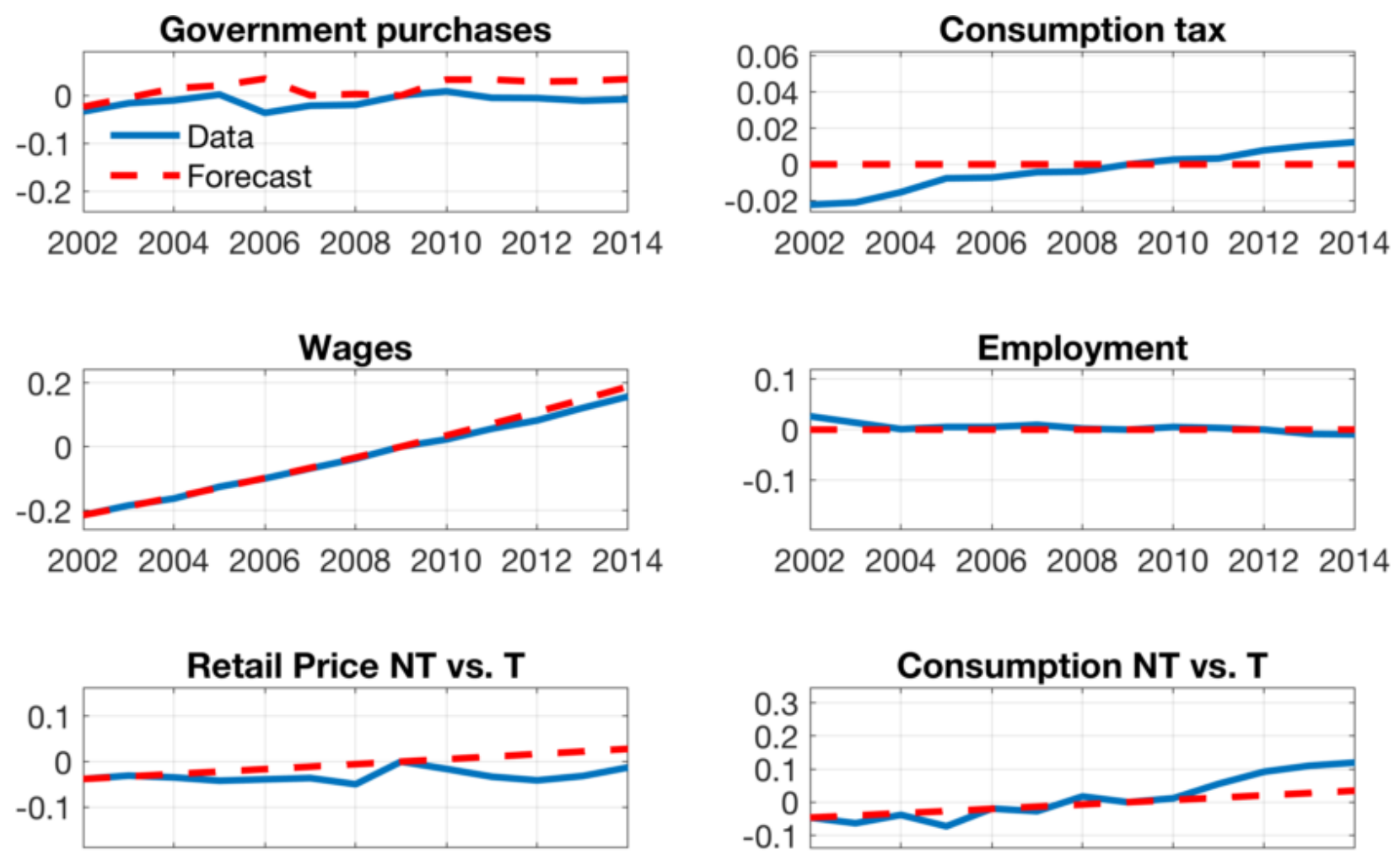

2002200420062008201020122014
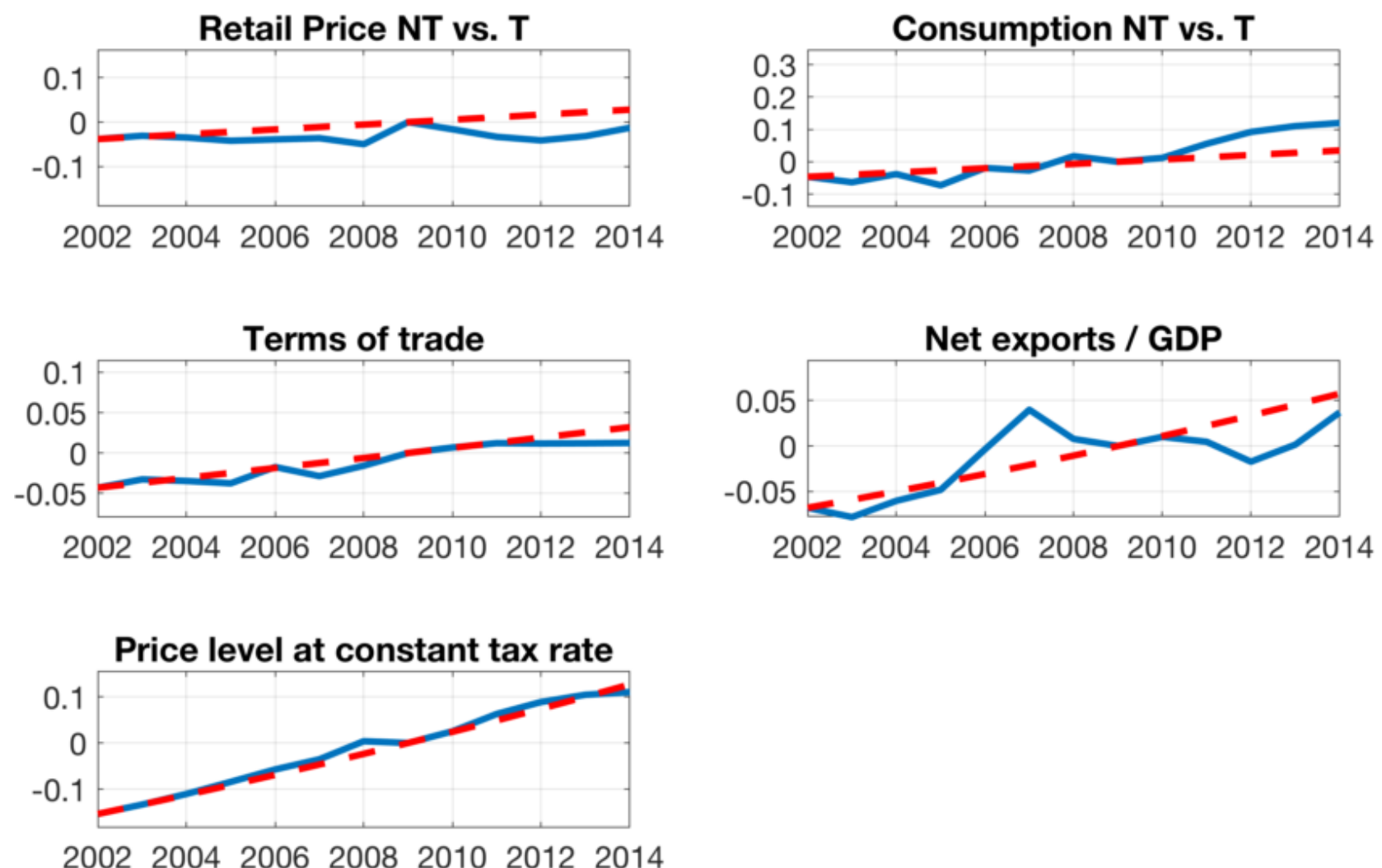

Figure A1j: LuxEMBOURG

Notes: See Figure A1a. 

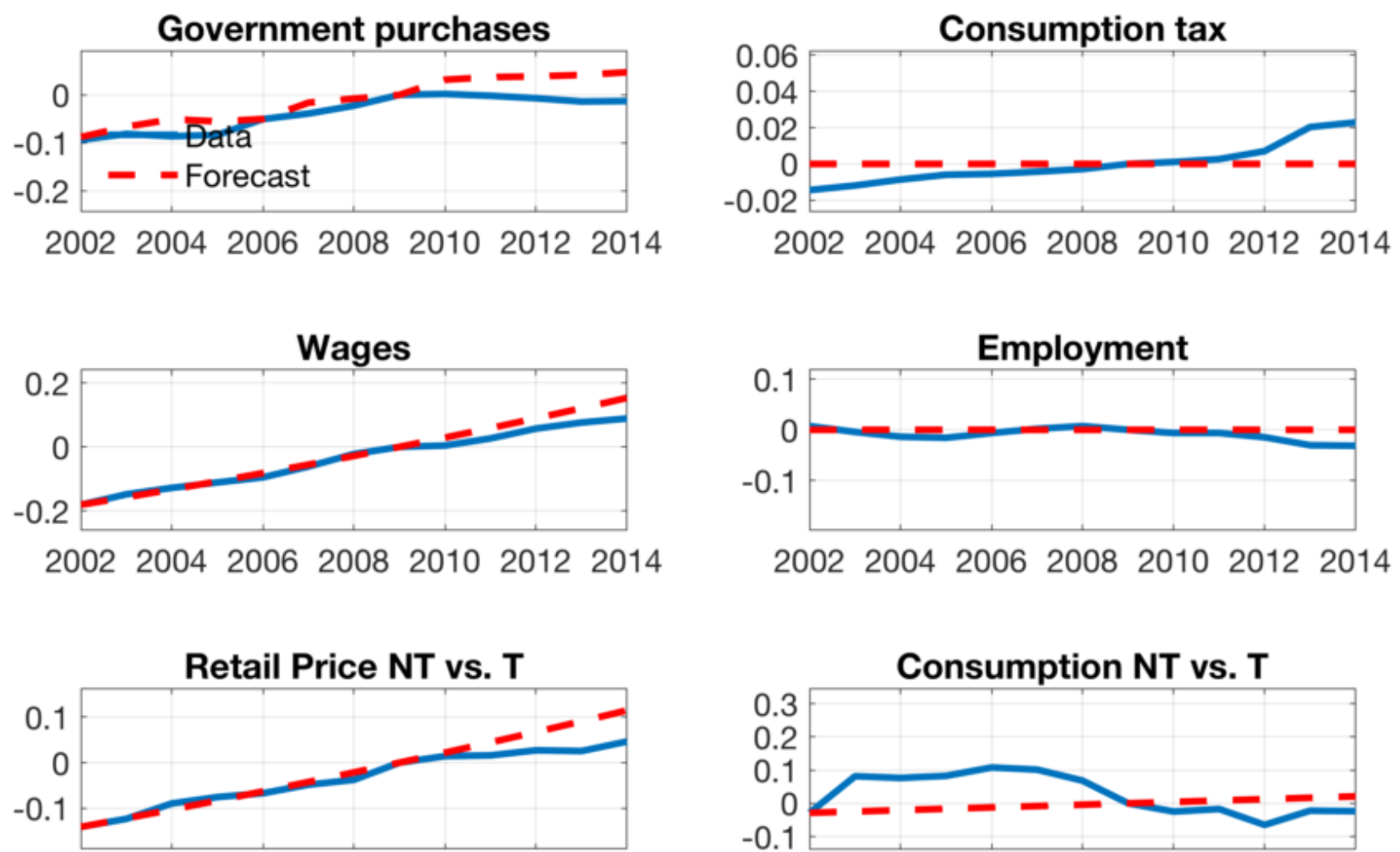

2002200420062008201020122014
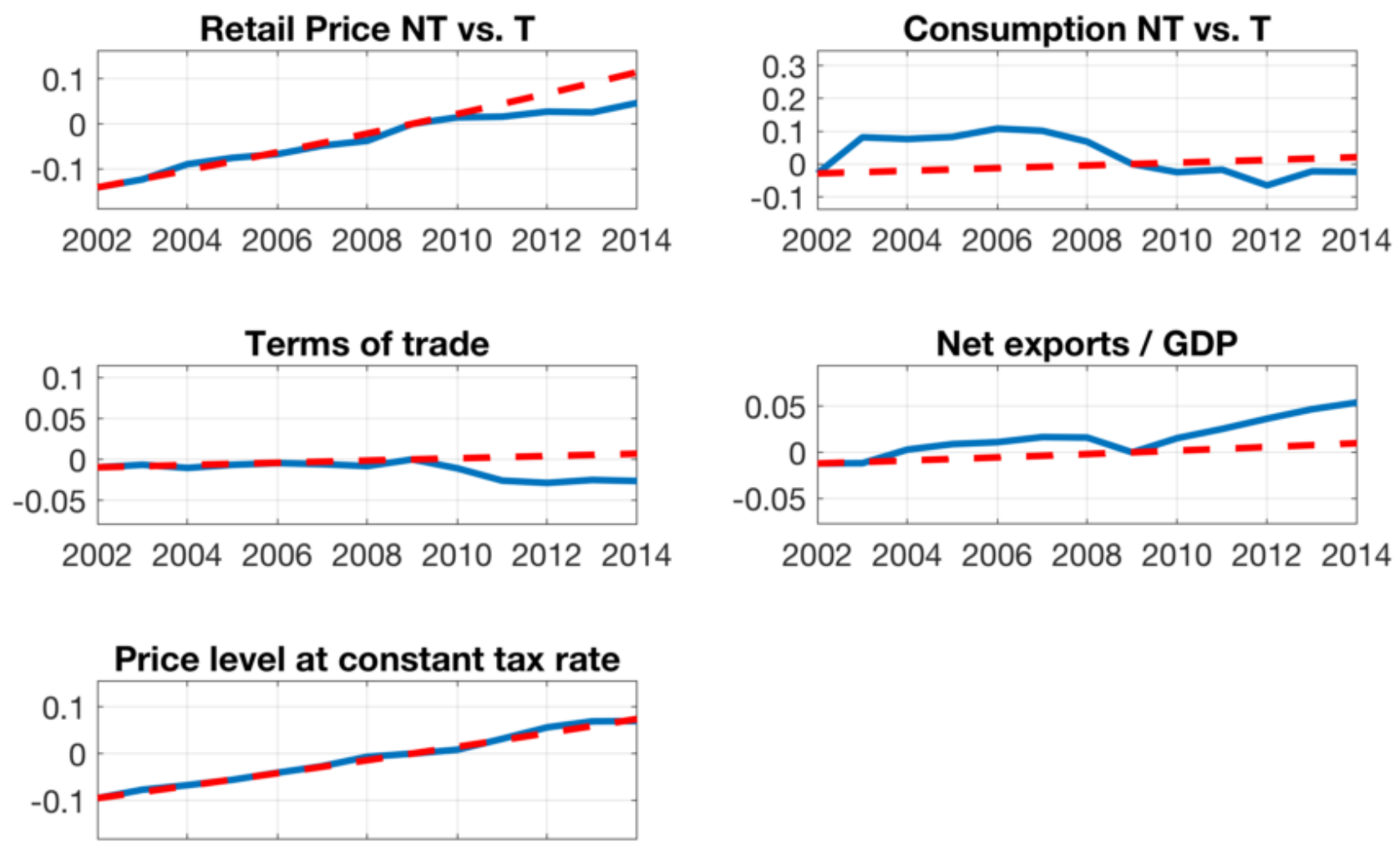

2002200420062008201020122014

Figure A1k: NeTHERLANDS

Notes: See Figure A1a. 

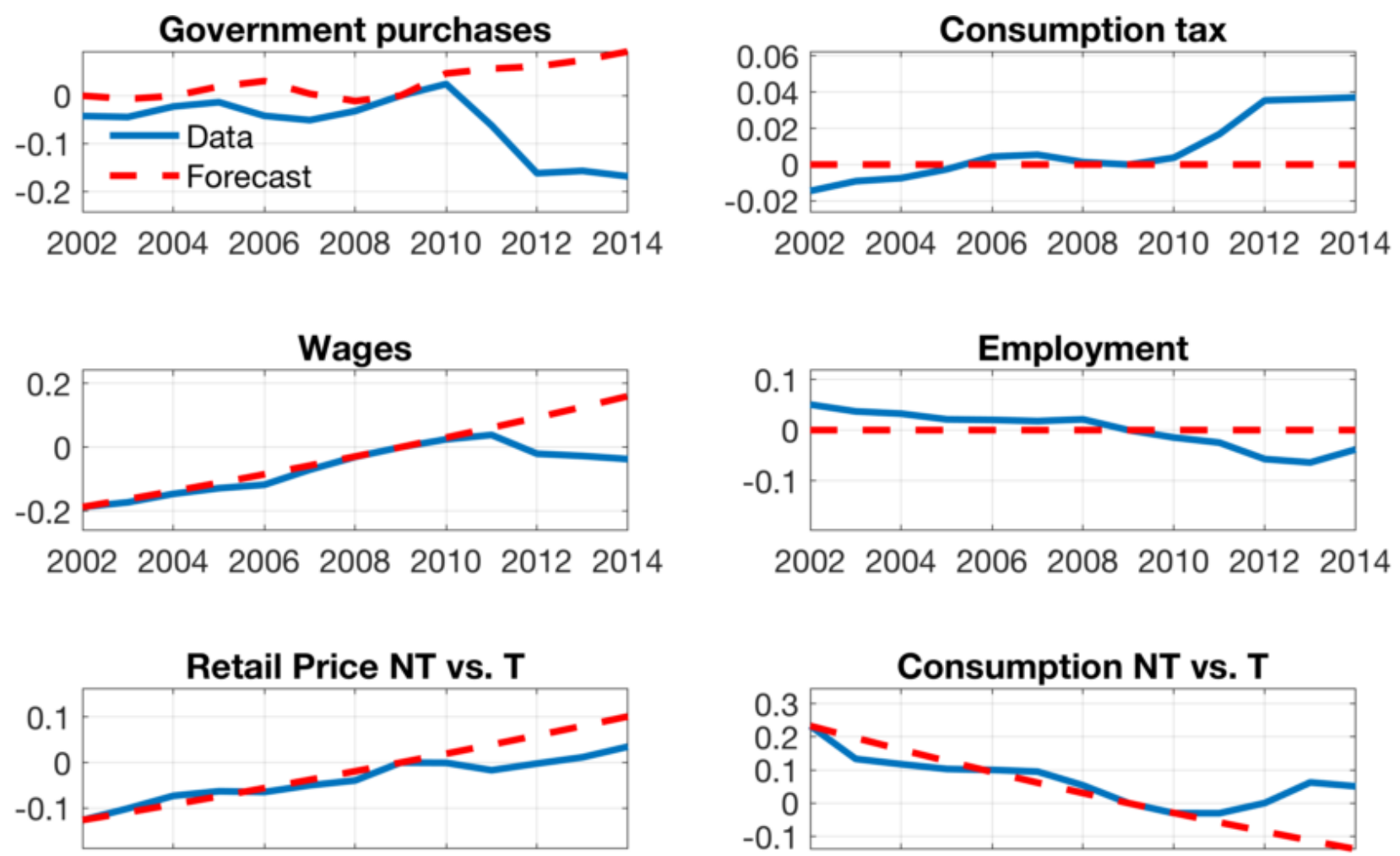

2002200420062008201020122014
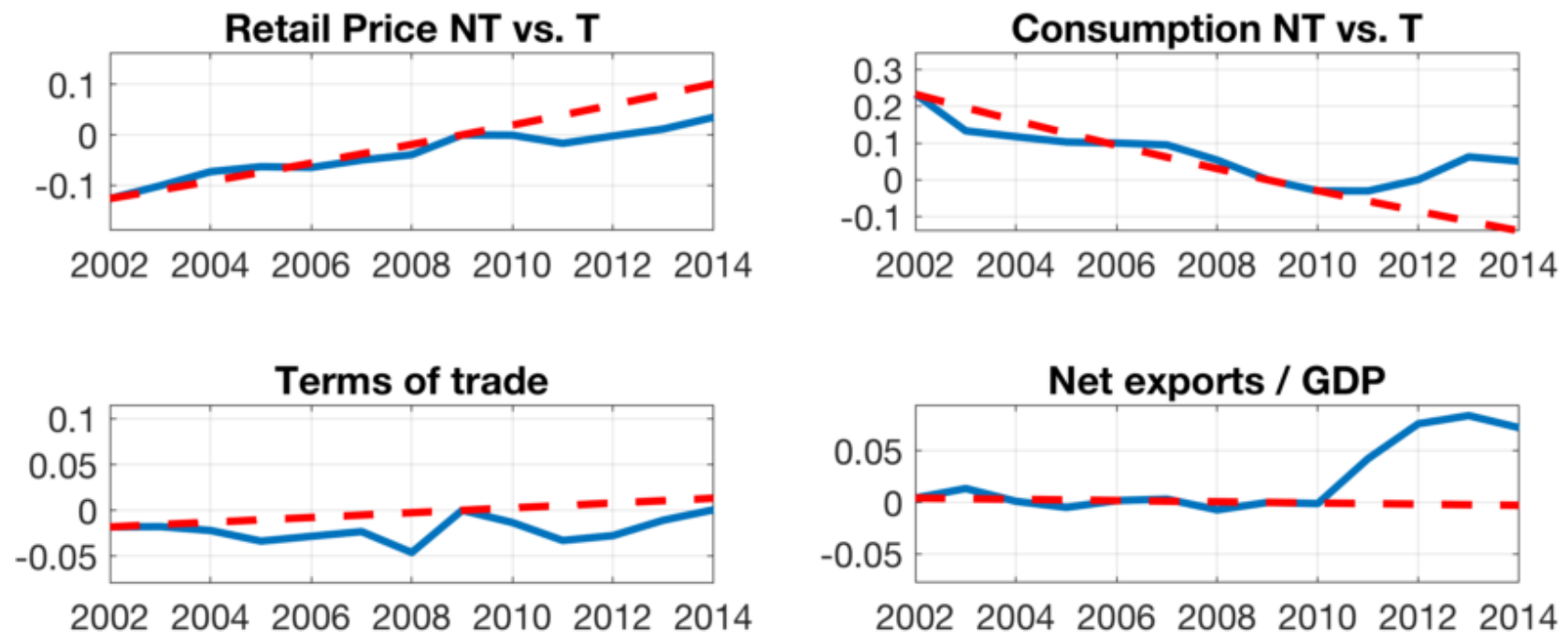

2002200420062008201020122014

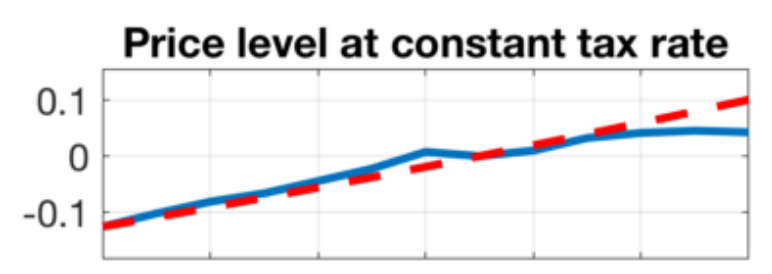

2002200420062008201020122014

Figure A1l: PorTugaL

Notes: See Figure A1a. 

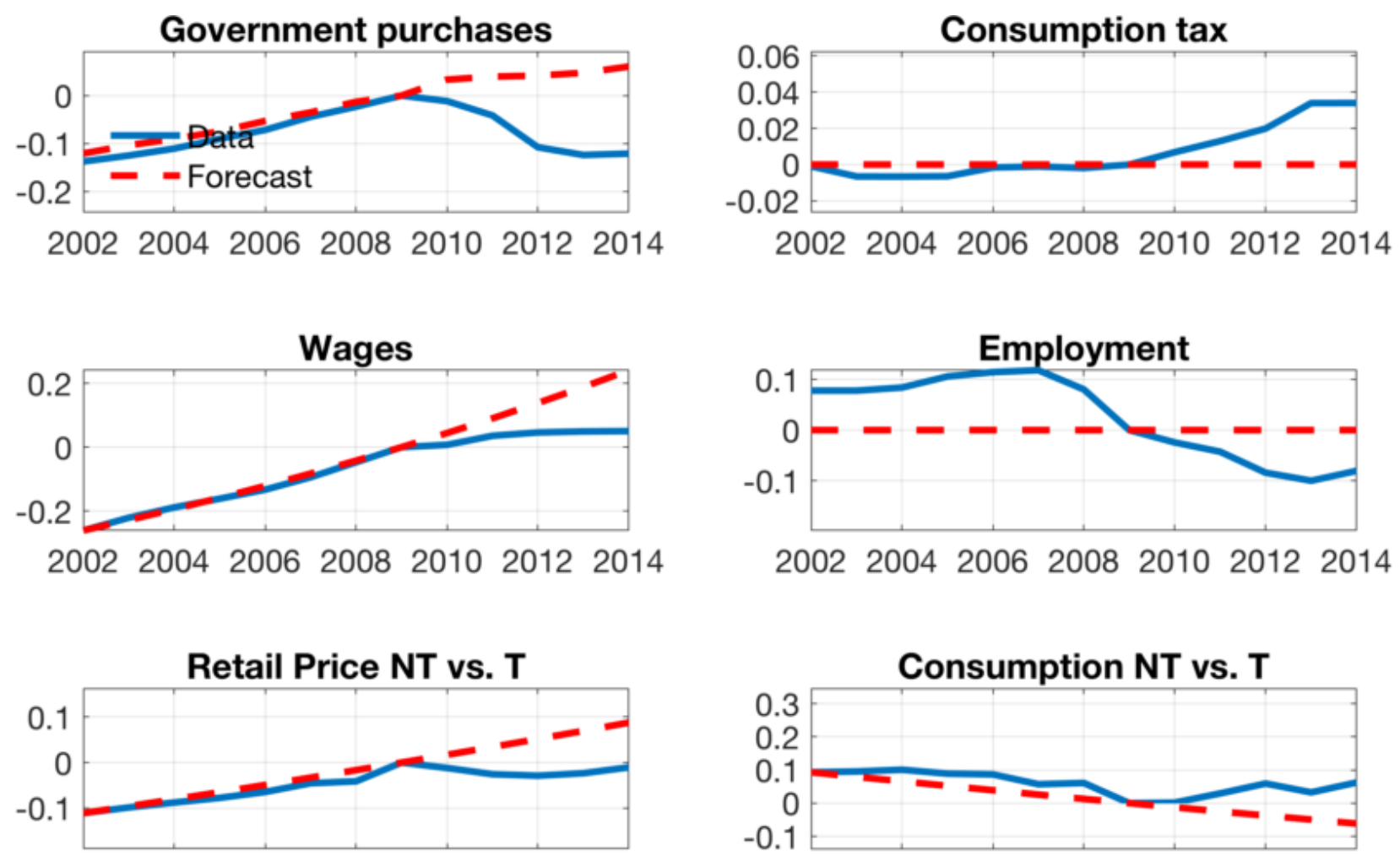

2002200420062008201020122014
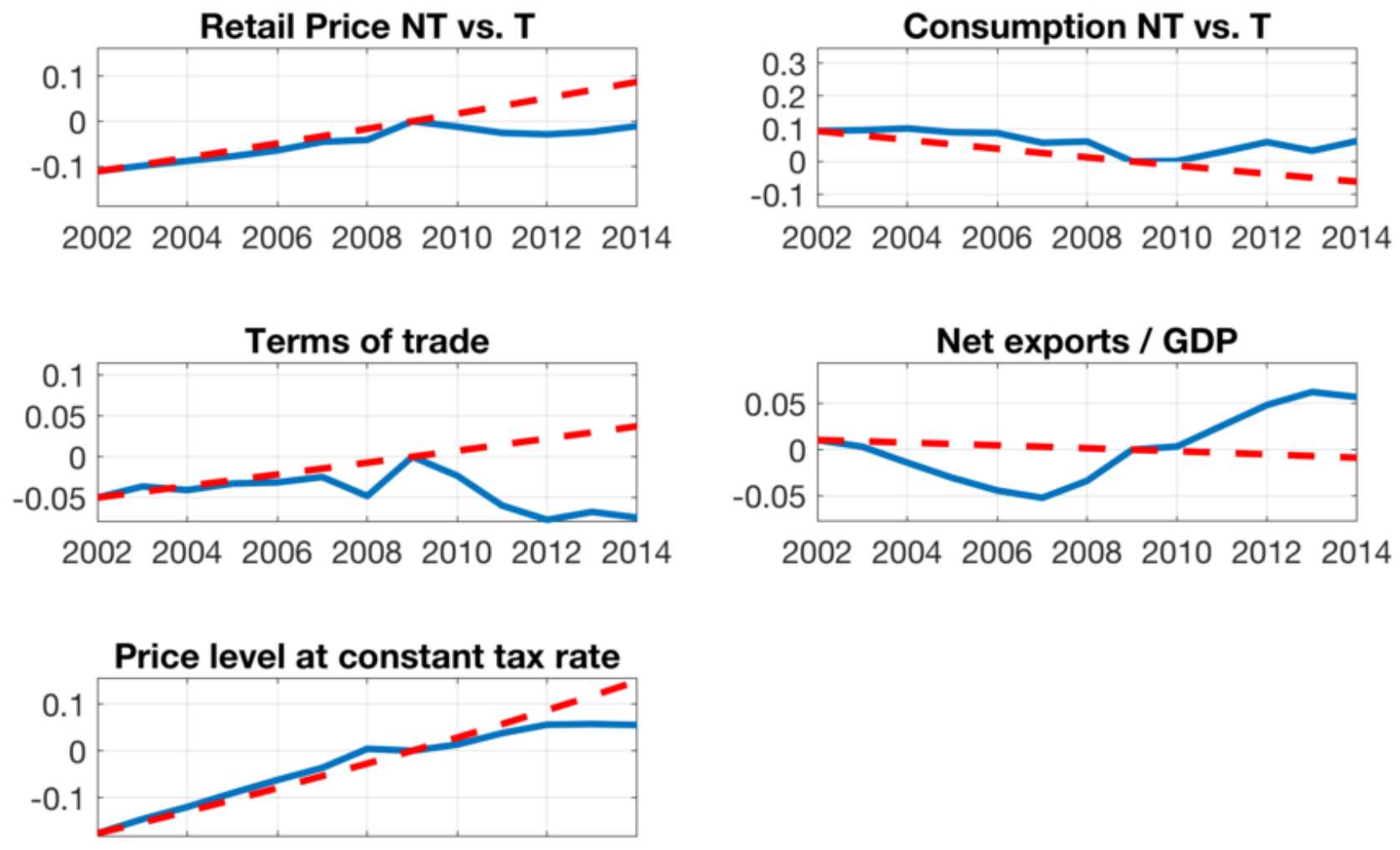

2002200420062008201020122014

Figure A1m: SPAIN

Notes: See Figure A1a. 